Maestría

en Psicologia de la

y Música

UniversidAd NACIONAL DE LA PLATA

\title{
El Rol del Movimiento Corporal Manifiesto en Tareas de Lectura Cantada a Primera Vista
}

\section{Tesis de Maestría}

\author{
Alejandro Pereira Ghiena
}

DIRECTOR: FAVIO SHIFRES 



\section{Resumen}

Esta Tesis estudia el rol del movimiento corporal manifiesto en la habilidad de cantar a primera vista a partir de la hipótesis de que los movimientos desplegados en tareas de este tipo vinculados temporal y morfológicamente con aspectos musicales, poseen una función epistémica, reduciendo la carga cognitiva que la tarea demanda.

Aborda la participación del cuerpo en los procesos de significación musical a partir de una revisión de los conceptos más relevantes de las Ciencias Cognitivas de Segunda Generación. Particularmente, intenta comprender los procesos cognitivos implicados en la habilidad de cantar a primera vista a la luz de los enfoques teóricos más actuales de la Teoría de la Cognición Musical Corporizada. A partir de las limitaciones explicativas, en relación con la participación del cuerpo en la habilidad de cantar a primera vista, que presenta la literatura investigativa sobre los aspectos cognitivos de la tarea, esta Tesis pretende brindar un enfoque alternativo que incluye al movimiento corporal manifiesto en los procesos cognitivos implicados en la habilidad.

En la primera etapa experimental se realizaron dos estudios exploratorios. En el primero se observaron los movimientos manifiestos en tareas de cantar a primera vista, se clasificaron en tres grandes categorías, se analizó la parte del cuerpo involucrada y se cuantificó su duración. En el segundo estudio se incorporó el concepto de gesto y sus categorías provenientes de diferentes disciplinas, y se diseñó una tipología específica para los gestos de la mano desplegados durante tareas de este tipo, focalizando en las relaciones morfológicas y temporales entre el gesto y los rasgos estructurales de la melodía leída. En la segunda etapa experimental se realizó un estudio en orden a determinar si los gestos vinculados al contorno melódico y a la estructura métrica podían ser considerados como acciones epistémicas que favorecieran aspectos de la cognición, o que incluso formaran parte de los procesos cognitivos que demanda la tarea. Para ello se estudio la incidencia del movimiento corporal restringido, pautado (vinculado al contorno y a la métrica) y libre en el desempeño en tareas de cantar a primera vista. Se encontró que los movimientos vinculados a la estructura métrica proporcionan un marco métrico temporal que favorece el desempeño en los aspectos temporales de la ejecución (por ejemplo, el ajuste rítmico). Sin embargo, sostener movimientos complejos (como los vinculados al contorno melódico) durante toda la ejecución perjudica el desempeño, aún cuando su realización espontánea lo favorezca. 



\section{Índice}

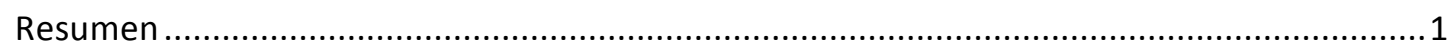

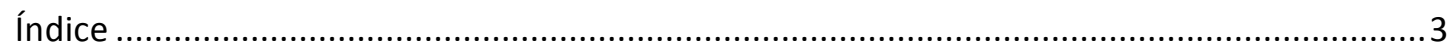

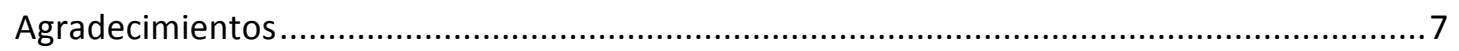

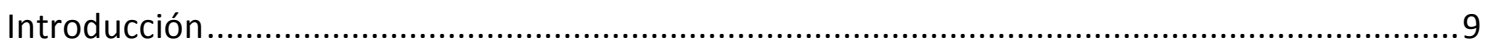

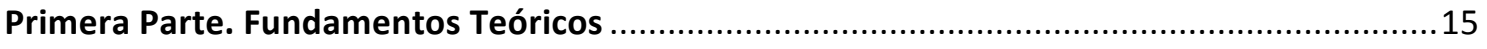

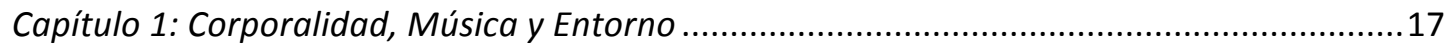

Ciencias Cognitivas y Cognición Musical .....................................................................

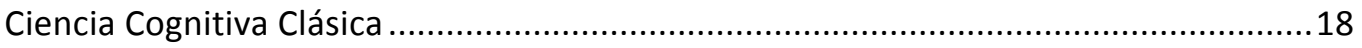

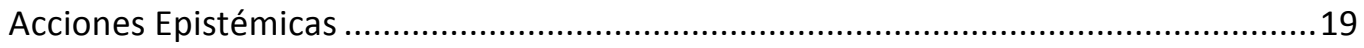

Ciencias Cognitivas de Segunda Generación (CC2G). Consideraciones Generales ........23

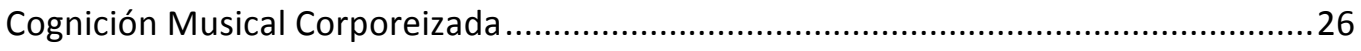

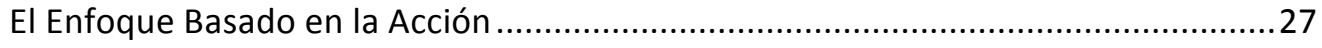

Teoría de la Metáfora Conceptual en la Comprensión Musical.................................28

El Flujo del Significado en la Música ..................................................................28

El Enfoque Ecológico de la Percepción Musical .........................................................30

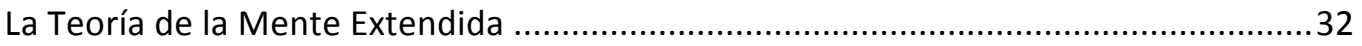

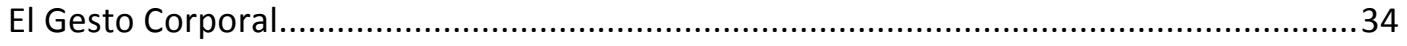

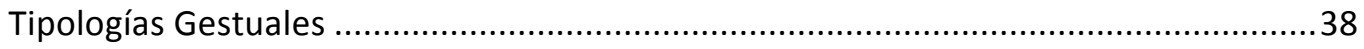

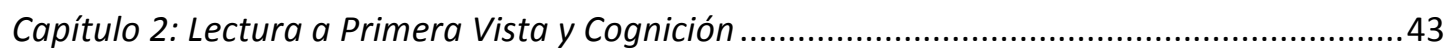

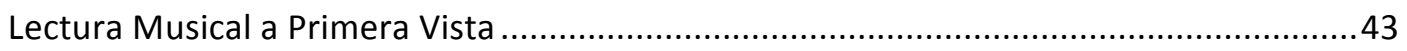

Concepciones y Enfoques para el Abordaje de la Lectura Musical a Primera Vista.......45

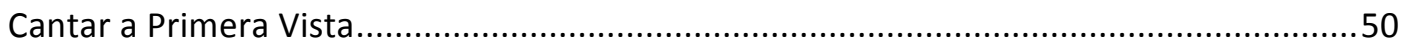


La Pedagogía Musical y su Tratamiento del Cuerpo en la Lectura a Primera Vista ........57

El Solfeo: Estrategia Tradicional para el Aprendizaje de la Lectura Musical...............57

El Movimiento Corporal como Estrategia Didáctica ...............................................58

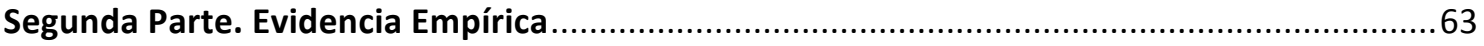

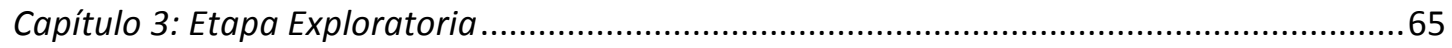

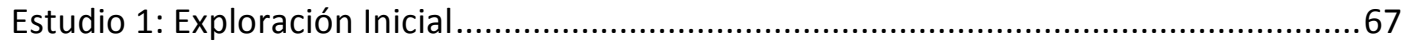

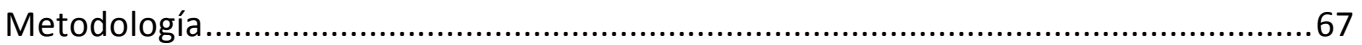

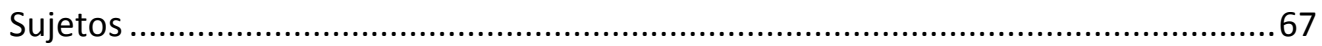

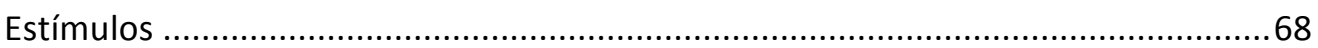

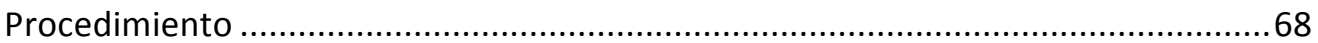

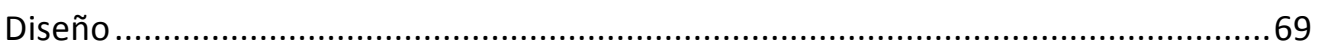

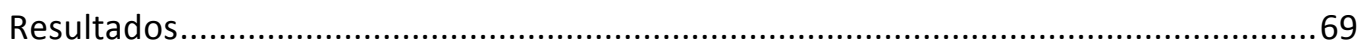

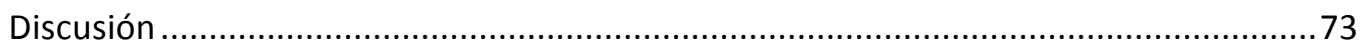

Estudio 2: Clasificación de los Gestos Manuales en la Tarea de Cantar a Primera Vista....75

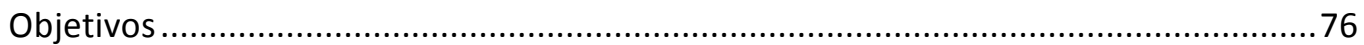

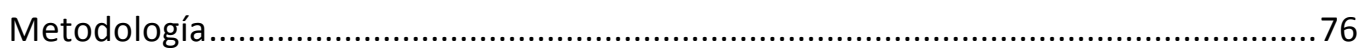

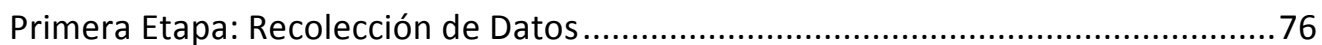

Segunda Etapa: Análisis de las Tipologías............................................................. 78

Tercera Etapa: Testeo de la Tipología Gestual Diseñada ...........................................79

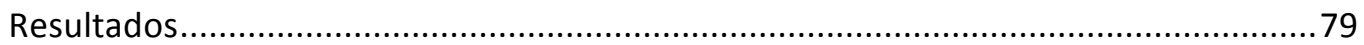

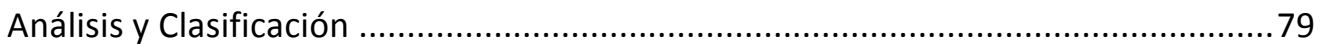

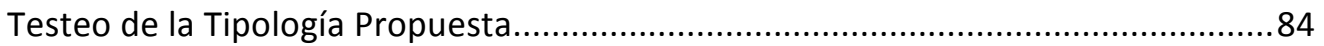

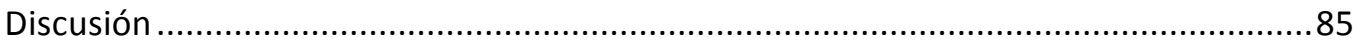

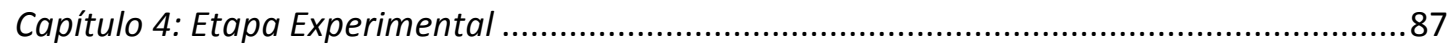

Estudio 3: El Gesto Corporal como Acción Epistémica ................................................... 87

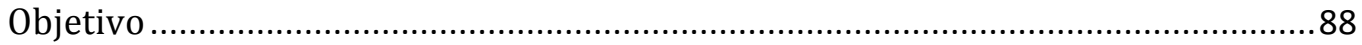




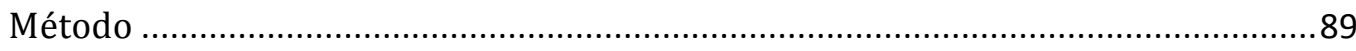

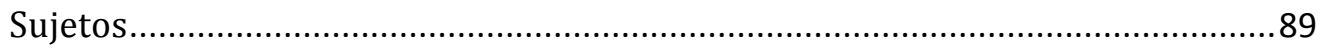

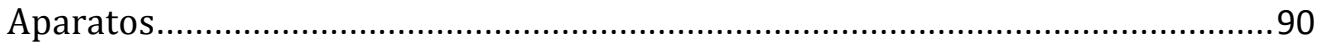

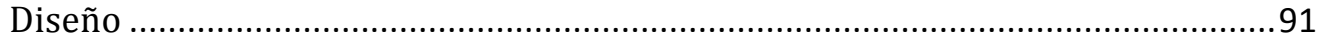

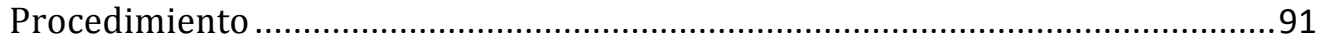

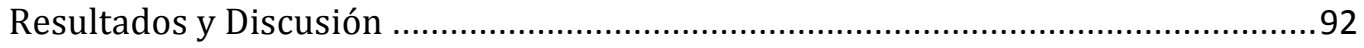

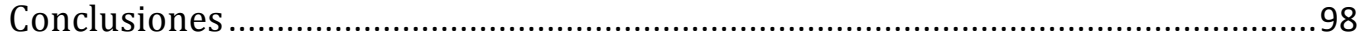

Estudio 4: Expresión y Movimiento en la Lectura Cantada a Primera Vista.......................102

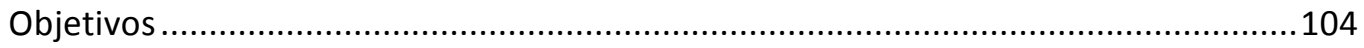

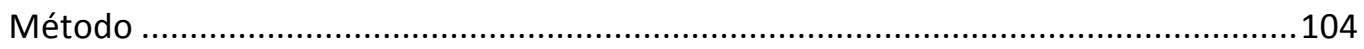

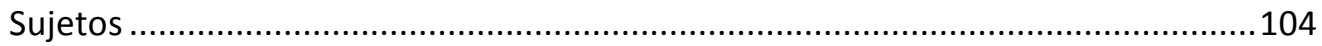

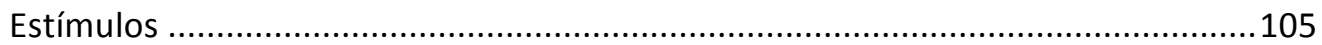

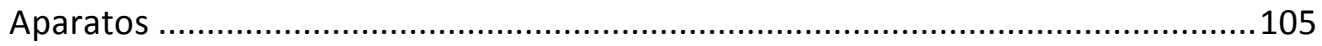

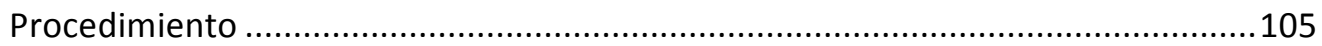

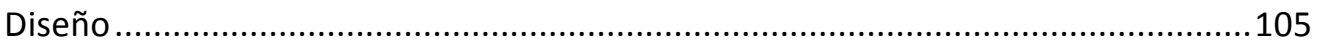

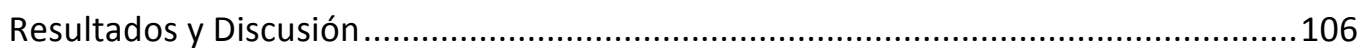

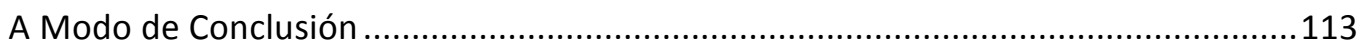

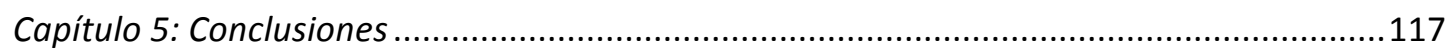

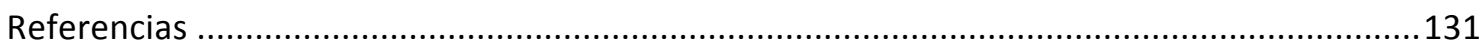

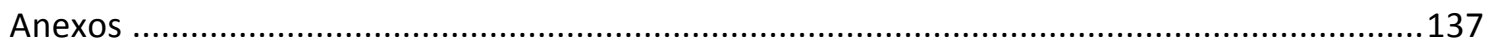

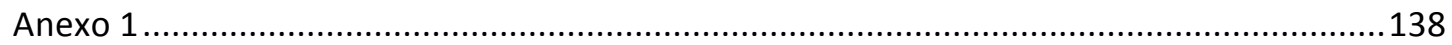

Descripción de los movimientos típicos desplegados con las manos por el participante seleccionado en el estudio 2

Descripción de todos los movimientos de las manos desplegados por el participante seleccionado en el estudio 2 
Protocolo para jueces (Estudio 2) ............................................................... 145

Clasificación de los gestos manuales en las tareas de lectura a primera vista ...........145

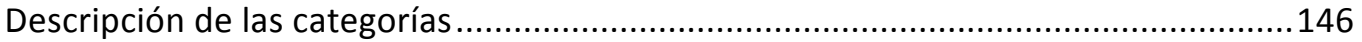

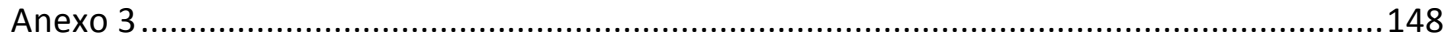

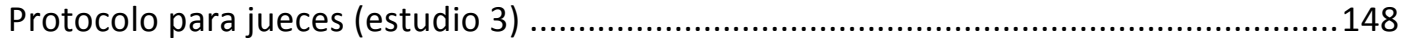

Evaluación de ejecuciones de melodías cantadas a primera vista..........................148

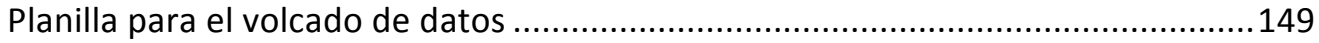

Partituras de las melodías utilizadas como estímulos en el estudio 3...................150 


\section{Agradecimientos}

Esta Tesis fue realizada en el marco de una beca Tipo B otorgada por la Universidad Nacional de La Plata.

Quiero expresar mi agradecimiento a todas las personas que participaron en la realización de esta Tesis. A mi director, Favio Shifres, por la guía, el apoyo, el aliento constante, la paciencia y la enorme generosidad académica y humana.

A mis compañeros de la cátedra Educación Auditiva (FBA-UNLP) y de los proyectos de investigación El oído musical y Cognición Musical Corporeizada, por las discusiones sobre los conceptos teóricos que sustentan esta Tesis y sobre los aspectos metodológicos de las pruebas, por alentarme en la concreción de este trabajo, y por participar directamente como panel de jueces expertos. A todos los participantes de los estudios, estudiantes de la asignatura Educación Auditiva 2 (FBA-UNLP).

A mis padres y a mis hermanos, por el aliento siempre presente y cercano en la distancia.

A Saio, Malena y Julieta, por el apoyo constante, la comprensión, la espera, el aliento y la inspiración. 



\section{Introducción}

La inquietud que da origen a la presente Tesis, surge como resultado de la observación docente en el ámbito de enseñanza musical académica de la percepción y de la lectura musical, más precisamente, durante mi labor docente en la asignatura Educación Auditiva de Facultad de Bellas Artes de la UNLP. Uno de los contenidos principales de esta asignatura es el desarrollo de la habilidad de leer partituras en el código convencional de escritura y, como parte de este contenido, la lectura cantada a primera vista ocupa una buena parte de sus esfuerzos pedagógicos. Mi actividad docente en este ámbito me permitió recolectar una serie de evidencias anecdóticas del modo en el que se mueven los estudiantes en tareas de cantar a primera vista, tanto en actividades pedagógicas en pos del desarrollo de la habilidad como en los exámenes realizados para evaluar este contenido. Fue justamente durante uno de los exámenes de lectura a primera vista que el movimiento corporal desplegado por los estudiantes comenzó a llamarme la atención. Mientras leían, algunos movían las manos como si estuvieran tocando un instrumento imaginario, principalmente el piano, marcaban pulsos con las manos o con el pie, representaban espacialmente con las manos el contorno de la melodía que estaban leyendo, movían la cabeza o levantaban las cejas, etc. En algunos casos, parecían necesitar realizar estos movimientos, o apoyarse en ellos para resolver la tarea. A partir de estas observaciones, tal vez no casuales pero tampoco intencionales, surgió una serie de interrogantes en relación con el rol que estos movimientos manifiestos podían desempeñar en la realización de la tarea: ¿tienen algún vínculo ostensible con los rasgos estructurales de la melodía?, ¿pueden ser considerados gestos en función de las definiciones mayormente aceptadas del término?, ¿pueden clasificarse en categorías en base a sus rasgos principales?, ¿tienen roles específicos en el desempeño de acuerdo con el tipo de movimiento desplegado?, ¿puede establecerse alguna relación entre el movimiento observado y la expresión musical en la ejecución? y, principalmente, ¿están vinculados con las estrategias cognitivas desplegadas por los estudiantes durante las tareas de cantar a primera vista?

Enmarcada en la Teoría de la Cognición Corporizada, esta Tesis intenta dar respuesta a estos interrogantes a partir de la realización de una serie de estudios empíricos que comienzan con una exploración de los movimientos desplegados en este tipo de tareas y finalizan con un estudio experimental basado en las observaciones previas. 
El advenimiento y la expansión de las Ciencias Cognitivas de Segunda Generación como alternativa al modo en el que tradicionalmente se entiende la cognición ha propiciado el surgimiento de investigaciones que reconsideran el rol del cuerpo en los procesos cognitivos implicados en la comprensión de la experiencia humana. Bajo este gran paraguas teórico se desarrollaron disciplinas que, aunque con importantes diferencias, coinciden en subrayar la importancia del cuerpo y de su interacción con el entorno en la cognición. En este sentido, conciben una idea más abarcadora de mente, que no se circunscribe a las operaciones simbólicas dentro de los límites del cerebro, sino que involucra al cuerpo y a los elementos del entorno conformando un complejo interactivo que posibilita la formación de significados acerca de las experiencias vividas. Como parte de este cuerpo teórico, la Cognición Musical Corporizada se basa en la idea de que la comprensión de la música responde al modo en ella es experimentada a través del cuerpo y la mente como un todo unificado e indivisible, y así, resulta un marco sumamente prometedor para indagar acerca del rol del movimiento corporal manifiesto en la lectura a primera vista (ver capítulo 1).

Como se desarrollará en el capítulo 2, los estudios que han abordado la habilidad de cantar a primera vista en relación con los procesos cognitivos implicados, han focalizado principalmente en la búsqueda de un modo exitoso de desarrollar la habilidad. Para tal fin, se han centrado especialmente en el modo en que procesan la información los lectores expertos para comprender aquellos aspectos cognitivos que los convierten en hábiles lectores en relación con los menos hábiles o novatos. Sin embargo, no se han ocupado de estudiar el movimiento corporal que acompaña la ejecución y su rol en los procesos cognitivos. Más bien, ha sido uno de los aspectos más desatendidos en este tipo de estudios, hecho que los asocia a una concepción clásica de cognición, en la cual, esquemáticamente, el cuerpo cumple las funciones de recibir la información a través de los sentidos (input), de ser el soporte material para los procesos cognitivos internos, y de efectuar la acción en respuesta a esa información recibida (output) (ver capítulo 1). Incluso, las menciones al movimiento corporal en tareas de este tipo carecen de una explicación que los vinculen con los aspectos cognitivos de la tarea, aun cuando esa relación resulte evidente. Por ejemplo, se ha observado que los lectores más hábiles utilizan como estrategia exitosa para cantar a primera vista, gestos de las manos vinculados a las funciones tonales de las alturas cantadas al estilo de los movimientos utilizados en el método del do móvil, entre otras (Killian y Henry, 2005). Sin embargo, no se ha indagado porqué resultan exitosas y qué relación tienen con la demanda cognitiva de la tarea y con los procesos desplegados para satisfacerla. 
La habilidad de cantar a primera vista es considerada como una tarea musical de alta demanda cognitiva, porque implica la decodificación de los símbolos plasmados en la partitura, la configuración de un centro tonal, de la escala y del marco métrico temporal en el que se desarrolla la melodía, la construcción de una representación de la música leída antes de escucharla, la ejecución vocal ajustada y continua, etc. De este modo, es posible que al cantar a primera vista los estudiantes necesiten generar recursos cognitivos externos, basados en la realización de movimientos corporales vinculados a las características estructurales de la melodía que están leyendo, que de otro modo no estarían disponibles. Es decir, que tal vez ellos piensen la música que cantan a primera vista a través de sus movimientos, los cuales podrían ser entendidos como acciones epistémicas que mejoran aspectos de la cognición, o incluso que forman parte de los procesos cognitivos desplegados para resolver la tarea.

En este sentido, la hipótesis que se pretende comprobar en la presente Tesis de Maestría es que los movimientos manifiestos desplegados en tareas de lectura cantada a primera vista que se vinculan temporal y morfológicamente con aspectos musicales poseen una función epistémica, actuando como un anclaje corporal externo y reduciendo la carga cognitiva que la tarea demanda.

La estructura del escrito consta básicamente de dos partes: la primera desarrolla los conceptos teóricos más relevantes que sustentan la realización de esta Tesis en dos capítulos, y la segunda incluye toda la evidencia empírica de los estudios exploratorios y experimentales desarrollados en otros dos capítulos.

El capítulo 1 describe el marco teórico de la Cognición Musical Corporizada en el que se encuadra esta Tesis, y aborda definiciones, conceptos y tipologías referentes al gesto. Parte de una explicación de la Ciencia Cognitiva Clásica describiendo los aspectos centrales de la concepción tradicional de mente y de cognición. Luego, desarrolla el concepto de acción epistémica como idea que, aun sustentada en la Ciencia Cognitiva Clásica, comienza a incluir al cuerpo y a la acción corporal en la explicación de los procesos cognitivos internos. Continua con una descripción de los aspectos generales de las Ciencias Cognitivas de Segunda Generación como conjunto de disciplinas que coinciden en resaltar el rol del cuerpo en la formación de significados acerca de la experiencia humana. Luego particulariza en la Teoría de la Cognición Musical Corporizada y describe algunos de los enfoques que resultan más relevantes para los fines de esta Tesis: el Enfoque Basado en la Acción, la Teoría de la Metáfora Conceptual en la Comprensión Musical, el Flujo del Significado en la Música y el Enfoque Ecológico de la Percepción Musical. También aborda la Teoría de la Mente Extendida, como una de las teorías corporizadas más radicales que incluye la participación del cuerpo y del 
entorno en la cognición, concibiendo una idea de mente que trasciende los límites del cerebro y se extiende hacia afuera del cuerpo, incorporando elementos externos. Finalmente, el capítulo 1 describe el problema de la definición del concepto de gesto en diferentes disciplinas y presenta algunas de las tipologías gestuales más aceptadas en el ámbito de la comunicación interpersonal y de la ejecución musical.

El capítulo 2 describe el estado del arte en la investigación sobre lectura cantada a primera vista, haciendo foco, principalmente, en los aspectos cognitivos de la habilidad. Parte de la definición tradicional de la tarea y de los rasgos comunes de la lectura a primera vista vocal e instrumental. Luego aborda los estudios sobre la habilidad de cantar a primera vista que se han desarrollado recientemente, señalando los procesos cognitivos que describen como implicados en este tipo de tarea, y las limitaciones en materia de análisis corporal que se observa en ellos. También se menciona brevemente la participación del cuerpo en algunos métodos de enseñanza de la habilidad de cantar a primera vista y la ausencia de una reflexión acerca de su relación con los aspectos cognitivos que demanda la tarea.

El capítulo 3, incluido en la segunda parte de la Tesis, describe dos estudios exploratorios. El primero de ellos, realiza una exploración inicial de los movimientos desplegados en tareas de cantar a primera vista, los describe con el fin de clasificarlos en categorías generales basadas en su vinculación con los rasgos melódicos y rítmicos de la melodía leída, y cuantifica su duración observando cada una de las partes del cuerpo implicadas en el movimiento. Luego, describe el segundo estudio exploratorio, realizado a partir de los resultados obtenidos en el primero y de la necesidad de encontrar categorías más específicas que permitan establecer más precisamente un vínculo entre el movimiento y los rasgos musicales de la melodía leída. Para este estudio se toman las tipologías gestuales abordadas en el capítulo 1, y se las aplica a los gestos de la mano desplegados durante la realización de la tarea. Finalmente, se describe una tipología gestual nueva, específica para este tipo de tareas diseñada a partir de las categorizaciones estudiadas, de las descripciones gestuales realizadas y de la necesidad de preservar los vínculos entre el gesto y la melodía.

El capítulo 4 presenta un estudio experimental que analiza la incidencia de restricciones corporales y de movimientos pautados vinculados a los rasgos estructurales de la melodía leída (contorno melódico y estructura métrica) en el desempeño en tareas de cantar a primera vista. En primer término, se analizan los desempeños a partir de la evaluación de un panel de expertos y se discute el modo en que la restricción corporal incide en la ejecución. En segundo término se analiza la expresión en la ejecución a primera vista en vinculación con la cantidad de movimiento realizado durante la tarea. A partir de los resultados se discute la relación entre 
el movimiento corporal y las estrategias cognitivas desplegadas por los participantes para resolver la tarea, en vinculación con el grado y tipo de restricción corporal impuesto en el estudio.

Finalmente, el capítulo 5 presenta las conclusiones de la Tesis, partiendo de una recapitulación de los conceptos teóricos más relevantes, del problema abordado y del estado del arte en relación con la investigación acerca de la lectura cantada a primera vista. Luego se discuten los resultados obtenidos en los estudios exploratorios y empíricos en función de la Teoría de la Cognición Musical Corporizada y de e que se amplía la explicación al considerar al movimiento corporal manifiesto en los procesos cognitivos desplegados para resolver tareas de lectura cantada a primera vista. Finalmente se describen las implicancias de la presente Tesis en el campo pedagógico musical. 



\section{Primera Parte}

Fundamentos Teóricos 



\section{Capítulo 1}

\section{Corporalidad, Música y Entorno}

Cuerpo, música y entorno han tenido una relación sumamente compleja a lo largo del tiempo. La teoría musical occidental, principalmente de la mano del racionalismo del siglo XVII, fue relegando paulatinamente a un segundo plano todo aquello que no correspondiera al mundo acústico (Shifres, 2007). Esto derivó en una subordinación de los aspectos somáticos y kinéticos a los sonidos, permitiendo que la descorporización de la música sucediera sin demasiado alboroto. Sin embargo, ciertos ámbitos musicales permanecieron estrechamente vinculados al cuerpo, tal como ocurrió con la ejecución musical. No es posible pensar en una ejecución musical sin la participación del cuerpo. Más allá de la prescindencia aparente del cuerpo, incluso en la música electrónica los oyentes suelen imaginarse movimientos corporales que podrían ejecutar la música aun cuando jamás haya sido ejecutada realmente (López Cano, 2005).

El estudio de la cognición musical, a partir del surgimiento de la Ciencia Cognitiva Clásica (en adelante, (CCC), fue uno de los ámbitos más fuertemente descorporizados. Aquí, la comprensión musical es vista como un proceso que ocurre en la mente del sujeto posible de ser exteriorizado corporal y verbalmente en función de los conceptos de la teoría musical. Sin embargo, en las últimas tres décadas diferentes vertientes de investigación musical comenzaron a poner el foco en la participación del cuerpo en los procesos de producción, percepción y comprensión musicales sustentadas en el desarrollo acelerado de las Ciencias Cognitivas de Segunda Generación (en adelante, CC2G). En este capítulo se abordarán los conceptos más relevantes de estas teorías haciendo foco en la Cognición Musical Corporizada como la línea que se ocupa de la comprensión y de la cognición musical.

\section{Ciencias Cognitivas y Cognición Musical}

En sus esfuerzos por comprender el pensamiento humano, la Ciencia Cognitiva constituye un conjunto de disciplinas en constante redefinición de sus límites y de su aparato conceptual 
(Martínez Manrique, 1999). De ese conjunto interdisciplinario, forman parte la psicología, la neurociencia, la inteligencia artificial, la lingüística, la antropología, la filosofía de la mente, la semiótica cognitivista, entre otras. Como estrategia explicativa, se propone partir desde una descripción sintética de la cognición desde la perspectiva de la CCC, para luego introducir la teoría de la Cognición Musical Corporizada, entendiendo que advertir las diferencias entre estas perspectivas cognitivas puede contribuir a comprender mejor el modelo corporizado y situado en el que se sustenta esta Tesis.

\section{Ciencia Cognitiva Clásica}

Partiendo de la base del dualismo cartesiano que concibe a la mente como una sustancia inmaterial completamente diferente del cuerpo y del entorno, la ciencia cognitiva clásica puso el foco sobre los procesos mentales que dan origen al pensamiento. Bajo esta perspectiva, la cognición humana es entendida como el procesamiento de la información recibida por los sentidos, realizada por un procesador central en una especie de caja negra que nos impide 'ver' lo que allí ocurre. El razonamiento, la conceptualización, la clasificación, etc. son considerados procesos de alto orden que ocurren en una entidad etérea denominada mente. Estos procesos están basados en la manipulación de representaciones simbólicas discretas estructuradas sintácticamente a partir de reglas específicas (Martínez Manrique, 1999; Gomila y Calvo, 2008). Gracias a la relación que estas representaciones pueden tener con el entorno y con otros símbolos, es posible asignarles contenidos semánticos a través de los cuales se comprende el mundo.

Los teóricos del cognitivismo clásico proponen comprender el funcionamiento cognitivo apelando a la metáfora computacional, (también conocida como metáfora del ordenador). Esta metáfora compara la mente con el software de las computadoras, es decir, con todos los sistemas y programas, mientras que el soporte físico que proporciona el hardware se compara con el cerebro. Cada estructura simbólica (mental) se corresponde con una estructura física en el cerebro (Fodor y Pylyshyn, 1998). Así, la mente incorpora datos nuevos que ingresan al sistema a través de los sentidos, los procesa, soluciona los problemas y ordena al cuerpo que actúe en respuesta a esos datos (Mithen, 1996). El proceso cognitivo depende completamente de un sistema centralizado, y refiere a la traducción a símbolos de la información de entrada y a la manipulación de esos símbolos en la caja negra.

Como puede observarse, el papel que esta teoría le otorga al cuerpo dista mucho de ser central. Aquí, el cuerpo es un mero soporte material para las operaciones realmente importantes ejecutadas por la mente, su rol se limita, en términos generales, a recibir el input 
(entrada) a través de los sentidos y ofrecer un output (salida) físico en respuesta al procesamiento mental.

Existen dos tipos de procesos cognitivos: de bajo orden (también denominados inferiores, básicos o de bajo nivel), y de alto orden (superiores o de alto nivel) (Gibbs, 2006; Gomila y Calvo, 2008). Los primeros refieren a aquellos procesos realizados naturalmente en respuesta al ambiente, y presentan una demanda cognitiva baja para el organismo. Las sensaciones, la percepción, la emoción, etc., son ejemplos de procesos cognitivos de bajo orden. Por su parte, el pensamiento abstracto, la planificación, la toma de decisiones, etc., son considerados procesos cognitivos de alto orden que resultan más complejos y que demandan mayores recursos cognitivos. Éstos permiten el procesamiento activo de la información entrante y requieren de la actividad de los lóbulos frontales del cerebro y, por tanto, a la luz de la teoría clásica, involucran mayor actividad mental.

En esta perspectiva representacional-computacional de la mente, el entorno posee una objetividad ontológica, es decir, que los objetos del mundo poseen cualidades objetivas e independientes del organismo que los percibe. Así, el entorno se circunscribe a proveer los estímulos externos necesarios para que se produzcan los procesos cognitivos, reduciendo la cognición al procesamiento central de la información.

Sin embargo, el cognitivismo clásico parece no poder explicar la realización de ciertas acciones corporales que son desplegadas con la finalidad aparente de mejorar el pensamiento y de resolver problemas cognitivos con mayor facilidad. A partir de esta incongruencia entre la explicación clásica de la cognición y la observación de la actividad corporal manifiesta en determinadas tareas cognitivas, surge la noción de acción epistémica, que si bien acepta la participación del cuerpo y del entorno en la cognición humana y cuestiona la exclusividad del procesamiento interno, se sustenta teóricamente en las ideas más relevantes de la CCC. Se dedicará el siguiente apartado a explicar este concepto entendiéndolo como uno de los antecedentes de los enfoques cognitivos corporizados en los que se sustenta esta Tesis, y como una de las ideas que, a priori, podrían explicar parte del movimiento corporal manifiesto al cantar a primera vista.

\section{Acciones Epistémicas}

El concepto de acción epistémica fue propuesto por David Kirsh y Paul Maglio (1994) para referirse a todas aquellas acciones que son realizadas en el mundo externo para mejorar aspectos de la cognición, modificando la naturaleza de las tareas mentales. Los autores distinguen las acciones epistémicas de las acciones pragmáticas, que son aquellas que alteran 
el mundo con el fin de alcanzar alguna meta física. Por ejemplo, si alguien pretende ir de visita a la casa de un amigo, debe realizar alguna acción pragmática que lo lleve hasta allí, como caminar o tomar un taxi. Si bien las acciones epistémicas también inciden en el mundo físico, son realizadas en base a las necesidades cognitivas y de procesamiento de la información de cada sujeto. Kirsh y Maglio postularon esta idea a partir de la observación de personas utilizando el conocido videojuego tetris. Este juego requiere tomar decisiones en tiempo real y realizar tareas interactivas perceptuales y cognitivas en fracciones de segundo. Esto les permitió observar el modo en que las personas trasladan sus tareas cognitivas al mundo externo con el fin de simplificar la resolución de problemas. Muchos de los movimientos de traslación y rotación de figuras (zoides) que realizaban los sujetos durante su participación en el juego pueden entenderse fácilmente como acciones que utilizan el mundo externo para mejorar la cognición. Así, notaron que los jugadores expertos realizaban una gran cantidad de acciones epistémicas cuyo fin no era alcanzar el objetivo físico inmediato, sino reducir la carga cognitiva. Por ejemplo, algunas de las rotaciones parecían ser efectuadas para reconocer de qué figura se trataba antes de que apareciera completamente en la pantalla, o para probar su coincidencia con las ubicaciones potenciales. Según los autores, realizar este tipo de tareas en el mundo externo parece ser mucho más rápido, confiable y económico que realizarlas mentalmente.

Los modelos cognitivos estándar descuidan muchas de las acciones realizadas por las personas, porque las consideran acciones superfluas o redundantes. Sin embargo, esta idea plantea que, lejos de ser superfluas, este tipo de acciones desempeñan un valioso rol en el mejoramiento de la actuación humana (Kirsh y Maglio, 1994).

“...las explicaciones tradicionales son limitadas, porque estiman que la acción tiene una única función: cambiar el mundo. Reconociendo una segunda función de la acción - una función epistémica - podemos explicar muchas de las acciones que el modelo tradicional no puede." (Kirsh y Maglio, 1994, p 513)

De acuerdo con Kirsh y Maglio, las acciones epistémicas mejoran los procesos cognitivos básicamente de tres modos: (i) reduciendo la memoria involucrada en la tarea mental (flexibilidad espacial); (ii) reduciendo el número de pasos involucrados en el proceso mental (complejidad temporal); y (iii) reduciendo la posibilidad de error del proceso mental (inestabilidad).

En la vida cotidiana, es muy común que se realicen acciones epistémicas que permiten ahorrar esfuerzo, memoria y tiempo. Por ejemplo, se ahorra esfuerzo recolectando la información 
pertinente antes de comenzar un trabajo; se ahorra memoria ubicando lo necesario sobre lo imprescindible para no olvidar nada; se ahorra tiempo preparando adecuadamente el espacio de trabajo, etc. Si bien estas tareas diferidas forman parte de la amplia gama de acciones que los autores denominan acciones epistémicas, son las actividades en tiempo real las que demandan rápidas respuestas y propician, en mayor medida, la realización de acciones epistémicas para favorecer la resolución de problemas en pequeños fragmentos de tiempo.

En este sentido, la lectura cantada a primera vista, entendida como una actividad de alta demanda cognitiva que implica la decodificación de símbolos, la creación de representaciones en tiempo real de la música plasmada en la partitura, y la ejecución vocal ajustada de la melodía que está siendo leída, emerge como una tarea cuya resolución podría requerir de la realización de acciones epistémicas.

En un trabajo posterior, Kirsh (1995) postula que al pensar se suelen realizar "estrategias complementarias" que podrían definirse como aquellas actividades organizativas que se aplican sobre elementos externos con el fin de reducir la carga cognitiva. Como ejemplos de actividades organizativas, el autor señala el acomodamiento de la posición y de la orientación de los objetos cercanos, tomar notas, manipular objetos que puedan simplificar la percepción, etc. Sin embargo, como señalan Hansjörg Neth y Stephen Payne (2002) la diferencia entre las acciones epistémicas y las estrategias complementarias es poco clara. Como se mencionó en los párrafos precedentes, Kirsh y Maglio (1994) explican el concepto de acción epistémica de manera amplia, como toda acción que mejora aspectos de la cognición, y presentan ejemplos de acciones diferidas que podrían considerarse como epistémicas. En este sentido, algunas de las acciones consideradas epistémicas a partir de esta definición entrarían también en la enunciación que Kirsh hace de estrategias complementarias, como por ejemplo, la preparación del lugar de trabajo. Sin embargo, Neth y Payne (2002) sugieren que la diferencia entre estos dos conceptos radica en que las acciones epistémicas modifican las estructuras cognitivas del organismo, mientras que las estrategias complementarias modifican el problema (por ejemplo, agrupando monedas para luego contarlas) para hacerlo más compatible con las capacidades cognitivas del organismo. Sin embargo, este planteo continúa siendo insuficiente para diferenciar estas dos ideas, ya que no está claro hasta dónde un cambio que fue realizado corporalmente en el problema, no genera modificaciones en las estructuras cognitivas del organismo y, del mismo modo, hasta dónde las acciones epistémicas que generan cambios en el entorno, no están modificando el problema. Más allá de estos posibles solapamientos conceptuales, resulta interesante considerar el concepto de acción epistémica como acción 
realizada en el entorno para mejorar la cognición, con el fin de contribuir a la explicación de la corporeidad en la lectura cantada a primera vista.

Más recientemente, Kirsh (2009) postuló diferentes modos en los que las representaciones externas (gráficos, símbolos, algoritmos, movimientos corporales, etc.) mejoran el poder cognitivo y, en línea con el concepto de acción epistémica, planteó que una parte importante de la cognición "puede ser entendida como un tipo de actividad epistémica externa" (p. 1107). Constantemente se reformulan las representaciones externas para que ellas codifiquen su contenido de manera que resulte (al propio sujeto y a los demás) más explícita y transparente. De acuerdo con Kirsh (2009), no se realiza esto internamente porque existen algoritmos públicos y artefactos compartidos fuera de la cabeza que facilitan la tarea. Los materiales externos (papel, lápiz, pizarra, etc.) permiten construir y manipular esas representaciones externas, las cuales juegan un papel importante en la interacción como un medio para compartir contenidos o significados. A este modo de construir, proyectar y compartir significados, Kirsh (2009) lo denominó interacción epistémica.

"...(U)n enfoque útil para entender la interacción epistémica es verla como un medio para reducir el costo de proyectar e imaginar mediante la creación de una estructura externa que puede soportar una proyección más compleja, un cómputo más eficiente, y un sentido más amplio, profundo y compartido del pensamiento." (Kirsh, 2009, p. 1108)

Si bien los conceptos de acciones epistémicas (Kirsh y Maglio, 1994; Maglio y Kirsh, 1996; Maglio y Wenger, 2000; Neth y Payne, 2002), estrategias complementarias (Kirsh, 1995; Neth y Payne, 2002) e interacción epistémica (Kirsh, 2009) involucran al cuerpo y al entorno en la cognición, parten desde la Ciencia Cognitiva Clásica, y en ese sentido, entienden a la cognición como procesamiento computacional de información. Estas ideas intentan echar luz sobre las razones por las que el pensamiento (entendido como cómputos mentales) resulta más eficaz y veloz cuando se apoya en el cuerpo y en el entorno. Sin embargo, se hace evidente que la perspectiva clásica, que entiende al cuerpo como un soporte material para el proceso mental y al movimiento como una respuesta a los datos procesados internamente, no alcanzan para explicar la participación del cuerpo en la cognición. Entonces, estos autores apelan a descripciones de procesos cognitivos que parecieran estar a medio camino entre una concepción clásica de la cognición y una perspectiva corporizada. Aquí, la mente sigue estando dentro de los límites del cerebro, pero el cuerpo y el entorno mejoran y/o facilitan los procesos que se realizan en ella. Como se verá más adelante, la idea de una participación de lo 
externo en la cognición puede ser vista como un punto de contacto fuerte con la teoría de la mente extendida (Clark y Chalmers, 1998) aun cuando las perspectivas sean básicamente diferentes y partan de concepciones distintas de mente y de cognición.

Durante mucho tiempo, el paradigma clásico tuteló la manera de entender la cognición musical ampliamente aceptada. La comprensión musical basada en la Ciencia Cognitiva Clásica se explica como un proceso simbólico-representacional que ocurre en la mente de los sujetos en función los conceptos que provee la teoría musical. A la vez, la comprensión puede ser exteriorizada corporal y verbalmente como un output del proceso mental, que puede constituirse en descripciones verbales, en transcripciones al código convencional de escritura musical, en movimientos corporales, en manifestaciones emocionales, etc.

Sin embargo, en las últimas tres décadas se desarrolló fuertemente un corpus de teorías cognitivas que plantean un modo diferente de entender la cognición humana, y por ende la cognición musical en particular, otorgándole un rol central al cuerpo y al entorno: la Teoría de la Cognición Corporizada.

\section{Ciencias Cognitivas de Segunda Generación (CC2G). Consideraciones Generales}

Gradualmente, el interés filosófico en la cognición corporizada comenzó a desarrollar alternativas al marco del dualismo cartesiano (Gomila y Calvo, 2008). Del mismo modo, los avances en neurociencia comenzaron a advertir que la separación entre mente abstracta y materia ya no podía sostenerse (ver por ejemplo, Damasio, 1999). Hallazgos como la plasticidad neuronal, según la cual el cerebro es un órgano dinámico y plástico que se modifica de acuerdo a las necesidades del organismo (Kandel, 2001); las neuronas espejo, que se activan cuando un individuo observa a otro realizar una acción como si la estuviese realizando él mismo (Rizzolatti et al., 2007); o la recurrencia de determinados patrones de activación neuronal en función de las características corporales del organismo y de su entorno que podrían entenderse como representaciones del mundo y de la experiencia en él (Damasio, 1999); son algunos ejemplos de los avances neurocientíficos que abonan las nuevas teorías cognitivas basadas en la interacción.

Esta nueva corriente de pensamiento planteó la necesidad de revisar el modelo clásico de la cognición, destacando al cuerpo en un papel activo, ya no como un sustento material para la mente etérea que carecía de él, sino como parte del sistema cognitivo mismo, que también incluye al entorno. 
Lejos de ser un cuerpo teórico uniforme, las $\mathrm{CC} \mathrm{G}^{1}$ constituyen un gran paraguas bajo el cual se desarrollan diferentes líneas teóricas con matices sumamente variados. Sin embargo, todas ellas coinciden en destacar el rol central del cuerpo y su interacción dinámica con el entorno en la producción de significados para las experiencias humanas (ver por ejemplo Gibson, 1979; Lakoff y Johnson, 1980; Varela, 1988; Clark, 1999, 2008; Nöe, 2004; Gibbs, 2006; Johnson, 2007; Calvo y Gomila, 2008; Chemero, 2009). Aquí, el conocimiento no se aloja en la mente ni en el entorno, sino que se produce en y por medio de la interacción.

Francisco Varela (1988) plantea que el enfoque enactivo ${ }^{2}$ surge a partir de una profunda insatisfacción por el concepto de cognición carente de sentido común que postula el cognitivismo: "...una representación atinada de un mundo externo que está dado de antemano" (pp. 88-89). Según Varela, las experiencias cognitivas cotidianas demuestran constantemente cuán incompleta es esta idea. En gran medida, la capacidad cognitiva humana implica poder plantear aquello que resulta relevante en las vivencias en función del sentido común. Las cuestiones relevantes no son predefinidas sino enactuadas, es decir, que dependen de la acción en cada situación dentro de un contexto particular. Además, Varela plantea que el cognitivismo presenta varias lagunas explicativas, entre las que menciona la limitación que significa el procesamiento simbólico secuencial cuando la tarea requiere una cantidad importante de operaciones, como por ejemplo, el análisis de imágenes. En este caso, las operaciones secuenciales, realizadas de una en una, consumirían gran cantidad de tiempo, y esto no se corresponde con la realización habitual de este tipo de tarea. Del mismo modo, la localización del procesamiento simbólico que postula el enfoque clásico implica que cualquier falla en una parte del sistema conlleva un daño irreparable en el mismo. Contrariamente, la cognición parece ser mucho más dinámica. Los límites que podrían trazarse entre las regiones de elementos discretos que intervienen, por ejemplo, en un juego de ajedrez, no son tan precisos en situaciones de movimiento entre objetos, por ejemplo, conducir un automóvil. Aquí, entran en juego una gran cantidad de elementos interrelacionados que requieren un uso continuo del sentido común (Varela, 1988).

De acuerdo con Toni Gomila y Paco Calvo (2008) la cognición es de naturaleza corporizada y está embebida en un entorno. Como tal, debe ser abordada considerando tanto al aparato motor y perceptual, que permiten la interacción con el entorno, como el entorno mismo.

\footnotetext{
${ }^{1}$ Este conjunto de teorías corporizadas también son conocidas como post-cognitivismo, enactivismo, cognición corporizada y Embodiment, entre otros.

2 Enactivo en este contexto refiere a todo aquello 'actuado' o 'puesto en acto' por el organismo pensante, destacando la acción corporal y la interacción con el entorno.
} 
"La cognición no es una cuestión de operaciones simbólicas o subsimbólicas, sino de interacción, de acoplamiento. Para entender un sistema cognitivo tenemos que tomar como unidad de análisis el 'sistema' integrado en su medio ambiente circundante - un tipo de interacción análogo a las nociones biológicas de las especies y los hábitats. (...) comprender la cognición implica la comprensión del sistema acoplado como tal, y no la mente/cerebro en sí mismo." (Gomila y Calvo, 2008, p. 7).

Esta explicación del modo de abordar la cognición desde la perspectiva corporizada, revela algunas de las rupturas con el modelo cognitivista clásico. En primer término, los autores ponen de manifiesto que se prioriza la interacción con el entorno y se descarta la simbolización clásica como descripción del proceso cognitivo. Del mismo modo, ya no se puede pensar en una mente ubicada en el cerebro como el lugar en donde se manifiestan los procesos cognitivos, sino que es necesario comprender la cognición como un sistema que involucra al cuerpo y al entorno.

En ese mismo sentido, Andy Clark (1997) plantea que las teorías del pensamiento corporizado, y las soluciones a problemas comunes que ellas postulan, exigen

"...abandonar la idea (común desde Descartes) de lo mental como una esfera distinta del ámbito del cuerpo; abandonar la idea de unas limpias líneas divisorias entre percepción, cognición y acción; abandonar la idea de un centro ejecutivo donde el cerebro lleva a cabo el razonamiento de alto nivel; $y$, sobre todo, abandonar los métodos de investigación que separan artificialmente el pensamiento de la actuación corpórea" (p. 33).

Aquí, Clark señala de manera concisa ciertas discontinuidades de las CC2G en relación con el cognitivismo clásico, pero lo hace desde la perspectiva del investigador. Resulta sugestivo el planteo acerca de la necesidad de abandonar líneas divisorias claras entre percepción, cognición y acción. Como se mencionó arriba, la CCC los toma como elementos separados que se accionan ordenadamente para constituir el proceso cognitivo: la percepción brinda el input a través de los sentidos, el comando central convierte la información en símbolos y los procesa, y el cuerpo se acciona para dar una respuesta física acorde al proceso cognitivo. Sin embargo, al poner el foco en la interacción corporal con el entorno como el modo de generar significados, el modelo de la cognición corporizada, como señala Clark, no da lugar a estas divisiones tajantes. Entender la cognición desde esta perspectiva implica partir desde una idea de mente que no circunscribe los procesos cognitivos al plano cerebral, sino más bien, es 
necesario concebir una mente que involucra la complejidad de la interacción entre organismo y entorno. No debe entenderse aquí a la cognición corporizada como un modo particular de cognición, como podría pensarse en contraste con una cognición estática por ejemplo, sino que es el modo natural en el que las personas conocen el mundo, producen significados, piensan y comprenden sus experiencias (Clark, 2008).

Por su parte, Varela (1988) señala algunos contrastes que surgen en el pasaje de las CCC a las teorías enactivistas, en función de las tensiones epistemológicas entre los modelos: de lo universal hacia lo contextual; de lo abstracto y simbólico hacia lo ligado al cuerpo y a la historia; de un mundo predefinido a un mundo enactuado, etc.

Esta superación del dualismo cartesiano implica reconsiderar el lugar y el rol del cerebro humano en los procesos de significación. Como se mencionó más arriba, la neurociencia aporta evidencia empírica que apoya la idea de una mente corporizada y embebida en un entorno (ver por ejemplo, Damasio, 1999). En este sentido, ya no es posible hablar de un cerebro como exclusivo contenedor de la mente y el significado. Siguiendo esta línea Mark Johnson (2007) plantea que

\footnotetext{
"el significado no reside en nuestro cerebro, no reside en una mente descorporizada. El significado requiere un cerebro funcional, en un cuerpo vivo que se comprometa con el medio -que es tanto social y cultural, como físico y biológico-" (p. 152).
}

En síntesis, el argumento de las CC2G se basa en una concepción más abarcadora de mente, que no se circunscribe a los límites del cerebro, sino que interactúa corporalmente con el entorno como un sistema integrado y en cuya interacción se generan los significados acerca del mundo y de las experiencias humanas. Comprender el modo en que se produce la cognición, implica abordar el sistema mente/cuerpo/entorno como tal, observando tanto las acciones que realiza el cuerpo en interacción con el entorno, como las características de ese entorno y los significados emergentes de esa interacción.

\section{Cognición Musical Corporeizada}

Las ideas de las CC2G tuvieron una fuerte repercusión en el ámbito de las investigaciones en cognición musical, que comenzaron a poner el foco en el modo en que el sujeto experimenta la música a través de su mente y su cuerpo como un todo unificado e indivisible. A partir de estas ideas, se desarrollaron diferentes enfoques corporizados de la cognición musical que 
comparten la relevancia de la participación corporal en la cognición, presentando matices muy variados.

\section{El Enfoque Basado en la Acción}

Sustentado en estas teorías, Marc Leman (2008) propone un enfoque basado en la acción para comprender el vínculo entre lo mental y lo físico. La música es entendida aquí como formas sónicas en movimiento, que "tienen un impacto directo en la fisiología humana porque evocan resonancias corporales que dan lugar a la significación." (Leman, 2008, p. 15). Esta significación, según Leman, es corporal y está basada en la realización de acciones subjetivas que pueden ir desde movimientos muy simples, como la marcación espontánea de un pulso, hasta movimientos complejos y convencionales que pueden estar asociados a las propiedades musicales de la obra, como coreografías, representaciones espaciales de la altura, señas estereotipadas en representación de las notas, etc. En este sentido, el compromiso musical tiene una base corporal que posibilita una variedad de interacciones con la música: gestos dependientes del contexto cultural (como los gestos simbólicos), mímesis (por ejemplo, la imitación del movimiento corporal de los ejecutantes), ejecución instrumental ensayada, etc.

De acuerdo con Leman (Ibíd.), es posible entender estas acciones corporales basadas en la resonancia con la música como descripciones del fenómeno musical. Así, el cuerpo humano recibe el impacto de la energía física de la música y resuena en función de esta energía significándola corporalmente. Esas resonancias se traducen en acciones subjetivas que permiten interactuar con ella y describirla por medio de las articulaciones corporales. Un ejemplo de articulaciones corporales que funcionan como descripciones musicales, son los movimientos de los pasos de danza espontáneos realizados al bailar con la música. Estos movimientos pueden presentar información acerca de una gran variedad de contenidos musicales, desde cuestiones estructurales formales, como la organización métrica, las unidades morfológicas, etc., hasta aspectos más expresivos como las fluctuaciones en el tempo, etc. También se puede pensar en los gestos de los directores de coros y de orquestas que deliberadamente conllevan descripciones detalladas de la música antes de que se produzca la energía física. En razón de esta particularidad podrían ser interpretados como una resonancia corporal con la idea previa de esa energía física que es imaginada por el director. Aunque no se forme parte de la orquesta que está siendo dirigida, es posible establecer correspondencias directas entre los movimientos que realiza el director y la música que está sonando, por lo que tales movimientos pueden constituir descripciones corporales de esa música. En tal caso, esto habilita la vinculación, a través de la resonancia física, de los 
significados corporales personales y subjetivos de las formas sónicas en movimiento con los rasgos musicales fenoménicos de la música que se está escuchando.

\section{Teoría de la Metáfora Conceptual en la Comprensión Musical}

Una de las teorías filosófico-cognitivas que destacan la participación del cuerpo en la cognición, y que más se ha aplicado a la música en los últimos años, es la Teoría de la Metáfora formulada por George Lakoff y Mark Johnson $(1980,1999)$. Según esta teoría, las personas cuentan con algunas estructuras cognitivas básicas que han sido desarrolladas por medio de la interacción corporal temprana con el entorno. Estas estructuras intervienen en los procesos de significación y comprensión de dominios abstractos, como la música. Se utiliza el conocimiento que proviene de un dominio de la experiencia para comprender otro por medio de un proceso metafórico que involucra la imaginación, y que se ha denominado mapeo entre dominios (Lakoff, 1990, 1993). De este modo, el conocimiento proveniente de dominios de base corporal y sensoriomotor acumulado a lo largo de la experiencia, es utilizado para ayudar a comprender dominios más abstractos como el dominio musical. Este proceso de transferencia de significados se hace evidente en la utilización de metáforas al hablar acerca de la música. Para hacer referencia a modificaciones en la frecuencia de un sonido, por ejemplo, comúnmente se dice que el sonido sube o baja, como si se tratara de un movimiento en el espacio. Incluso en ocasiones se realizan movimientos con la mano hacia arriba o hacia abajo para representar un movimiento melódico determinado. Este uso de la metáfora no es meramente lingüístico, sino que conlleva un modo de significar y conceptualizar aspectos del dominio abstracto. Es decir, los cambios de altura en las notas musicales son entendidos como esos movimientos de ascenso y descenso en el espacio. En virtud de la naturaleza abstracta de la música, la teoría de la metáfora conceptual brinda una explicación plausible de cómo se construyen los significados musicales.

Sustentados en esta teoría, se han desarrollado numerosos trabajos que abordan diferentes aspectos de la comprensión musical entendida como mapeo entre el dominio corporal y el musical (ver por ejemplo: Johnson y Larson, 2003; Zbikowsky, 1997; Martínez, 2005; Peñalba, 2005; Martínez y Anta, 2009; Jacquier y Callejas Leiva, 2011; Kohn y Eitan, 2009).

\section{El Flujo del Significado en la Música}

De acuerdo con Johnson (2007), el prejuicio de que el significado surge únicamente a partir del lenguaje, ha guiado a los teóricos clásicos a explicar el significado musical de acuerdo a categorías lingüísticas, como las palabras, las frases, las oraciones, etc. Si la música es 
entendida solamente como analogía del lenguaje verbal, entonces todo significado se limita a un contenido referencial y se excluye todo significado no verbal. La sintaxis musical que derivó de estas ideas aportó un marco interesante para el análisis musical formal, pero propició, al mismo tiempo, la descorporización de la música, al desestimar el rol del cuerpo en la significación. Sin embargo, Johnson propone una idea muy diferente de significación musical de base corporal y experiencial.

"... la música es significativa porque puede presentar el flujo de la experiencia humana, del sentimiento $y$ del pensamiento en concreto, en formas corporizadas, y esto es significativo en su más profundo sentido. Un hecho fundamental acerca de la música es que llama a nuestro sentido vivenciado de la vida" (Johnson, 2007, p. 236).

Más allá de la escucha mediada por los conceptos teóricos musicales que pueden tener los músicos formados, Johnson (2007) plantea que en general la música se escucha 'metiéndose' imaginativa y emocionalmente dentro de ella. La música llama a mover el cuerpo y emociona a través del impacto de los atributos métrico, tonal, rítmico, melódico, armónico, tímbrico, etc., que se siente en él. "La música nos captura, nos lleva a lo largo de una sensual aventura rítmico-tonal, y luego nos deposita, cambiados, en un lugar diferente de donde empezamos." (Ibid., p. 237).

La experiencia de involucrarse imaginativamente con la música conlleva todas las cualidades musicales percibidas, generando significados que no son lingüísticos ni verbales, sino corporizados, sentidos y enactuados a través del compromiso corporal con la música.

De acuerdo con Damasio (1999), el significado consiste en series de imágenes relacionadas, las cuales constituyen patrones de activación neuronal. Estas imágenes refieren a patrones mentales estructurados que el sujeto construye a partir de cualquiera de las modalidades sensoriales. Siguiendo esta idea, Johnson (2007) plantea que el entendimiento de la música se basa en imágenes relacionadas, que son entendidas como patrones de la experiencia acerca de los eventos y objetos musicales. Estos patrones que son construidos a partir del sistema auditivo (y sensorial en general), evocan respuestas sentidas y pensamientos acerca de la música, y definen su significado. 


\section{El Enfoque Ecológico de la Percepción Musical}

Sustentado en el enfoque ecológico de la percepción visual postulado por James Gibson (1979), Eric Clarke (2005) plantea entender el significado musical desde una perspectiva similar basada en la relación ecológica con el mundo que nos rodea.

Según la teoría de Gibson (1979) el entorno se presenta altamente estructurado, y la percepción se encarga de captar o recolectar esa información perceptual ya estructurada por la naturaleza y por la cultura. Clarke (2005) plantea que lo importante aquí no es atender a la construcción que el organismo puede hacer a partir del entorno, sino "considerar qué es lo que está directamente especificado por la información ambiental." (p.17). El sistema perceptivo se ajusta a la información estructurada del entorno, captando las especificaciones que brinda esa información, tales como el color, la forma, la textura, la amplitud de los sonidos, la altura, etc. En este sentido, la percepción es considerada como

"un proceso de autoajuste, en el que la recolección de información ambiental está intrínsecamente reforzada, de modo que el sistema se autoajusta automáticamente a fin de optimizar su resonancia con el medio ambiente" (Clarke, 2005, p. 19)

Para que se produzca este proceso, es necesario que el organismo cuente con un sistema perceptivo capaz de resonar en consonancia con el entorno. La percepción no es considerada como un proceso pasivo, sino que está estrechamente vinculada a la acción. Cuando se percibe la información del ambiente surgen reacciones corporales espontáneas que demuestran esta relación entre percepción y acción, por ejemplo, las marcaciones de pulsos con los dedos o con los pies al escuchar música, el llanto, la danza, etc. Estas acciones corporales permiten la vinculación del organismo con la información del entorno y su comprensión de manera acabada. La acción involucrada en los procesos perceptivos resalta la intervención del cuerpo en la comprensión del entorno. Es aquí donde este enfoque se vincula con las ideas que se pretenden desarrollar en esta Tesis.

Para comprender el enfoque ecológico de la percepción, es necesario considerar también la idea de que el sistema perceptual humano puede modificarse a través del aprendizaje. De acuerdo con Clarke (2005), los organismos se vuelven más sensitivos a detalles del entorno que antes no percibían. Este aprendizaje ocurre a lo largo de la vida a través de un proceso que se da sin instrucción o entrenamiento particular, pero que se vincula con las acciones que 
realizan los organismos en determinados entornos del que cada vez captan mayor información.

Según el enfoque ecológico, en el entorno existen invariantes que le permiten al organismo entenderlo de un modo más o menos estable a pesar de los continuos cambios que presenta. Estas invariantes pueden ser entendidas como las relaciones entre las propiedades de los estímulos que no se modifican a pesar de los cambios que sufre el entorno (Clarke, 2005). En contextos musicales, las invariantes pueden estar presentes en una misma obra (como por ejemplo, la estructura métrica estable, la tonalidad, ciertos motivos repetidos o elaborados, la instrumentación, etc.) o en un conjunto de obras con rasgos comunes (como por ejemplo, la estructura métrica superpuesta en la zamba, la instrumentación típica, la forma, etc.). En este último caso, el conjunto de invariantes en un grupo de obras determina el estilo, y son justamente estas invariantes las que permiten clasificar perceptualmente una obra en determinado estilo o género musical.

Al percibir las características invariantes de un determinado objeto del entorno, inmediatamente se perciben las posibilidades (oportunidades) que ese elemento brinda para la acción. Es decir, cuando al ver una silla, por ejemplo, ésta se ofrece perceptualmente como un elemento para sentarse, descansar, etc. Gibson (1979) denomina a este tipo de posibilidades para la acción como affordances ${ }^{3}$, y es uno de los conceptos centrales del enfoque ecológico. Si bien dependen de las propiedades del objeto, son producto tanto de las propiedades objetivas como de las necesidades del organismo perceptor, y en este sentido, se pueden percibir diferentes affordances de un mismo objeto dependiendo de esas necesidades (Clarke, 2005). La perspectiva ecológica entiende a la percepción como un proceso en el que interviene la acción corporal, y como tal, es considerada un flujo perceptual.

De acuerdo con Clarke (2005), el enfoque ecológico de la percepción constituye una alternativa al modelo del procesamiento de la información impulsado por las CCC, que da una respuesta coherente a la multiplicidad de respuestas inmediatas de los oyentes a los atributos que presenta el entorno que incluye tanto la localización física de la fuente como la función estructural del sonido y su calor cultural.

\footnotetext{
${ }^{3}$ Se utiliza aquí el término en lengua inglesa affordances tal como lo presenta Gibson por no hallar una traducción apropiada que defina la naturaleza del concepto. Esta decisión se corresponde además con el modo en que aparece este concepto en la literatura en castellano sobre el tema. El término refiere a las posibilidades $u$ oportunidades para la acción que un elemento del entorno ofrece al organismo perceptor.
} 
"Las ventajas de este enfoque en cuanto a la música se refiere, es que pone el énfasis en la investigación de las invariantes que especifican todos los fenómenos que la música es capaz de ofrecer (afford) en relación con la diversidad de las capacidades perceptivas de los diferentes oyentes, y que ofrece un marco en el que los atributos de la música que previamente han sido considerados como polos opuestos (desde las fuentes físicas y las estructuras musicales hasta el significado cultural y el contenido crítico) pueden ser entendidas juntas." (Clarke, 2005, p. 47)

Hasta aquí, se han presentado algunas de las perspectivas corporizadas de la percepción y de la cognición musical sustentadas en la participación del cuerpo y su interacción con el entorno, que resultan relevantes para este estudio, y que se erigen como alternativas al modelo clásico. Se retomaran algunas de estas ideas para explicar la participación del cuerpo en las tareas de cantar a primera vista que será analizada más adelante.

\section{La Teoría de la Mente Extendida}

De acuerdo con la Teoría de Mente Extendida delineada por Andy Clark y David Chalmers (1998), la mente humana trasciende los límites del cerebro y se extiende hacia los elementos que conforman el mundo externo, incorporando el entorno físico y social a los procesos cognitivos mediante la interacción corporal. Así, los componentes del mundo externo tendrían un rol activo en la cognición humana, incidiendo tanto en el organismo como en su conducta. Clark y Chalmers denominaron a este proceso externalismo activo. Los autores no niegan la importancia del cerebro en la cognición, ni tampoco la correspondencia de ciertos estados mentales con estados internos, sino que sostienen que muchos de los procesos cognitivos que son desplegados para construir significados incluyen elementos del entorno a través de la interacción corporal. En este sentido, Clark y Chalmers (1998) mencionan las investigaciones de Kirsh y Maglio (1994; Kirsh,1995), haciendo foco especialmente en el concepto de acción epistémica, como un antecedente que comienza a considerar la participación del cuerpo y el entorno en la cognición. Sin embargo, señalan que las acciones epistémicas exigen la extensión del crédito epistémico fuera de los límites del cerebro. A partir de esta idea los autores postulan un principio en el que equiparan el proceso cognitivo interno con un proceso cognitivo que incluye al mundo externo, que posteriormente fue denominado principio de paridad (Clark, 2008). 
"Si al enfrentarnos a una tarea, una parte del mundo funciona como un proceso que si ocurriera en la cabeza no duraríamos en aceptarlo como parte del proceso cognitivo, entonces, esa parte del mundo es (desde ese momento) parte del proceso cognitivo." (Clark y Chalmers, 1998, p.8)

Por ejemplo, si se realizan cálculos matemáticos valiéndose de un papel y un lápiz para facilitar el proceso, entonces ese papel y ese lápiz son parte del proceso cognitivo desplegado para resolver el cálculo. Sin embargo, para que ciertos elementos del mundo externo puedan ser incluidos en un sistema cognitivo individual deben cumplir cuatro criterios complementarios (Clark, 2008):

(i) El recurso debe estar "confiablemente disponible" y ser "típicamente invocado" (p. 79). Clark y Chalmers (1998) explican su teoría apelando al ejemplo de Otto, un enfermo del mal de Alzheimer que siempre lleva consigo un anotador (por lo que estaría confiablemente disponible), y lo consulta cada vez que lo necesita para recuperar alguna información (por lo que sería típicamente invocado). Otto no responde que no sabe hasta no consultar en su anotador.

(ii) Toda información recuperada debe ser automáticamente aceptada, es decir, que no debe dar lugar a dudas y cuestionamientos. Otto confía plenamente en la información que recupera del anotador, y quienes interactúan con él, no cuestionan esos datos.

(iii) La información contenida en el recurso externo tiene que ser fácilmente accesible cuando se la requiere. Otto solamente necesita abrir su anotador en la sección correspondiente para consultar la información que necesita.

(iv) La información contenida en el recurso externo debe haber sido conscientemente aceptada en algún momento, y por lo tanto, esa aceptación tendrá una consecuencia. Cuando Otto decide incorporar nueva información en su anotador es porque acepta su veracidad.

Sin embargo, concebir el entorno como un recurso cognitivo tiene algunas consecuencias que merecen ser enunciadas y eventualmente discutidas, por ejemplo, reconocer que no hay un límite preciso entre el pensador y su mundo, sino que tal vez sea necesario considerar al "sistema inteligente como un proceso extendido en el espacio y en el tiempo" (Clark, 1999, p. 279). Así, la inteligencia no sería un ingenio abstracto, incorpóreo e interno limitado por la piel y los huesos, sino, por el contrario, un sistema integrado y extendido en el espacio que incluiría al cuerpo y a el entorno. 
Esta teoría entiende que el pensamiento no depende de un comando ejecutivo central. Por el contrario asume que la cognición se realiza de manera extendida a través de diversos modos en los que el sujeto se vincula con su entorno. De este modo, el pensamiento no es el resultado de cómo los sistemas perceptuales conllevan la información a los sistemas centrales de manera adecuadamente codificada y, luego, de cómo esa información sale procesada de esos sistemas con el objeto de activar algún tipo de respuesta de acción (conductual). Así, la distinción entre percepción y cognición, por caso, aparece desdibujada, si ya no se trata de una división del trabajo entre los componentes del sistema.

De acuerdo con estas ideas, la frontera entre la mente y el mundo se torna difusa y plástica, lo cual permite entender a la cognición humana como un proceso interactivo entre el cerebro, el cuerpo y el mundo, conformando un sistema cognitivo unificado e indivisible. La radicalidad de esta teoría ha recibido numerosas críticas, especialmente vinculadas a la idea de que algunos elementos del mundo puedan ser parte del proceso cognitivo, constituyendo una mente extendida en el entorno (ver por ejemplo, Fodor, 2009; Menary, 2010). Sin embargo, esta idea de una mente que piensa dentro de los límites de la piel y el cráneo, pero que también sobrepasa esos límites, se extiende y piensa afuera, valiéndose de todo el entorno físico y social como recurso e interactuando con él a través del cuerpo, resulta al menos sugerente.

\section{El Gesto Corporal}

El estudio de la participación del cuerpo en los procesos de significación y comunicación humanas ha puesto el foco en la gestualidad corporal como uno de los sustentos de estos procesos. No obstante, el abordaje del gesto corporal presenta numerosas alternativas que incluyen conceptos, definiciones y categorías particulares, revelando un ámbito de estudio sumamente heterogéneo y complejo. Se presentarán aquí algunas de las ideas acerca del gesto en diferentes disciplinas, que resultan relevantes para esta Tesis, con el fin de echar luz sobre este concepto que implica un cuerpo participativo, generador de significado y comunicativo. Luego, sobre esta base se describirá el movimiento corporal en la lectura a primera vista como un modo de explicar la participación del cuerpo en esta tarea.

Una de las definiciones más comunes del término gesto refiere al "movimiento del rostro, de las manos o de otras partes del cuerpo con que se expresan diversos afectos del ánimo." (Diccionario de la Real Academia Española, 2012). Sin embargo, existen múltiples definiciones de gesto dependiendo del ámbito disciplinar en donde emergieron, por lo que resulta necesario explicitar las características principales y definir un grupo de categorías específico de 
acuerdo al contexto donde han surgido (Mauleón, 2008). En línea con esta idea, Claude Cadoz y Marcelo Wanderley (2000) analizaron exhaustivamente una importante cantidad de conceptos relativos al gesto vinculados tanto a la interacción humano-humano y humanomáquina, como al dominio musical. A pesar del amplio cuerpo de investigaciones que abordaron, los autores consideran que no es posible extrapolar definiciones y categorías gestuales de otros ámbitos al dominio musical, sin un examen cuidadoso y una adaptación en función de las características del campo.

Aun así, muchos de los hallazgos en investigación sobre el gesto en la comunicación humana son aplicables, con los cuidados pertinentes, a diferentes ámbitos y brindan un punto de partida para la investigación del movimiento corporal en variados contextos disciplinares.

En el ámbito de los estudios lingüísticos del gesto, David McNeill (1992) ha planteado que los gestos no son accesorios del lenguaje, sino que poseen sistemas de procesamiento diferentes, y se integran con el fin de dar a entender lo que se comunica. Para McNeill (1992), es a través de los gestos que las personas hacen visibles sus recuerdos y sus pensamientos internos. Aun cuando presentan propiedades específicas diferentes, el habla y el gesto son co-expresivos y poseen una sincronía semántica, es decir, que ambos presentan los mismos significados al mismo tiempo. El gesto posee la propiedad de ser global y sintético. Es global porque el todo determina el significado de las partes, y es sintético porque un único gesto puede combinar muchos significados. Sin embargo, no poseen una estructura jerárquica, por lo que dos gestos sucesivos no pueden combinarse para conformar un gesto más grande y de mayor complejidad (propiedad no combinatoria). Cada gesto es una completa expresión de significado en sí mismo. No obstante, McNeill acuerda con Kendon (1980) en que existe una jerarquía kinésica, en la que una unidad gestual, definida como el período de tiempo desde que una extremidad comienza a moverse hasta que vuelve a la posición de descanso, está compuesta por varios gestos o frases gestuales. Aunque a simple vista parece existir una contradicción entre la jerarquía kinésica y la propiedad no combinatoria de los gestos, esto no es así, ya que los gestos no se combinan para formar uno más complejo, sino que se agrupan en unidades gestuales de acuerdo a la detención del movimiento. Estas propiedades básicas resultan sumamente interesantes para el análisis del gesto en la lectura musical cantada, porque brindan la posibilidad de pensar los gestos como una unidad completa de significado, de agruparlos en frases gestuales, y de analizar sus vinculaciones con las unidades de significado musical.

Siguiendo a Kendon (1980), McNeill señala que existen tres fases básicas del gesto de acuerdo a su desarrollo temporal: preparación, ataque y retracción. Por ejemplo, tómese por caso el de 
un hablante que le dice a su interlocutor en el contexto de una conversación que otra persona "tomó el picaporte y abrió la puerta" y que al decirlo realiza los movimientos implicados en la acción real de mover el picaporte para abrir una puerta. De acuerdo con las observaciones y descripciones de McNeill, la fase de preparación podría consistir en levantar la mano derecha y moverla hacia adelante al mismo tiempo que se va abriendo; el ataque consistiría en cerrar la mano y desplazarla hacia atrás y hacia la derecha representando la apertura de la puerta; y la retracción podría ser el regreso de la mano a la posición inicial. También podría existir una fase de sostén previa al ataque y otra posterior al ataque. Sin embargo, algunas de estas fases podrían no estar presentes; solamente la fase del ataque del gesto es obligatoria para que éste sea considerado como tal.

En el ámbito de los estudios musicales vinculados al gesto, Leman (2008) diferencia el gesto de la acción, entendiendo que el primero refiere a "un movimiento con un significado definido que se vale de sí mismo" (p. 132), mientras que el segundo alude a un control gestual que tiene una meta particular, como por ejemplo, ejecutar un sonido en un instrumento musical. En términos generales, Leman (2010) plantea que los gestos se vinculan estrechamente tanto al movimiento corporal como al significado musical. Más allá de las múltiples relaciones que pueden mencionarse entre música y movimiento físico (resonancia pasiva, sincronización, afinación, empatía, etc.) y entre música y significado (vinculados al compromiso emocional expresivo, a la interacción social, a la metáfora, etc.) lo realmente importante, según Leman (2010) es el rol del movimiento corporal como mediador entre la mente y el entorno físico. Aquí es donde entra en juego el gesto como articulador de esa mediación, y en ese sentido "el gesto no es ni puramente físico ni puramente mental, sino que es corporizado por naturaleza" (Leman, 2010, p. 130).

El enfoque que plantea Leman $(2008,2010)$ en relación con la participación del movimiento corporal y del gesto en los procesos de significación musical resulta un aporte sumamente relevante para el campo de las investigaciones en cognición musical corporizada. Sin embargo, la idea de la mediación corporal gestualmente articulada entre dos mundos bien definidos (el mental y el físico) resulta por lo menos insuficiente. La relación cuerpo/mente/entorno parece ser un poco más compleja en la cognición humana. Volviendo a las ideas de Gomila y Calvo (2008), comprender la cognición implica considerar este complejo como un sistema integrado, y no como mundos independientes relacionados por el movimiento corporal. En una visión más radical, Clark (1999) plantea que la mente humana puede extenderse al entorno, y que, de este modo, tanto el cuerpo como ciertos elementos externos pueden formar parte de la mente. Si bien estas ideas no son completamente opuestas, matizan de diferente manera el 
modo en que el cuerpo participa en la cognición. Entenderlo únicamente como un mediador entre la mente y el entorno parece no despegarse completamente de las ideas clásicas, y podría derivar en una subestimación del rol del cuerpo en la significación musical. Más adelante, se revisarán estas ideas y se elaborarán algunas alternativas basadas en los conceptos presentados en las diferentes perspectivas corporizadas y gestuales abordadas.

De acuerdo con Marc Leman y Rolf Godøy (2010) un gesto es, en términos generales, "un movimiento de una parte del cuerpo, por ejemplo una mano o la cabeza, para expresar una idea o significado" (p. 5). De manera interesante, los autores señalan que en el contexto musical, los gestos pueden ser entendidos de acuerdo al modo de participación musical. En la ejecución, por ejemplo, los gestos son movimientos desplegados para controlar el instrumento cuando se tocan figuras melódicas, para coordinar diferentes aspectos de la ejecución entre los músicos, o incluso para impresionar a la audiencia (en los solos, por ejemplo). En el contexto de la escucha musical, los gestos son aquellos "movimientos que acompañan o expresan la actividad del oyente" (Ibíd., p. 5), como por ejemplo, mover alguna parte del cuerpo en sintonía con el pulso, bailar, etc.

Sin embargo, no todo movimiento corporal puede ser entendido como un gesto. Para que esto ocurra, hace falta que el movimiento conlleve algún significado (Ibíd.). Esta idea resulta sumamente interesante, porque no solo separa los conceptos de gesto y movimiento estableciendo una línea divisoria, sino que también enfatiza el vínculo entre gesto y significado o, para ser más preciso, entre gesto y expresión de significado. Aquí, expresión de significado refiere al modo en que el cuerpo comunica algún significado en relación con la intención de quien lo realiza, y que puede ser comprendido por quienes lo observan. Pero es necesario considerar que esta apelación a la expresión de significado implica incluir aspectos subjetivos en el concepto de gesto. Un observador, en un contexto dado, puede considerar que un movimiento determinado expresa un significado en particular, mientras que otro, aun en idéntico contexto, puede estimar que ese mismo movimiento no conlleva ningún significado (lbíd.). Tal vez el carácter subjetivo y contextual del gesto sea uno de los aspectos más conflictivos al que se enfrenta el estudio de los gestos y de su rol en la cognición. Más adelante, al observar y analizar la posibilidad de considerar a los movimientos desplegados durante tareas de lectura a primera vista como gestos, se retomará esta idea y se discutirá la aplicación del concepto en este ámbito (ver estudio 2 en el capítulo 3). 


\section{Tipologías Gestuales}

El abordaje del gesto corporal en diversos ámbitos disciplinares, sumado a la complejidad que esto implica, ha propiciado el surgimiento de diferentes tipologías gestuales, bajo la idea de que la clasificación constituye una de las principales herramientas para su estudio. En este apartado, se describirán algunas de las tipologías que han tenido mayor impacto en el ámbito musical, y que podrían ser consideradas para su aplicación en la lectura cantada a primera vista.

McNeill (1992) propuso cinco categorías para el análisis de los gestos durante el habla: gestos icónicos, gestos metafóricos, batidos, gestos cohesivos y gestos deícticos. Para ilustrar estas categorías se utilizarán los ejemplos que propone McNeill a partir de observaciones de hablantes que describen, a un interlocutor, diferentes episodios de dibujos animados. Los gestos icónicos poseen una relación muy cercana con el contenido semántico del discurso hablado, y son representaciones figurativas de objetos o acciones. Por ejemplo, al describir una escena en la que el personaje dobla un árbol hasta el piso el hablante realizó un movimiento como si tomara algo con la mano en lo alto, y lo tirara hacia abajo. Los gestos metafóricos también son figurativos, pero ilustran una idea o concepto abstracto, como ocurrió con un hablante que le explicó a su interlocutor que le iba a contar un dibujo animado haciendo el movimiento de entregarle algo que parecía una caja cuadrada, como si la idea del género 'dibujo animado' estuviera contenida en esos límites que establecían los brazos y las manos. Los batidos, similares a la marcación del tiempo musical, son los movimientos de la mano que van junto con la pulsación rítmica del discurso hablado, y suelen ser movimientos cortos y repetitivos. Los gestos cohesivos cumplen la función de unir dos partes del discurso que están temáticamente relacionadas pero temporalmente separadas, a través de la repetición de la forma gestual, del movimiento, o del lugar en el espacio gestual. Pueden ser gestos icónicos, metafóricos o batidos, el punto está en la reaparición que señala la recurrencia o continuación de un tema. Tal es el caso de un hablante que realizó el gesto icónico de entrecruzar las manos para referirse a una red de cableado del tranvía, luego interrumpió el relato para enfatizar que estaba hablando del sistema de tranvía realizando un movimiento con la mano hacia adelante y hacia atrás al costado de la cabeza, y finalmente continuó con la historia volviendo a mencionar la red de cableado y entrecruzando las manos una vez más. En este caso, el mismo gesto fue realizado dos veces para dar a entender que estába continuando con la historia luego de la interrupción, y en ese sentido, funciona como un gesto cohesivo. Los gestos deícticos son gestos de señalamiento hacia objetos y lugares concretos, aunque en muchos casos también se utilizan para indicar ideas abstractas. Por 
ejemplo, en una charla entre dos estudiantes, uno de ellos le pregunta al otro de dónde viene, señalando un punto en el espacio. Aquí, el gesto deíctico no está indicando un objeto o lugar en particular, sino el concepto abstracto de dónde había estado previamente su interlocutor.

Otra de las categorizaciones gestuales ampliamente reconocidas fue propuesta por Paul Ekman y Wallace Friesen (1969) para clasificar los gestos producidos en la comunicación no verbal, y presenta cinco categorías: gestos emblemáticos o emblemas, gestos ilustrativos o ilustradores, gestos que expresan estados emotivos, gestos reguladores de la interacción y gestos adaptativos o adaptadores. Los emblemas son gestos que poseen un significado claro y preciso, como por ejemplo, levantar el pulgar para expresar ok. Los gestos ilustrativos son movimientos conscientes e intencionales que acompañan a la comunicación verbal para ilustrar los significados de las palabras. Los gestos que expresan estados emotivos, como su nombre lo indica, reflejan el estado emocional momentáneo, como por ejemplo, una mueca de dolor. Los reguladores son gestos que sincronizan la comunicación, y se utilizan para indicar el relevo de turnos en la conversación, para iniciar o finalizar la interacción, etc., como por ejemplo, el gesto de invitar al interlocutor a hablar con un movimiento de la mano hacia adelante, o un gesto conclusivo de retracción de la mano indicando que ha finalizado la locución. Por su parte, los gestos adaptativos son movimientos que no poseen una intención comunicativa observable, y suelen realizarse para buscar relajación o calmar los nervios, etc. Este tipo de gestos puede estar dirigido a objetos, como por ejemplo acomodarse la ropa, o hacia el propio cuerpo como rascarse o pellizcarse.

En el ámbito de la ejecución musical existen diferentes estudios que se ocuparon de observar y de analizar el gesto corporal en la música. François Delalande (1988) planteó una clasificación de gestos en tres grandes categorías a partir de observaciones de las ejecuciones del pianista Glenn Gould: gestos efectores, gestos de acompañamiento y gestos figurativos. Los gestos efectores son todos aquellos que producen mecánicamente el sonido musical, como por ejemplo, el movimiento del dedo que presiona la tecla del piano. Los gestos de acompañamiento no son necesarios para la producción de sonido pero aun así aparecen durante la ejecución, y está involucrado todo el cuerpo, como el movimiento de la cabeza hacia atrás o el balanceo del torso durante la ejecución. Los gestos figurativos son movimientos que, aunque no sean realizados efectivamente por el ejecutante, son percibidos por la audiencia a partir del sonido, como es el caso de un balanceo en una ejecución de un segmento melódico.

A partir de la clasificación propuesta por Delalande (1988), Cadoz y Wanderley (2000) analizaron los gestos en tres interacciones típicas con instrumentos acústicos, postulando 
algunas variantes. En primer lugar, desestimaron para su análisis la categoría de gestos figurativos, porque su interés radicaba en los gestos que efectivamente realizan los instrumentistas y no en la recepción que los oyentes pudieran tener. De este modo, su clasificación constó de dos grandes categorías: gestos instrumentales y gestos auxiliares ${ }^{4}$, que se corresponden con los gestos efectores y de acompañamiento de Delalande respectivamente. Ademas, Cadoz y Wanderley propusieron considerar tres tipos de gestos instrumentales: (i) gestos excitadores, los cuales proveen la energía física que luego es percibida en el fenómeno sonoro; (ii) gestos modificadores, referidos a aquellos movimientos que modifican las propiedades de los sonidos que provienen de los instrumentos, introduciendo una dimensión expresiva, como por ejemplo, un vibrato; y (iii) gestos de selección, entendidos como aquellos que consisten en la elección entre los elementos similares de un instrumento, como por ejemplo, la rotación de la mano derecha en la ejecución del violoncelo para seleccionar la cuerda que va a ser excitada. De acuerdo con los autores, estas tres categorías internas de los gestos instrumentales representan diferentes funciones gestuales que se dan en la manipulación y ejecución de diferentes instrumentos musicales.

Jane Davidson (2001) realizó un estudio de caso sobre los gestos producidos por la cantante Annie Lennox durante la ejecución vocal de la canción Who's that girl? de The Euritmics, basándose en las categorías propuestas por Ekman y Friesen (1969). De este modo, Davidson encontró cuatro tipos de gestos en la ejecución de Lennox: (i) gestos adaptativos, que ayudan a la regulación interna de la cantante y pueden exhibir características personales y estados internos, como acariciarse, acomodarse la ropa o tocarse el pelo; (ii) gestos reguladores, que permiten sincronizar y coordinar la ejecución entre los músicos, como marcaciones de las entradas, movimientos acordes a la estructura métrica, etc.; (iii) gestos ilustrativos y emblemáticos, que están destinados a apoyar la narrativa del texto de la canción, como por ejemplo el levantamiento del dedo índice para ilustrar el verso de la canción que dice 'allí hay solamente una cosa'; y (iv) gestos de exhibición, utilizados para mostrarse o lucirse ante la audiencia, como por ejemplo, bailar con los músicos o acercarse al borde del escenario y pedir al público que palmee. Según Davidson los gestos reguladores, ilustrativos y de exhibición están claramente orientados hacia afuera, hacia la audiencia o hacia los músicos, mientras que

\footnotetext{
${ }^{4}$ Esta categoría también ha sido denominada gestos ancillares (ver por ejemplo, Peñalba 2008; López Cano 2009), de acuerdo al neologismo que surge de castellanizar el término de habla inglesa ancillary. Sin embargo, se considera apropiado utilizar el término auxiliar para hacer referencia a este tipo de gestos en esta Tesis, respetando la traducción literal porque preserva el sentido que los autores definieron de la categoría.
} 
los gestos adaptativos se orientan hacia el interior del individuo, y se vinculan con los estados internos.

Como se mencionó más arriba, las tipologías gestuales aquí abordadas constituyen un instrumento de análisis muy valioso para el estudio del gesto en diferentes contextos, y particularmente en el ámbito de la ejecución musical. Sin embargo, como suele ocurrir en todo uso descontextualizado, las aplicaciones que pueden darse de tipologías construidas y elaboradas en otros campos disciplinares corren el riesgo de ser forzadas y estériles. En este sentido, se considera prudente analizar la posibilidad de aplicar estas tipologías en el ámbito de la lectura a primera vista a la luz de las particularidades de la tarea, pero también respetando la naturaleza de las categorías aplicadas de acuerdo al contexto en el que fueron desarrolladas.

Hasta aquí, se ha presentado un panorama general del estudio del cuerpo y del movimiento corporal en los procesos de significación y comunicación de las experiencias desde diferentes perspectivas, incluyendo el estudio del gesto, pero poniendo el foco en la cognición como un proceso interactivo en el que participa el cuerpo y el entorno. En este sentido, algunas de las teorías y conceptos abordados en este capítulo, apoyan la idea de que la interacción corporal con el entorno físico y social está íntimamente vinculada a la cognición, y que por tanto, las personas se valen del cuerpo para comprender su experiencia con el medio, en el caso de esta Tesis, el medio musical. Estas ideas serán el sustento para el estudio del rol del movimiento corporal manifiesto en la lectura cantada a primera vista, asumiendo un papel activo del cuerpo en los procesos cognitivos desplegados para realizar tareas de este tipo. 



\section{Capítulo 2}

\section{Lectura a Primera Vista y Cognición}

\section{Lectura Musical a Primera Vista}

La lectura musical a primera vista ha sido definida como la "interpretación de una música escrita que el cantante o instrumentista no conoce previamente" (Latham, 2008, p. 857). Si bien esta definición resulta satisfactoria, en un sentido estricto, atendiendo a la denominación de la tarea, la cual supone una ejecución musical que se origina en una fuente escrita que el lector desconoce, dista mucho de ser una descripción acabada de la tarea con precisión en los aspectos musicales, corporales y contextuales que se ponen en juego durante su realización. Por esta razón, resulta necesario avanzar en una definición que posibilite un mayor acercamiento a las particularidades que la diferencian de otras actividades. A partir de los aportes de diferentes autores, se intentará caracterizar la lectura musical a primera vista que involucra tanto la ejecución instrumental como vocal, y se incluirán aspectos que han sido descuidados en los abordajes tradicionales de esta tarea. Luego, se abordará específicamente la lectura cantada a primera vista, poniendo el foco en los aspectos cognitivos que demanda la tarea y en las diferencias con la lectura instrumental.

Para comenzar a caracterizar el objeto de estudio de esta Tesis se considera conveniente señalar algunas de las múltiples diferencias entre la lectura alfabética comprometida en la comunicación escrita del lenguaje verbal y la lectura musical como proceso.

(i) La lectura en el sistema alfabético implica establecer un encadenamiento lineal de signos que representan un atributo del sonido (fonemas). Por ejemplo, la palabra casa, escrita, presenta un encadenamiento lineal de cuatro letras, cada una de las cuales se corresponde con un fonema que se pronuncia en orden idéntico al escrito (letra c: fonema /k/; a: /a/; s: /s/; a: /a/). Los signos musicales representan por lo menos dos atributos, alturas y duraciones. Una nota escrita con la figura de negra en el tercer espacio del pentagrama y en clave de sol, representa la nota do4 con una duración proporcional determinada de acuerdo al compás 
indicado. Del mismo modo, la lectura musical se complejiza mucho más cuando va más allá de lo lineal (varias voces, lectura pianística, orquestal, etc.).

(ii) En el sistema alfabético existe un repertorio de sonidos (fonemas) que se corresponden uno a uno con cada signo. En el sistema musical los signos representan alturas, pero el lector no tiene en la mente el repertorio de alturas (a excepción de quienes tienen oído absoluto) sino el repertorio de relaciones que se pueden determinar entre esas alturas en un contexto tonal determinado. Por lo tanto mientras que para el lenguaje ver $\mathrm{M}$ y $\mathrm{A}$ significa asociar los grafemas a los fonemas, en la música ver el Do y el Mi no comunica exactamente como suena eso, hasta que no es relacionado en ese contexto en particular. Algo similar ocurre con las duraciones establecidas en el sistema musical. Si bien, por convención, las relaciones proporcionales de duración que representan las figuras son fijas (una negra equivale a dos corcheas, etc.) el modo entender esas relaciones depende del contexto métrico particular en el que se desarrolla la lectura. Es decir, no es lo mismo la relación negra-corchea en una melodía en pie binario que en una en pie ternario. Las relaciones duracionales se resignifican en el contexto métrico. De este modo el conocimiento estructural del sistema implicado resulta más complejo en la lectura musical que en la lectura del lenguaje verbal.

(iii) El contexto sobre el cual se establecen las relaciones varía. Por ejemplo, pueden presentarse cambios en el centro tonal que complejizan el establecimiento de esas relaciones. Por su parte, los cambios de contexto que puede presentar un texto en el lenguaje (cambio de estilo de redacción, de tipo de texto -de prosa a verso, por ejemplo-, de persona verbal, etc.) no alteran las relaciones lineales que el lenguaje establece $y$, por lo tanto, no complejiza la tarea de lectura.

(iv) Mientras que la lectura del lenguaje se ejercita permanentemente porque vivimos en una cultura letrada (libros, diarios, carteles, computadoras, etc.), el contacto con la lectura musical es mucho más esporádico y, por lo tanto, la posibilidad de automatizar relaciones es más improbable.

Considerar estas particularidades de la lectura musical que la diferencian de la lectura del lenguaje alfabético, contribuye a caracterizar el problema de la lectura a primera vista como proceso psicológico. Este proceso se concreta en el desarrollo de una habilidad sumamente útil para el desenvolvimiento de los músicos en diferentes contextos en los que se requiere la ejecución de obras desde una partitura, como por ejemplo, orquestas, coros, instrumentistas sesionistas, etc. En los ámbitos de enseñanza musical académica, este desarrollo es 
considerado como uno de los objetivos centrales de la enseñanza, a alcanzarse tanto a través del canto como de la ejecución instrumental.

\section{Concepciones y Enfoques para el Abordaje de la Lectura Musical a Primera Vista}

Leer música a primera vista ha sido considerado también como una tarea de transcripción, en la cual la información dispuesta en forma escrita es traducida a una forma cinestésica (ver Fine et al., 2006). Se entiende por cinestesia a la sensación de la posición del cuerpo, del peso, de los músculos y del movimiento corporal. Siguiendo esta idea, se puede decir que la tarea de leer a primera vista implica una puesta en movimiento de aquello de se encuentra escrito y permanece estático en la partitura. Pero esa acción requiere un ajuste preciso en función tanto de los conceptos provenientes de la teoría musical como de las convenciones en la que se basa la escritura. El lector debe ser capaz de vincular conceptos teóricos tales como tónica, dominante, escala, estructura métrica, etc., con las convenciones de la escritura musical como por ejemplo, el modo en el que se dispone la armadura de clave, las barras de compás, las alteraciones, las posiciones de las notas en el pentagrama, etc. Esta idea de lectura como puesta en acción de lo escrito resulta interesante porque añade la dimensión corporal en la resolución de la tarea que, si bien ha estado siempre presente y ha sido la base de cualquier ejecución leída, no se le ha prestado demasiada atención en el análisis de los aspectos implicados en la habilidad de leer música a primera vista. Más allá de la actividad corporal que implica la traducción cinestésica, aquí se planteará que el cuerpo podría cumplir un rol cognitivo fundamental en la resolución de este tipo de tareas, basados en las teorías de la Cognición Corporizada descriptas en el capítulo 1. En este sentido, la participación del cuerpo como sustento de la acción y como ejecutor cinético de la lectura, es decir, como realizador de los movimientos que permiten ejecutar la música leída, resulta prácticamente trivial. Por ello, la actividad de leer música a primera vista emerge como un ámbito interesante para el estudio de la corporalidad ya no como condición material necesaria para la producción de sonido, sino como participante esencial en la construcción de significado. Considerando esta diferenciación en la perspectiva analítica de la participación del cuerpo en la tarea, la individualización de las variables intervinientes puede ser más clara y precisa cuando se hace evidente que el foco no está puesto en las particularidades cinestésicas de la producción de sonido, sino en el rol cognitivo del movimiento corporal.

De acuerdo con Alison Latham (2008) en la lectura a primera vista intervienen diferentes elementos entre los que se incluyen la imaginación, el conocimiento relativo al estilo, la 
anticipación de lo que puede venir en el discurso musical (expectativa), etc. Así, cuanto más se pueda anticipar lo que va a venir en la partitura que se está leyendo, mejor se podrá resolver la tarea. Y esa anticipación será más precisa cuanto más conocido sea el estilo de la música que se está leyendo. Por ejemplo, al leer una obra para piano que comienza con movimientos melódicos por grado conjunto, con notas diatónicas, presenta una armonía basada en las funciones pilares, etc., que recuerda al período clásico, es muy probable que el lector espere que continúe de la misma manera, tal vez organizada con un antecedente y un consecuente, o como una frase período, con ciertos movimientos melódicos típicos del estilo y vinculados a los anteriores, etc. Incluso, si conoce quién fue el compositor de la obra podrá anticipar ciertos rasgos del comportamiento melódico y armónico en relación con su conocimiento de la idiosincrasia compositiva de tal compositor.

Los estudios que han abordado la lectura a primera vista han puesto el foco principalmente en la ejecución instrumental, y más precisamente en la ejecución pianística (ver por ejemplo, Sloboda, 1974, 1983; Lehmann y Ericsson, 1993; Banton, 1995; Kornicke 1995; Waters et al. 1998) que presenta características propias de notable diferencia con otras formas de lectura musical a primera vista. Sin embargo, algunas de las ideas postuladas por diferentes estudios que se han ocupado de este tema y las conclusiones a las que arribaron, refieren a las condiciones de la lectura a primera vista en términos generales, y como tales, merecen ser consideradas también en el abordaje y en la caracterización de la lectura cantada.

Andreas Lehmann y Reinhard Kopiez (2009) distinguen el modo en que realizan el proceso de lectura musical los principiantes y los expertos.

"Mientras que el lector principiante de música tiene que superar los mismos problemas a los que se enfrentan todos los lectores cuando aprenden a leer otros textos, es decir, ir desde un emparejamiento tedioso de símbolos a los sonidos y al significado, el lector experto ha automatizado el proceso de codificación y transformación de las señales en acción corporizada." (Lehmann y Kopiez, 2009, p. 344)

Siguiendo esta idea, aprender a leer música de manera experta significaría desarrollar la habilidad de transformar automáticamente los símbolos de la notación musical en acciones corporales. Como toda automatización, la lectura experta se convertiría en una tarea simple que no consumiría demasiados recursos cognitivos, en contraposición con la gran demanda cognitiva implicada durante el aprendizaje de la habilidad. La comparación entre el lector principiante de música y el lector principiante del sistema alfabético asume una similitud entre 
ambas tareas. Sin embargo, esta equivalencia podría derivar en una visión simplificada del problema de la lectura musical. Como se mencionó más arriba, existen diferencias importantes que impiden un emparejamiento uno a uno entre la lectura alfabética y la lectura musical. Por ejemplo, la asociación del símbolo a más de un parámetro (al menos altura y duración), la fuerte vinculación contextual, la pauta temporal rígida pero en contextos que pueden ser variables, la menor ejercitación, etc., necesariamente implican una mayor demanda cognitiva en la lectura musical, tanto para lectores principiantes como para expertos. Si bien considerar las particularidades de la lectura del lenguaje verbal puede contribuir, al menos por diferenciación, a una mejor caracterización de la tarea de leer música a primera vista, son actividades ontológicamente diferentes, y como tales, no debieran considerarse equivalentes para evitar caer en definiciones y caracterizaciones simplistas que subestimen el problema.

Si bien la lectura a primera vista implica una traducción de signos musicales a sonidos como se ha señalado hasta aquí, leer música también es comunicar contenidos. Esto requiere tanto comprender lo que está pasando en la música estructuralmente como generar una ejecución inteligible para el auditor. Con el fin de avanzar en la caracterización de las variables implicadas en la lectura musical considerando estos aspectos de la lectura musical vinculados a la comunicación de contenidos, se considera oportuno volver a la definición de la tarea como disparadora y marco explicativo de tal caracterización.

Lehmann y Kopiez (2009) definen a la lectura musical a primera vista como "la ejecución -vocal o instrumental- de fragmentos largos de música sin haberlos ensayado o con muy poco ensayo, con una fluidez aceptable y con una expresión adecuada." (p. 344). Lo que se busca en este tipo de ejecución es la apropiación de la música escrita por parte del lector, o lo que los autores denominan una ejecución auténtica. De este modo, más allá del grado de experticia que haya alcanzado el lector, resulta necesario que le imprima su impronta personal a la ejecución como modo de apropiación de esa música. Este punto es clave en el desarrollo de la habilidad de lectura musical. En los ámbitos académicos de formación musical es habitual que se relegue la expresión y todo lo que no puede ser escrito en una partitura en un intento de favorecer el desempeño de aspectos estructurales como las notas, el ritmo, etc. Pero este descuido podría estar impidiendo la apropiación de la música por parte del lector, es decir, limitando la construcción de significados a partir de la lectura y la articulación expresiva vinculada a ese proceso de significación, y en ese sentido, tal vez se estarían perjudicando justamente los aspectos que se pretenden favorecer. Esto pone en discusión la idea de que "primero deben estar las notas resultas para luego imprimirle algo de expresión". Más bien, podría ser que la expresión y la impronta personal que el lector le imprime a la ejecución 
favorezcan su apropiación de la música resultando en un desempeño más ajustado y auténtico. Conviene aclarar que esta idea excede el planteo de Lehmann y Kopiez (2009), quienes sugieren que los lectores expertos 'agregan' expresión a la ejecución sólo cuando saben lo que va a venir en la música porque la han entendido. Sin embargo, podría ser que existiera un juego de interrelación entre la significación musical y la expresión que conlleva la ejecución sin la necesidad de que una de ellas se anteponga a la otra. Se entiende así la ejecución musical como un proceso dialéctico que se construye a partir de la tensión entre significación y expresión, en el cual el significado surge de la posibilidad de expresar convenientemente un enunciado, al tiempo de que la expresión surge de la posibilidad de construir el significado. Más adelante se discutirá esta idea en función de los resultados obtenidos en los estudios realizados sobre lectura cantada a primera vista.

De un modo similar a lo que ocurre en la improvisación musical, la lectura a primera vista requiere una adaptación instantánea a nuevos problemas y restricciones, y en ese sentido, puede ser vista como una tarea de resolución de problemas en tiempo real (Lehmann y Kopiez, 2009). En un estudio en el que los sujetos debían leer estímulos presentados en lapsos breves, se encontró que los fragmentos diatónicos, con intervalos pequeños y en secuencias congruentes con las expectativas tonales eran mejor resueltos en la lectura (Ortmann, 1934). A partir de los resultados obtenidos por Ortmann (1934), Lehmann y Kopiez (2009) sugieren que al leer a primera vista el lector tiende a formar unidades significativas relacionadas con su conocimiento previo y con sus expectativas. Así, por ejemplo, cobra gran importancia la claridad con la que se advierta la coherencia tonal del estímulo leído, principalmente durante etapas del desarrollo de la habilidad. Así, una melodía o una obra que presente rasgos típicos de un estilo o período particular (giros melódicos, enlaces armónicos, grupos rítmicos, relaciones morfológicas, etc.), cuyas características son conocidas por el lector (como se mencionó arriba), podría favorecer la conformación de unidades significativas y redundar en una mejor lectura.

Un aspecto habitualmente asociado al abordaje de la lectura a primera vista es la noción de audición interna, entendida como la representación mental de la música antes de que se produzca el sonido, o en otras palabras, saber cómo va a sonar la música escrita en la partitura antes de que suene por la acción de ejecutarla en el instrumento. Diferentes autores han postulado que la habilidad de leer a primera vista está vinculada estrechamente con la audición interna y con la formación de representaciones auditivas (ver por ejemplo, Kornicke, 1995; Waters et al., 1998; Fine et al., 2006). Este vínculo abona a la idea de que la representación mental de la notación musical implica la construcción de expectativas 
melódicas, rítmicas, armónicas, morfológicas, etc. (Lehmann y Kopiez, 2009). De acuerdo con esa hipótesis estas expectativas musicales guían la ejecución vocal o instrumental a primera vista y están relacionadas con las unidades significativas construidas durante la lectura.

Para sintetizar estas ideas tómese por caso un lector experto que habitualmente escucha y ejecuta al piano música tonal. Este lector entonces, conocerá al menos ciertos rasgos del lenguaje musical tonal (giros melódicos y enlaces armónicos típicos, grupos rítmicos habituales, modelos cadenciales, etc.). Al enfrentarse a la lectura a primera vista de una obra que identifica con el sistema tonal, es decir con las particularidades del lenguaje musical que conoce, podrá, basado en tales conocimientos previos, generar expectativas de lo que va a venir a medida que va realizando la ejecución. Por ejemplo, después de un acorde de dominante con séptima es muy probable que venga un acorde de tónica. Esas expectativas forman parte de las representaciones mentales implicadas en la audición interna, y se vinculan con la coherencia musical interna de la obra leída en función de los comportamientos musicales típicos. Asimismo, mientras el lector se va enfrentando a los problemas que van surgiendo a medida que decodifica y transforma en acción la partitura, va construyendo unidades de sentido musical que pueden ser motivos melódicos, patrones rítmicos o armónicos, etc. En función de la experticia del lector y de los rasgos de la obra musical leída, las unidades de significación pueden ser de mayor duración. Al mismo tiempo, se apropia de la música que está leyendo, le imprime su impronta personal y la enuncia de manera expresiva.

Además de todos los aspectos aquí mencionados de la ejecución a primera vista, conviene destacar uno que habitualmente no ha sido considerado en los estos abordajes: el movimiento corporal. Si bien se ha hablado de la traducción a la acción que implica la lectura a primera vista, existe una amplia gama de movimientos que los ejecutantes despliegan cuando leen y que no necesariamente se corresponden con la traducción directa de la partitura a sonidos. Más adelante se pondrá el foco en ellos y en el rol cognitivo que podrían cumplir en este tipo de tareas.

Hasta aquí se ha abordado la tarea de leer música a primera vista diferenciándola de la lectura propiamente dicha, tomando algunas definiciones existentes desde distintas miradas (como traducción de signos a sonidos y como comunicación de contenidos), Asimismo, se ha caracterizado la tarea como una habilidad cognitiva que implica: (i) traducción cinestésica, (ii) asociación entre los signos del código visual con las representaciones sonoras de esos signos, (iii) resolución de problemas en tiempo real, (iv) imaginación y audición interna que involucran la construcción de significados a partir de la utilización del conocimiento de base (configuraciones musicales conocidas). Si bien esta caracterización abarca la lectura musical 
tanto vocal como instrumental, resulta necesario focalizar en la lectura cantada a primera vista con el fin de distinguir los aspectos cognitivos propios de dicha tarea, en función de las necesidades explicativas de la temática que aborda esta Tesis.

\section{Cantar a Primera Vista}

Cantar a primera vista presenta algunas particularidades que la distinguen de la ejecución instrumental y que merecen ser mencionadas. Como se ha señalado, una parte importante de los estudios sobre lectura musical a primera vista ha puesto el foco en la ejecución pianística, principalmente de manera individual. Más allá de la práctica en el instrumento, tocar el piano sin el acompañamiento de otros instrumentos o voces no es una tarea que resulte ajena a los pianistas, ya que una parte muy importante de la música escrita para este instrumento implica la ejecución individual (Fine et al., 2006). Sin embargo, la tarea de cantar en las prácticas musicales habituales suele realizarse con acompañamiento de otras voces (por ejemplo, en coros) o de instrumentos (en bandas, orquestas, grupos de música popular, etc.). De acuerdo con Philip Fine, Anna Berry y Burton Rosner (2006) los cantantes suelen tomar pistas o claves de las otras partes vocales o instrumentales que están sonando, con el fin de ajustar las melodías que deben cantar. Pero la lectura cantada a primera vista se realiza generalmente de manera individual, tanto en los estudios que se ocupan del tema como en su abordaje pedagógico (para una revisión de los estudios sobre lectura a primera vista en los últimos diez años ver Kuehne, 2010). Mas allá de estas situaciones particulares, la lectura en solitario sin la posibilidad de tomar pistas del contexto, no es una práctica que los músicos realicen frecuentemente en sus actividades musicales. Probablemente, la práctica pedagógica de la lectura a primera vista obedezca a la idea de atender a la necesidad de crear una imagen mental antes de que se produzca el sonido de la propia ejecución, con la supuesta finalidad de preparar a los músicos profesionales para diferentes prácticas musicales en las que podrían desempeñarse. Por ejemplo, las prácticas de enseñanza de instrumentos de afinación movible (como el violín) han estado vinculadas a este problema, con la idea de que cuanto mejor sea la representación mental previa a la producción del sonido del instrumento, más ajustada resultará la ejecución. Sin embargo, esta idea subestima prácticas de ajuste instrumental como tomar pistas de las otras partes para ajustar la afinación modificando la posición de la mano, realizar el movimiento de ajuste luego de escuchar el sonido producido en función de la tonalidad, etc. Tal vez la ejecución en este tipo de instrumentos implique todas estas prácticas más allá de una anticipación a partir de una imagen mental acabada de la música que se 
ejecuta. Otro tanto podría pasar con tareas musicales a las que subyace la misma idea de representación mental previa al sonido, como la dirección orquestal o coral. Sin embargo, podría ser que estas prácticas se basen en otros aspectos que formen parte del contexto musical en el que se desarrollan, como el conocimiento del lenguaje, del estilo, e incluso de la misma obra, la sonoridad resultante, las pistas sonoras de las diferentes partes, etc., y de este modo, la finalidad que perseguiría la práctica pedagógica vinculada a la lectura cantada a primera vista de manera individual perdería fuerza. Esto no significa que cantar a primera vista no se base en representaciones mentales de la música plasmada en la partitura, como se adelantó y como se explicará más adelante, sino más bien que la búsqueda del desarrollo de la habilidad a partir de la construcción de esas imágenes internas podría tener poco asidero en las actividades musicales habituales de los músicos profesionales.

Teniendo en cuenta la limitación de la práctica de lectura a primera vista habitual vinculada a la ausencia de acompañamiento y a la diferencia que esto implica con la lectura instrumental, Fine, Berry y Rosner (2006) investigaron el rol de diferentes atributos de la estructura musical en la habilidad de ajustar alturas en tareas de cantar a primera vista. Principalmente estudiaron los efectos de la coherencia melódica y armónica, utilizando cuatro corales de J. S. Bach que fueron alterados de tres modos: (i) alteración armónica (la voz del participante permaneció intacta y se modificaron las otras tres líneas); (ii) alteración melódica: (se modificó la línea melódica de la voz del participante); y (iii) alteración armónica más melódica (se modificó tanto la línea del participante como las otras tres líneas. La tarea consistió en cantar a primera vista los cuatro corales, tanto en sus versiones originales como en las versiones alteradas. Los autores encontraron que las alteraciones, tanto de la melodía como de la armonía provocaron un aumento en los errores de altura en las ejecuciones. Los lectores menos expertos (de acuerdo con un test de intervalos realizado previamente) fueron significativamente más afectados por la disrupción armónica que los expertos. Esta afectación se manifestó en la necesidad de realizar autocorrecciones de notas inicialmente mal cantadas que, de acuerdo con los autores, no se correspondían con la representación interna que los novatos tenían de cómo debería sonar esa nota. Los expertos, por otro lado, necesitaron realizar menos correcciones debido a que podían calcular mejor internamente las alturas requeridas aun en contextos con alteraciones armónicas. A partir de los resultados, los autores sugieren el rol de las representaciones auditivas internas aumenta con la experticia. Es decir que cuanto más experto sea el lector, mayor será su utilización de las representaciones auditivas para guiar su ejecución. Considerando la naturaleza de la tarea y los procesos cognitivos implicados que se han descripto hasta aquí, estos resultados no parecen constituir 
una novedad en la investigación sobre el tema, más bien parecen confirmar el basamento de la habilidad de cantar a primera vista en las representaciones auditivas de la música plasmada en la partitura.

Otra diferencia notable entre tocar un instrumento y cantar a primera vista, vinculada a los hallazgos de Fine, Berry y Rosner (2006) es el modo en el que construyen las relaciones de altura instrumentistas y cantantes. Mientras que el pianista, por ejemplo, puede ajustar las alturas simplemente poniendo el dedo en el lugar correcto y presionando la tecla que corresponde de acuerdo a la nota escrita en la partitura, el cantante debe construir la tonalidad y las relaciones de altura a partir de las representaciones mentales de la música que está leyendo. En este sentido, cantar a primera vista demanda una carga cognitiva mayor. De acuerdo con Fine, Berry y Rosner (2006), los pianistas pueden tocar las notas correctas sin tener una representación auditiva interna de lo que va a sonar, mientras que los cantantes necesitan basar su ejecución en ese tipo de representaciones. Si bien esto podría ser cierto, y efectivamente representa una diferencia entre cantar y tocar a primera vista, resulta muy poco probable que un lector pueda lograr una ejecución adecuada solamente bajando las teclas correctas. Más bien necesita, como se señaló en el apartado anterior, comprender de qué se trata la música que está ejecutando, entender las partes, sus relaciones, generar expectativas en función del movimiento melódico, el contexto armónico, los patrones rítmicos, etc. En este sentido, las representaciones auditivas juegan un rol central en este tipo de habilidades de lectura, ya sea que se trate de cantar o de ejecutar un instrumento. No obstante, se considera importante destacar que la carga cognitiva que demanda la construcción de esas representaciones en uno y otro caso puede ser muy distinta. La retroalimentación auditiva de las alturas que reciben los instrumentistas puede ayudar a generar esas representaciones, mientras que los cantantes deben construir una parte importante de las representaciones antes de comenzar la ejecución (cómo suena la tonalidad, el modo, los grados de la escala, los giros melódicos implicados, etc.).

Sin embargo, los cantantes utilizan la retroalimentación auditiva para ajustar la afinación y mantenerse en la tonalidad (Ward y Burns, 1978, citado en Fine et al., 2006). En su estudio acerca del efecto del reconocimiento de patrones y de la predicción tonal sobre la habilidad de cantar a primera vista, Fine, Berry y Rosner (2006) analizan el rol de las representaciones internas y de la retroalimentación en este tipo de tareas.

"Esta retroalimentación es necesaria presumiblemente para emparejar la ejecución actual con las representaciones auditivas internas. En ocasiones, 
nuestros participantes cantaron inicialmente una nota incorrecta, pero cambiaron muy rápidamente a la nota correcta, con frecuencia de una sola vez o glissando. El papel de las representaciones auditivas y de la retroalimentación auditiva se puede ver en estas autocorrecciones que algunas veces producen los cantantes a primera vista menos hábiles." (Fine, Berry y Rosner, 2006, p. 443)

Siguiendo el razonamiento de los autores citados, al cantar a primera vista el lector construye representaciones auditivas que va cotejando con la retroalimentación sonora generada por su propia ejecución. Cuando esta comparación no resulta idéntica, es decir, cuando la unidad significativa percibida por retroalimentación no coincide con la representación de esa unidad, el lector corrige la ejecución buscando emparejar las unidades cotejadas. De este modo, la intervención de la retroalimentación auditiva y la construcción de representaciones auditivas en la tarea de cantar a primera vista juegan un papel fundamental, principalmente en los estadios iniciales del desarrollo de la habilidad, ya que permite a los lectores principiantes advertir errores y corregirlos durante la ejecución. Si bien esta idea resulta sumamente interesante porque da una explicación del modo en el que participan tanto la retroalimentación como las representaciones mentales en la lectura a primera vista, es una explicación computacionalista clásica que apela solamente a las operaciones con esas representaciones mentales para describir el proceso cognitivo. Más allá de la intervención obligatoria del cuerpo como emisor de sonido (aparato fonador) y como receptor del sonido emitido (sistema auditivo), el movimiento corporal manifiesto podría formar parte de las representaciones que el lector construye de la música escrita. En este sentido, las representaciones no serían solamente auditivas e internas, sino que también podrían ser corporales y externas. Esta es una de las ideas que se discutirán más adelante.

Janice Killian y Michele Henry (2005) investigaron la incidencia de un lapso de 30 segundos de preparación antes de cantar individualmente a primera vista y compararon las estrategias utilizadas tanto en ese lapso como durante la ejecución. Para ello, utilizaron dos melodías con una dificultad similar, qué debían ser cantadas en diferentes condiciones: la primera con 30 segundos de preparación para practicarla y estudiarla, y la segunda sin tiempo previo a la ejecución. Las autoras encontraron que la precisión general en la lectura a primera vista aumentó significativamente cuando los participantes tuvieron el lapso de preparación. Sin embargo, los lectores menos expertos o con puntajes bajos no lograron aumentar significativamente su desempeño. En este sentido, pareciera ser que el tiempo de preparación no es útil para aquellos que no han alcanzado determinado nivel de experticia en la tarea de cantar a primera vista. Sin embargo, también podría pensarse que los lectores más expertos 
son justamente los que logran un mejor uso del tiempo de preparación, es decir, que tienen un mejor desempeño en la lectura porque han aprendido a aprovechar el tiempo previo desplegando estrategias que les resultan útiles para realizar la tarea. Así, el aumento de la precisión en la lectura en función del tiempo de preparación podría estar vinculado a las estrategias que fueron utilizadas durante ese lapso. Las autoras consideran como estrategias exitosas desplegadas durante los 30 segundos de preparación, en función del desempeño posterior y de la comparación con los desempeños sin preparación a: ubicase en la tonalidad, cantar en voz alta, realizar signos con las manos, mantener el pulso con el cuerpo, y finalizar la ejecución de la melodía. Esta última está vinculada con la habilidad que mostraron los expertos de saltear partes repetidas, similares o simples y poner el foco en las posibles dificultades para finalizar la lectura en el tiempo de preparación. Todas estas estrategias fueron realizadas significantemente de manera más frecuente por los lectores que obtuvieron los puntajes más altos, y además fueron usadas consistentemente también durante la ejecución.

Particularmente, resulta interesante para los fines de esta Tesis poner el foco en dos de las estrategias mencionadas por Killian y Henry (2005), por su relación directa con el movimiento corporal manifiesto: realizar signos con las manos y mantener el pulso con el cuerpo. Conviene aclarar que el uso de signos manuales que señalan las autoras refiere a los signos propuestos por John Curwen (ver Colles/Ward Jones y Rainbow, 2001) para aplicar al método de lectura musical del do móvil desarrollado por Sarah Glover (ver Curwen y Glover, 1885). En este método, se utilizan sílabas similares a los nombres de las notas musicales para representar el grado de la escala y la función de cada altura. Así, la sílaba do siempre va a estar asociada a la nota tónica independientemente de la tonalidad en la que esté escrito y/o se ejecute la obra. A partir de esta idea, Curwen diseñó una serie de signos manuales que equivalen a cada uno de los grados de la escala ${ }^{5}$. Luego, este sistema de lectura musical fue tomado por Kodály para elaborar su método de la enseñanza musical que tuvo una amplia difusión, principalmente en Europa y en Norteamérica. Así, es sistema de do móvil se convirtió en uno de los métodos más usados para el desarrollo de la lectura a primera vista en Estados Unidos (ver Kuehne, 2010). Esta sintética explicación obedece a la necesidad de considerar que los signos manuales a los que se refieren Killian y Henry (2005) como estrategia exitosa para cantar a primera vista deviene de un sistema de signos ampliamente conocido y utilizado en el lugar geográfico en donde se desarrolló la investigación. En este sentido, los movimientos de la mano desplegados por los lectores expertos tanto durante el período de preparación como durante la ejecución

\footnotetext{
${ }^{5}$ Para una ilustración gráfica de los signos manuales propuestos por Curwen ver https://upload.wikimedia.org/wikipedia/commons/b/bf/Curwen_Hand_Signs_MT.jpg
} 
corresponden a movimientos estereotipados, aprendidos en la práctica de adquisición de la habilidad. Estos movimientos parecieran volverse significativos para los lectores cuando logran establecer una relación precisa entre el movimiento y la estructura tonal de la melodía que están leyendo. Tal vez esta es la razón por la que esta estrategia aparece más en los lectores más hábiles, porque han logrado establecer esa relación significativa.

La segunda estrategia destacable mencionada por Killian y Henry (2005) vinculada al movimiento corporal es mantener el pulso con el cuerpo. A diferencia del los signos manuales, este es un movimiento más espontáneo que podría estar vinculado con los aspectos temporales de la ejecución, como por ejemplo, el tempo, la continuidad, la estructura métrica, el ritmo, etc. De acuerdo con Luiz Naveda y Marc Leman (2011), el movimiento corporal juega un rol sumamente importante en la configuración del metro musical. Más aun, los autores plantean que probablemente la métrica musical haya surgido a partir de la existencia primigenia de una unidad conformada por música y danza, que luego evolucionó en de modo fragmentado mediado por las teorizaciones musicales. Esto podría explicar las relaciones entre las características temporales de las coreografías y la métrica musical. Según los autores, los movimientos corporales de la coreografía del samba brasilero proporcionan una gran cantidad de elementos suficientes para definir la estructura métrica y sustentar el concepto de metro en la música. A partir de estas ideas, se podría sugerir que el movimiento corporal vinculado con el pulso desplegado por el lector a primera vista durante el lapso temporal preparatorio es el sustento para la configuración de la estructura métrica y la organización rítmica de la música que está comenzando a leer. Más adelante se estudiará más en detalle este tipo de movimientos corporales en relación con los aspectos temporales de la ejecución a primera vista.

Las ideas que dan origen a los estudios que abordan la lectura a primera vista como proceso cognitivo, así como sus resultados y conclusiones ponen de relieve que, como se señaló al comienzo de este capítulo, leer música no puede ser considerado un proceso análogo al de leer un texto en notación alfabética del lenguaje verbal. Ambos procesos presentan diferencias ontológicas que conviene destacar. Cuando un lector se apresta a leer un texto no necesita un tiempo de preparación para desplegar estrategias que le permitan desarrollar la tarea. No hay estrategias previas más que comenzar a leer. Es más, si se piensa en las estrategias que las autoras consideraron exitosas, aun si el lector de textos tuviera la obligación de tomarse 30 segundos para preparar la lectura, probablemente no los dedicaría a buscar las sílabas y palabras difíciles, a saltearse las partes similares, a gesticular, etc., si no más bien, a leer y comprender el tema del texto; es decir, a comenzar la lectura y continuarla linealmente 
evitando saltearse partes. Por otra parte, los resultados que muestran una mayor utilización de estrategias exitosas en el tiempo de preparación por parte de los lectores expertos, revela que el aprovechamiento de ese lapso de tiempo previo no se abandona con la experticia, por el contrario, cobra más valor. Esta idea se contrapone con la concepción del automatismo en la lectura musical a primera vista como modo de adquirir la habilidad. Los lectores expertos no son quienes leen automáticamente, sino quienes logran aprovechar mejor el tiempo previo y desplegar mejores estrategias para resolver la tarea.

En la lectura cantada a primera vista participan dos sistemas perceptuales simultáneamente: el visual y el auditivo (Segalerba, 2009). Cuando se lee a primera vista,

"...el canto y la lectura deben tratarse de manera simultánea. Sabemos que en ambos procedimientos hay expectativas de una mejor continuación (en términos de la teoría de la Gestalt) y que la continuación más 'esperada', es tanto 'visual' como 'vocal'. Por eso, si una nota o un evento resulta 'menos' esperado, entonces se produce, desde el punto de vista cognitivo, un efecto de interferencia que, en definitiva, 'obstaculiza' la continuidad." (Ibíd., p. 6)

En este sentido, las expectativas estarían presentes tanto en la percepción y decodificación de los símbolos que exhibe la partitura como en la audición de la propia puesta en acción de esa información. En términos pedagógicos, resulta fundamental que la melodía a ser leída conlleve cierta coherencia interna y cumpla con las expectativas de continuidad que puedan tener los estudiantes de acuerdo con el nivel de desarrollo de la habilidad en el que se encuentren. $\mathrm{Si}$ bien esta idea de la relevancia que adquiere la coherencia musical de la melodía ya se mencionó en los párrafos precedentes, se considera oportuno retomarla en este punto para vincularla con el movimiento corporal.

Para los fines de esta Tesis, resulta interesante considerar la posibilidad de que la ruptura de la buena continuidad esperada provoque una interferencia cognitiva. Tal vez esa disrupción genere una mayor demanda cognitiva que se vincule directamente con el movimiento corporal manifiesto como parte de la estrategia cognitiva de resolución del problema. Podría ser, por ejemplo, que los movimientos de la mano representando los ascensos y descensos melódicos que surjan luego de una interrupción, fueran desplegados como estrategia cognitiva para resolver el problema que originó la interrupción. Se considerará esta idea al momento de explorar los movimientos manifiestos desplegados espontáneamente en tareas de cantar a primera vista. 


\section{La Pedagogía Musical y su Tratamiento del Cuerpo en la Lectura a Primera Vista}

\section{El Solfeo: Estrategia Tradicional para el Aprendizaje de la Lectura Musical}

La lectura cantada a primera vista ocupa buena parte de los esfuerzos de enseñanza de los enfoques audioperceptivos, entendidos como aquellos que procuran el desarrollo del oído musical $^{6}$. Estos enfoques han tomado diferentes nombres dependiendo tanto del ámbito de enseñanza musical en el que intervienen como del alcance de la asignatura. Educación Auditiva, Audioperceptiva, Lenguaje Musical, Elementos Técnicos, etc., son ejemplos de asignaturas que se ocupan del desarrollo de la habilidad de cantar a primera vista en diferentes contextos de la enseñanza musical formalizada. En la práctica pedagógico-musical tradicional de Occidente, el solfeo fue el método de enseñanza de la lectura musical durante largo tiempo. Ya desde el siglo XVIII se planteaba la necesidad de que los jóvenes músicos solfearan la escala (Jander, 2001). Específicamente, el término solfeo ${ }^{7}$ refiere al ejercicio vocal entonado a partir de la lectura de partituras, que puede realizarse con una misma vocal, o con las sílabas de la solmización (Latham, 2008). Se conoce como solmización, al "uso de sílabas en asociación con alturas como un recurso mnemotécnico para indicar intervalos melódicos" (Hughes, 2001, s/p). Las sílabas utilizadas para la realización de este ejercicio (do, re, mi, fa, sol, la y si) son arbitrarias y fueron concebidas por Guido d'Arezzo en el siglo XI, pero se han convertido en una convención ampliamente difundida (para una reseña histórica sobre la solmización ver Hughes, 2001 y Gerson-Kiwi, 2001). La práctica del solfeo, como recurso para la enseñanza de la lectura musical, tuvo un fuerte impacto en los contextos latinoamericanos, y presentó muchas variantes en su aplicación. En algunos casos, significó la lectura ensayada de melodías progresivamente más complejas, entonadas y ajustadas temporalmente a una marcación de compás realizada con la mano. Aquí aparece un movimiento corporal manifiesto convencionalizado, que se vincula con el ajuste a un marco temporal dado por la estructura métrica. Sin embargo, en otros casos esta marcación no estaba presente, o incluso la práctica podía incluir un recitado de las sílabas de la solmización sin la entonación de las alturas. Este modo de 'solfeo recitado' se fue generalizando como práctica rítmica en diferentes contextos musicales (clases de instrumento, instrumentistas de orquesta, etc.) alejando el solfeo del

\footnotetext{
${ }^{6}$ La noción de oído musical es compleja y difusa. Para un abordaje de esta noción en relación con la Educación Auditiva como espacio curricular en la formación del músico profesional ver Shifres, en prensa.

${ }^{7}$ Traducción al español del término italiano solfeggio, que deriva del nombre de las notas sol y fa (ver Latham, 2008, solfeggio).
} 
objetivo inicial de entonación melódica. Esta transformación podría explicar, de algún modo, las prácticas de solfeo en los contextos de enseñanza musical institucionalizada (principalmente instrumental), que priorizó la decodificación rítmica por sobre la entonación de la melodía. Más allá de estas variantes, y de los diferentes métodos de solfeo que se desarrollaron principalmente en Italia y Francia, y que luego fueron ampliamente difundidos (ver Jander, 2001), estas prácticas rigieron la enseñanza de la lectura cantada a primera vista en el contexto musical occidental. Aquí, el cuerpo tenía una participación limitada a la marcación de compás, que si bien, en el mejor de los casos posibilitaba un ajuste al marco métrico temporal, su rol no se fundamentaba en los aspectos cognitivos de la lectura vinculados a la participación corporal en estos procesos. Tal vez, la ausencia de una reflexión cognitiva y pedagógica acerca del rol del movimiento corporal en la lectura, impida su valoración y su utilización significativa en este tipo de prácticas de solfeo.

\section{El Movimiento Corporal como Estrategia Didáctica}

Una parte importante de la pedagogía musical se ha ocupado del desarrollo de las habilidades de audición y lectura musical. Estos enfoques abordan la habilidad de lectura a primera vista como método eficaz de aprendizaje de lectura de partituras para todo desempeño musical que lo requiera. Si bien realizar un relevamiento de la aplicación del movimiento corporal como estrategia en los diferentes métodos musicales excede largamente a esta Tesis, se considera necesario aludir a la problemática y ejemplificarla con uno de los métodos de enseñanza musical que se ocupa explícitamente de la lectura a primera vista, y que ha tenido una amplia aceptación en el ámbito pedagógico musical. Gary Karpinski (2000), señala que el medio más ubicuo para desarrollar y evaluar la lectura musical es cantar a primera vista. A partir de allí, el autor plantea y describe una serie de habilidades que entran en juego en tareas de este tipo, y que necesitan ser desarrolladas por los estudiantes, como por ejemplo, la producción vocal, la solmización (distinguiendo los métodos de do fijo y do móvil), el manejo y aprendizaje de la escala por inculcación, el establecimiento de una colección de alturas diatónicas y de la tónica, el establecimiento del pulso, el tempo y el metro, y la imaginería auditiva previa a la ejecución. Karpinski (2000), hace referencia a la participación del cuerpo en la lectura al señalar algunos puntos que considera importantes para una buena producción vocal: postura corporal cómoda, soporte abdominal desde el diafragma y respiración adecuada. En esta primera alusión al cuerpo, se observa que el interés radica en propiciar una resultante sonora adecuada, es decir, que el cuerpo cumple el rol de emisor de la ejecución final. Sin embargo, resulta más interesante a los fines de esta Tesis, la participación del movimiento corporal 
manifiesto que Karpinski propone para el establecimiento del pulso y del tempo previo a la ejecución a partir de la lectura y durante la misma.

"Es importante que exista una continuidad -tanto mental como física- entre el pulso y el tempo establecidos antes de la ejecución y los que se utilizan durante la ejecución. Los músicos deben ser capaces de llevar el tempo que establecen para sí mismos directamente y sin alteraciones, en la música para la cual fue establecido. Para ello, es útil alentar a los estudiantes a realizar movimientos físicos para corporizar el pulso que establecen. Algunas sugerencias para estos movimientos incluyen golpecitos siguiendo el pulso (tapping) con el pie, movimientos con la cabeza o el torso y el gesto de dirección." (Karpinski, 2000, p. 155)

Aquí, el autor señala que la realización de movimientos corporales vinculados a la estructura métrica, como puede ser la marcación del pulso, antes y durante la ejecución favorece la estabilidad métrico-temporal de la misma. En este sentido, pareciera reconocer, aunque no de manera explícita, un rol cognitivo del movimiento corporal como colaborador en los procesos implicados en el ajuste temporal de la tarea de cantar a primera vista. Sin embargo no lo plantea en estos términos, sino más bien como una actividad útil para propiciar la continuidad y la permanencia de un mismo tempo a lo largo de la ejecución. Además, Karpinski (2000) señala también la importancia de que los procedimientos apoyados en acciones corporales, como establecer la tónica, el set de alturas, el tempo, el pulso y el metro, se internalicen lo antes posible. De acuerdo con el autor, los estudiantes deben desarrollar la capacidad de oír internamente la tonalidad y la métrica antes de comenzar a ejecutar y a comprender las notas individuales, sin realizar sonidos o movimientos. Esta idea deja entrever una concepción clásica de cognición basada en una mente que procesa internamente. Si bien en una primera etapa del desarrollo de la habilidad de cantar a primera vista el estudiante puede apoyarse en la realización de ciertos movimientos (marcación del pulso, gestos de dirección, etc.) y/o sonidos (cantar la tónica, la escala, etc.) debe aprender a pensar internamente y lograr abandonar rápidamente esas estrategias corporales iniciales. Sin embargo, como se discutirá más adelante, los movimientos manifiestos podrían formar parte del pensamiento mismo, es decir, podrían tener un rol cognitivo importante aportando recursos para resolver la tarea. Por esta razón, limitarlos podría perjudicar el desarrollo de la habilidad y el desempeño en la lectura a primera vista. 
Hasta aquí, se ha descripto el estado del arte en la investigación sobre la lectura cantada a primera vista, poniendo el foco principalmente en los aspectos cognitivos de la tarea, y se han mencionado algunas ideas provenientes del ámbito pedagógico en relación con el desarrollo de la habilidad. Notablemente, se observa una ausencia de la participación del cuerpo en la formación de significados durante la lectura tanto en la investigación como en el ámbito pedagógico. Esto no significa que no se considere la participación del cuerpo en ningún aspecto, pues como se mencionó, algunos trabajos señalan, por ejemplo, su intervención en la traducción kinética implicada en la lectura (Fine et al., 2006), la utilización de gestos realizados con las manos como estrategia de lectura exitosa (Killian y Henry, 2005), o también, el apoyo gestual para el desarrollo de la lectura (Curwen y Glover, 1885), el gesto de marcación de compás en la práctica del solfeo, la marcación del pulso y el gesto de dirección antes y durante la ejecución (Karpinski, 2000), etc. No obstante estas aproximaciones, no se vislumbra en la literatura investigativa vinculada a la habilidad de cantar a primera vista, un interés por entender el rol de cuerpo en la formación de los significados en los que se basa esta habilidad. Por el contrario, parece ser que estas investigaciones parten de una concepción clásica de mente (tal como se explicó en el capítulo 1 ) en la que el procesamiento cognitivo interno realizado por un comando central se basa en operaciones con representaciones simbólicas del mundo real. Desde esta visión clásica, la lectura a primera vista podría entenderse, resumidamente, como un proceso que comienza con una entrada de información visual codificada (observación de la partitura), con la que la mente opera simbólicamente para decodificarla, construir representaciones internas y producir una respuesta corporal que se constituye en la ejecución ajustada de esa melodía por parte del aparato fonador. Además, entra en juego la retroalimentación auditiva de la propia ejecución, que posibilita un ajuste de la resultante sonora. Aquí, el cuerpo es la base material para los sentidos que participan del proceso (visión y audición) y el responsable de la salida de la información procesada puesta de manifiesto en la conducta vocal que implica cantar la melodía leída. Sin embargo, el movimiento corporal manifiesto podría desempeñar un papel importante en la formación de significados participando en los procesos cognitivos desplegados para realizar la tarea, es decir, que podría estar aportando recursos cognitivos que de otro modo no estarían disponibles. De este modo, se considera necesario incluir esta dimensión corporal en explicación de la formación de significados musicales a partir de la lectura a primera vista y de los procesos cognitivos que son desplegados durante tareas de este tipo, en base al marco teórico de las Ciencias Cognitivas de Segunda Generación descriptas en el capítulo 1. 
En síntesis, la literatura disponible permite caracterizar la tarea de cantar a primera vista como una combinación de habilidades de diferente naturaleza y complejidad, tales como: la decodificación de los símbolos del sistema de escritura, la construcción de una representación mental en tiempo real de la música plasmada en la partitura basada en las expectativas que el lector construye en función de sus conocimientos previos, la interpretación como proceso de significación, la construcción del marco métrico temporal, del centro tonal y de las condiciones de estabilidad de las alturas, el emparejamiento de las representaciones auditivas con el resultado sonoro a través de la retroalimentación auditiva, el control de la emisión vocal y la ejecución ajustada. En este sentido, la lectura cantada a primera vista es considerada como una tarea de ejecución musical de alta demanda cognitiva, cuya resolución podría apoyarse en la formación de recursos cognitivos corporales a través del movimiento manifiesto.

A partir de esta concepción de la habilidad de cantar a primera vista y del estado del arte descripto en este capítulo que da cuenta de una utilización pedagógica del movimiento corporal en las estrategias didácticas de la lectura musical, y en función del marco teórico expuesto en el capítulo 1, es posible hipotetizar que los movimientos manifiestos desplegados en tareas de lectura cantada a primera vista vinculados temporal y morfológicamente con aspectos musicales poseen una función epistémica, actuando como un anclaje corporal externo y reduciendo la carga cognitiva que la tarea demanda. 

Segunda Parte

Evidencia Empírica 



\section{Capítulo 3}

\section{Etapa Exploratoria}

En este capítulo se presentan dos estudios realizados a partir de la necesidad estratégica de conocer los movimientos corporales desplegados en tareas de cantar a primera vista, para describirlos y clasificarlos en función de sus vinculaciones con las características de la melodía. El primero de ellos explora la ocurrencia y permanencia de los movimientos describiendo las partes del cuerpo involucradas y clasificándolos en grandes categorías ad hoc que permiten comenzar a asociarlos con los rasgos musicales de la melodía leída. A partir de los resultados obtenidos en el primero, el segundo estudio de esta etapa exploratoria se focaliza en los movimientos de la mano, los describe y propone una tipología original para clasificar los gestos en este tipo de tareas en base a un análisis crítico de tipologías gestuales existentes, destacando las vinculaciones entre las características del movimiento y los rasgos musicales de la melodía que está siendo leída.

Como se ha mencionado al desarrollar el estado del arte en el capítulo 2, los estudios que se han ocupado de analizar aspectos cognitivos de la habilidad de leer a primera vista han puesto el foco en el modo en el que los lectores más hábiles procesan la información, con el fin de comprender los procesos cognitivos en los que se basa la habilidad y promover su desarrollo exitoso. En este sentido, se han destacado procesos cognitivos como la escucha interna y la construcción de representaciones mentales (Kornicke, 1995; Waters et al., 1998; Fine et al., 2006; Lehmann y Kopiez, 2009), el rol de la retroalimentación auditiva (Ward y Burns, 1978, citado en Fine et al., 2006), la resolución de problemas cognitivos en tiempo real (Lehmann y Kopiez, 2009) y la realización de estrategias exitosas que permite resolver los problemas (Killian y Henry, 2005) entre otros. Al focalizar en la participación del movimiento corporal en este tipo de tareas se notó que es abordada básicamente de dos modos: (i) como resultado de la traducción kinética de escritura a movimientos implicada leer a primera vista (ver Fine et al., 2006); y (ii) como estrategia exitosa empleada por los lectores más hábiles tanto durante el tiempo de preparación previo a la ejecución como durante la misma (ver Killian y Henry, 2005). En el último caso, los movimientos son entendidos como gestos convencionales realizados con las manos, basados en el desarrollo de la lectura a partir del método del do móvil (Curwen y 
Glover, 1885). De este modo, existe una relación directa entre el movimiento de la mano y la jerarquía tonal de la nota cantada, pero no está claro el rol que cumple este movimiento en los procesos cognitivos desplegados para cantar a primera vista. Por otro lado, existe evidencia anecdótica de que los ejecutantes realizan una amplia gama de movimientos durante las tareas de lectura a primera vista, que exceden esos usos y que al mismo tiempo no parecer ser necesarios para la producción de sonido. Sin embargo, estos movimientos no han sido descriptos, clasificados y analizados en la literatura que ha abordado la habilidad de cantar a primera vista. 


\section{Estudio 1: Exploración Inicial}

A partir de las limitaciones, que en materia de análisis corporal, muestran los estudios existentes sobre el tema, y en el marco de la Teoría de la Cognición Corporizada que se ha descripto en el capítulo 1 , se propuso la realización de las primeras observaciones de los movimientos desplegados en este tipo de tareas, con el fin de describirlos, clasificarlos, cuantificar su duración, analizar las partes del cuerpo involucradas y establecer vínculos entre el movimiento y los componentes musicales de la melodía leída. Como se mencionó en el capítulo 1, las tipologías gestuales descriptas provienen de diferentes disciplinas y obedecen a situaciones particulares, como por ejemplo, el diálogo con un interlocutor, la comunicación no verbal, etc. Particularmente, las tipologías que estudian los gestos desplegados en tareas musicales fueron desarrolladas para explicar los movimientos realizados en tareas de ejecución musical expresiva en el contexto de relaciones entre el ejecutante y la audiencia (Delalande, 1988; Cadoz y Wanderley, 2000; Davidson, 2001). Esta especificidad situacional de las categorizaciones estudiadas sugiere la necesidad de tener una tipología que se ajuste a las particularidades de la tarea de cantar a primera vista, con el fin de entender los gestos desplegados en este contexto particular de ejecución musical. Así, se diseñó una estrategia para la exploración preliminar de los movimientos corporales efectuados en este tipo de tareas, que no corresponden a los denominados efectores de acuerdo a la tipología de Delalande (1988; ver capítulo 1) con el fin de clasificarlos en categorías generales ad hoc basadas en los vínculos con la melodía. Esto involucra determinar qué partes del cuerpo se hallan mayormente involucradas en tales movimientos y explorar su permanencia cuantificando la duración, y vincularlo a características propias de la tarea.

\section{Metodología}

\section{Sujetos}

Participaron del estudio 11 estudiantes de la asignatura Educación Auditiva de la Facultad de Bellas Artes de la Universidad Nacional de La Plata. Al momento de la realización del estudio, los sujetos se encontraban cursando el segundo nivel de la asignatura, lo que aseguraba el conocimiento de ciertos contenidos musicales básicos y del procedimiento de lectura a primera vista. 


\section{Estímulos}

Para este primer estudio exploratorio se diseñaron especialmente 2 melodías, atendiendo a que tuvieran ciertas características similares, como el compás (6/8), los grupos rítmicos involucrados (tres corcheas, negra-corchea, negra con puntillo), la organización morfológica (ab-a-b'), el modo (mayor), las características del movimiento melódico (movimiento por grado conjunto y saltos dentro del acorde de tónica) y la cantidad de alteraciones en clave (ver figura 3.1).

\section{Melodía 1}
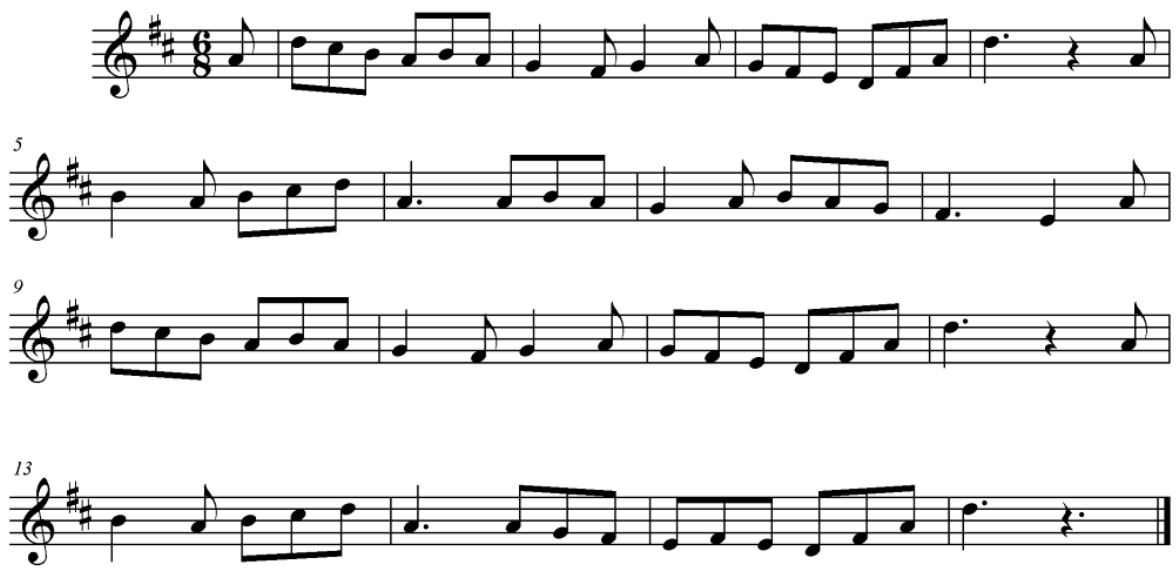

\section{Melodía 2}
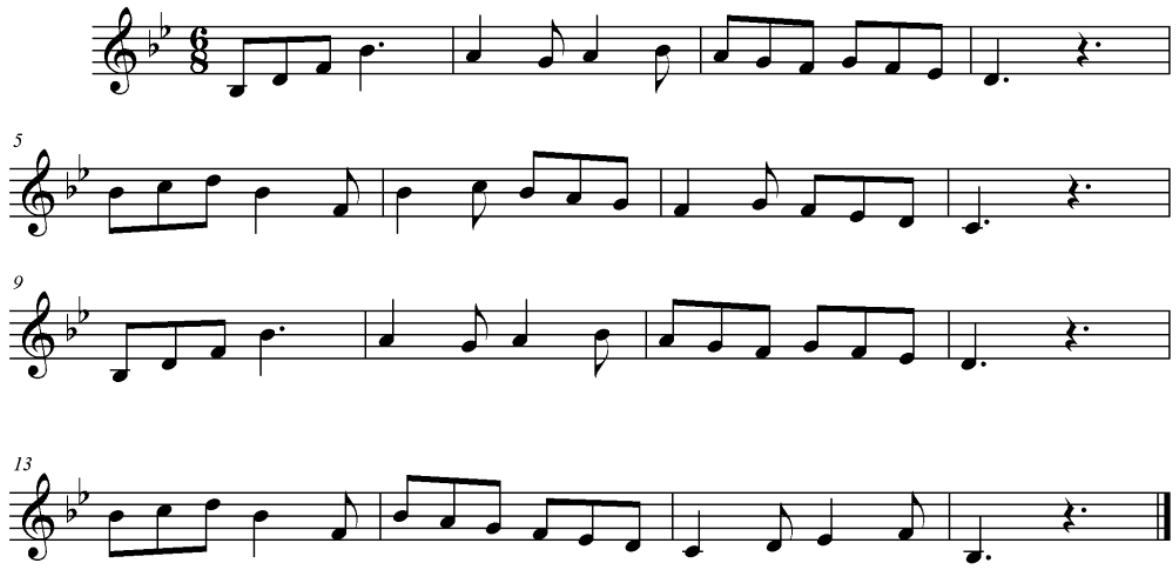

Figura 3.1. Melodías utilizadas en el estudio exploratorio 1.

\section{Procedimiento}

La tarea consistió en leer tres veces consecutivas una de las melodías seleccionada al azar. Antes de comenzar la lectura, los sujetos disponían de unos segundos para ubicarse en la 
escala correspondiente de acuerdo a la melodía que debían leer, pero sin realizar una medición estricta del tiempo de preparación. Considerando los resultados obtenidos por Fine, Berry y Rosner (2006) quienes observaron que los ejecutantes cometen menos errores a medida que se familiarizan con la melodía que están leyendo, y teniendo en cuenta que todos los participantes del presente estudio realizaban ejecuciones más continuas en las sucesivas versiones, se tomó la tercera ejecución de cada uno de los sujetos para el análisis de los movimientos.

\section{Diseño}

Para la realización de la prueba se dispuso un atril sobre una mesa para sostener la partitura de la melodía. Además, se dispusieron dos cámaras filmadoras fijas, ubicadas a 90 grados una de otra y a la altura de un plano medio del sujeto, para realizar tomas de frente y de perfil con el fin de registrar todos los movimientos que los sujetos realizaban durante la lectura, y el sonido resultante de la ejecución.

\section{Resultados}

En una primera instancia se observaron ambas tomas (la de frente y la de perfil) con el objeto de identificar los movimientos presentes durante la realización de la tarea de lectura a primera vista. Se midió la duración de cada uno de los movimientos y se los categorizó de acuerdo a un sistema rudimentario ad hoc que incluía tres grandes categorías a partir de la relación observable entre los movimientos y la melodía leída: (i) movimientos vinculados al ritmo y a la estructura métrica; (ii) movimientos vinculados a la altura y (iii) otros movimientos.

En la primera categoría se incluyeron todos los movimientos realizados por los sujetos que evidencian alguna relación con el ritmo o con la métrica de la melodía, como por ejemplo: batir la mano sobre la mesa coincidiendo con la división o con el tiempo, mover el pie coincidiendo con cada articulación del canto, etc. La segunda categoría involucra movimientos tales como elevaciones de la cabeza en ascensos melódicos, movimientos de las manos en relación a los movimientos melódicos al estilo de la quironimia, etc. En la tercera categoría se incluyeron todos los movimientos que aparentemente no tienen relación con las categorías anteriores, y que no se vislumbra claramente una vinculación con las características propias de la melodía, como fruncir el entrecejo, realizar movimientos circulares con el tronco no relacionados con la métrica, reírse, rascarse una pierna, acomodarse, etc.

En la figura 3.2 se presentan dos gráficos que muestran los resultados del análisis de estas categorías generales. Si bien todos los sujetos realizaron algún movimiento que no se 
relaciona, al menos en un primer análisis, con las características estructurales de las melodías leídas, el $73 \%$ de los sujetos realizaron movimientos vinculados al ritmo y a la métrica, y el $91 \%$ movimientos vinculados a la altura (solamente un participante no realizó movimientos de este tipo).

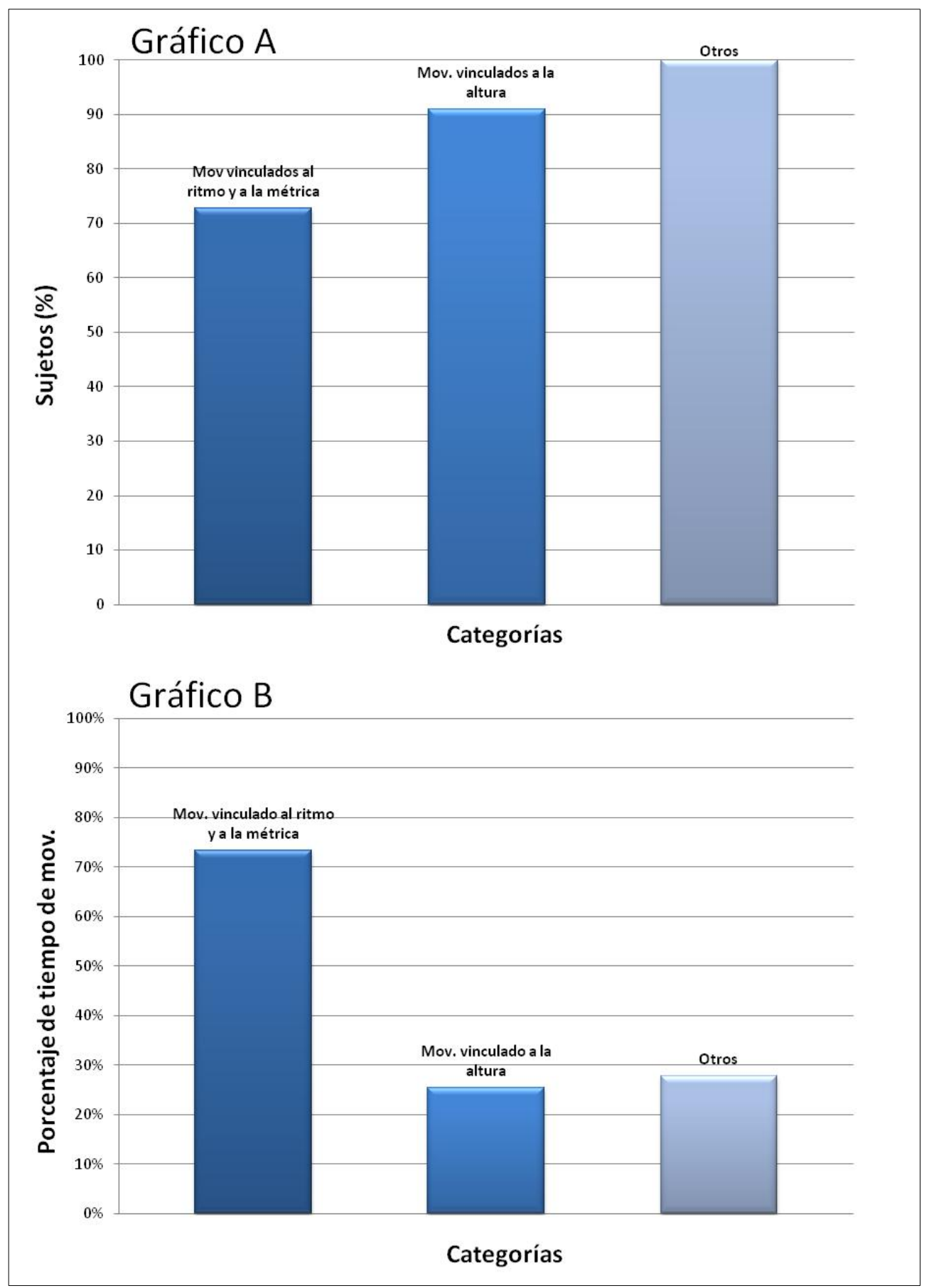

Figura 3.2. Resultados del análisis de acuerdo a las tres categorías generales propuestas. El Gráfico A muestra el porcentaje de sujetos que realizó movimientos incluidos en cada categoría general. El Gráfico B muestra el porcentaje general de tiempo que se realizaron movimientos de cada una de las categorías. 
Al cruzar los datos entre las categorías, se observó que todos los que realizaron movimientos vinculados a la estructura métrica y al ritmo, también desplegaron tanto movimientos vinculados a las alturas como otros movimientos. Es decir, que el $73 \%$ de los participantes del estudio, que inicialmente se reportaron incluidos en la categoría (i), también estaban incluidos en las categorías (ii) y (iii). Asimismo, el único sujeto que no se movió en vinculación con las alturas, tampoco lo hizo en relación con la estructura métrica y el ritmo, pero sí efectuó otros movimientos.El porcentaje de tiempo que se muestra en el gráfico B de la figura 3.2 refiere a la relación entre el total del tiempo de ejecución y la cantidad de tiempo en que se realizan movimientos vinculados a alguna de las categorías propuestas. Esta cuantificación temporal de las categorías mostró que la mayor parte del tiempo (73\%) los sujetos desplegaron movimientos que tienen que ver con la métrica y con el ritmo. Se observó además que solamente el $25 \%$ del tiempo realizaron movimientos vinculados a la altura, mientras que el $28 \%$ efectuaron otros movimientos.

Notablemente, al cruzar los datos de la medición temporal con la cantidad de sujetos incluidos en cada categoría, se observó que si bien el porcentaje de sujetos que desplegó movimientos vinculados a la estructura métrica y al ritmo fue menor que los que realizaron movimientos vinculados a las alturas, estos movimientos permanecieron mucho más tiempo. Al observar los videos y analizar los momentos en los que fueron realizados los movimientos, se observó que mientras aquellos que se vinculaban con la estructura métrica y el ritmo aparecían durante largos tramos de la lectura e incluso durante la ejecución completa, los movimientos vinculados a las alturas surgían en momentos particulares de la ejecución, principalmente en fragmentos cortos. Al analizar esos momentos, se observó que los participantes se trababan, repetían el fragmento, lo desaceleraban, etc., mientras desplegaban movimientos vinculados a las alturas similares a la quironimia. Esto podría sugerir que tales movimientos aparecían en fragmentos que presentaban mayor dificultad para los participantes y que, por consiguiente, podrían estar siendo realizados como recurso para resolver esa dificultad.

En una segunda instancia se observaron las partes del cuerpo involucradas en los movimientos y se cuantificó la duración temporal del movimiento de cada una de ellas. Es conveniente aclarar que la categoría brazos se refiere al movimiento de éstos que no es realizado como consecuencia del movimiento de la mano, por ejemplo: separar el codo del cuerpo y volverlo a juntar, etc. En la figura 3.3 se presentan los gráficos que muestran los resultados del análisis del movimiento de los sujetos vinculado a las partes del cuerpo involucradas y a la duración de tales movimientos. En el gráfico $\mathrm{C}$ puede observarse que las únicas partes con las que todos los sujetos efectuaron algún tipo de movimiento son las manos y la cabeza. Del mismo modo, el 
gráfico D muestra que tanto las manos como la cabeza estuvieron involucradas en el movimiento durante la mayor cantidad del tiempo utilizado en las lecturas.

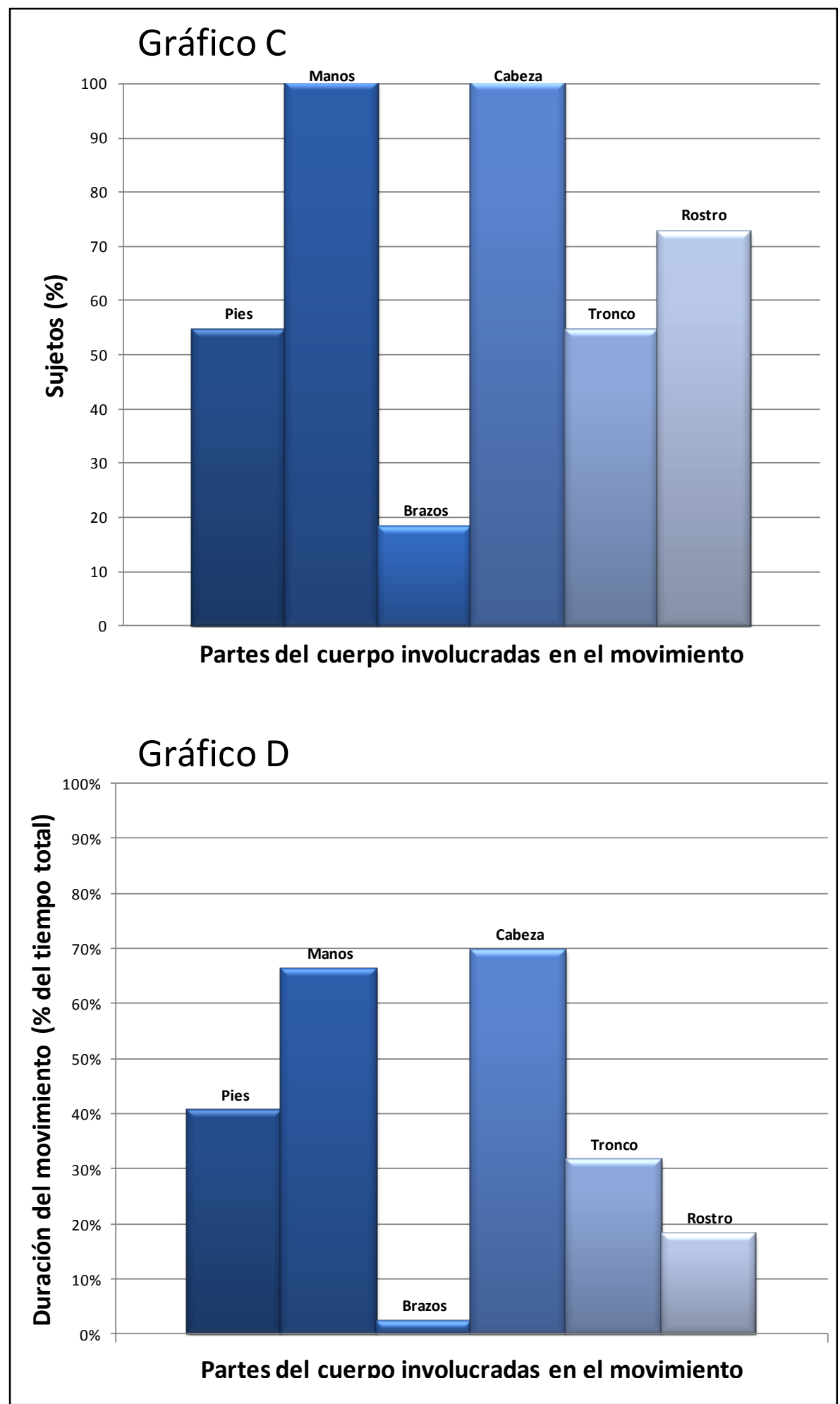

Figura 3.3. Resultados del análisis de los movimientos en relación a las partes del cuerpo involucradas. El Gráfico C muestra el porcentaje de sujetos que realizó movimientos con las partes analizadas, y el Gráfico D muestra el porcentaje general de tiempo que se realizaron movimientos de cada una de las partes del cuerpo involucradas. 
Al cruzar esta información con las categorías de movimientos descriptas anteriormente, se observaron algunos datos interesantes. Los movimientos vinculados a las alturas se realizaron principalmente con las manos y con la cabeza. Por su parte, los movimientos vinculados a la estructura métrica y al ritmo incluyeron movimientos de los pies, de las manos, de la cabeza, de los brazos y del tronco (como balanceos vinculados al pulso). Asimismo, se observó que los movimientos realizados con los pies se vinculaban casi exclusivamente a la estructura métrica, como batidos que coincidían con las pulsaciones del tiempo musical que presentaba la ejecución. Por otro lado, los movimientos de la cabeza, que incluyeron movimientos vinculados a las alturas y a la estructura métrica, también incluyeron una porción importante de otros movimientos. Finalmente, el análisis del movimiento de las manos mostró que se vinculaba principalmente con las alturas y con la estructura métrica y el ritmo, aun cuando en pocas ocasiones aparecieron otros movimientos.

\section{Discusión}

Este trabajo se propuso realizar una primera exploración de los movimientos manifiestos en las tareas de lectura a primera vista, con el fin de clasificarlos, medirlos temporalmente y observar las partes del cuerpo involucradas. En este sentido, los movimientos se agruparon en tres grandes categorías que los vinculan con algunas características de las melodías leídas, y se cuantificaron temporalmente. Estas vinculaciones permiten suponer que un análisis más detallado de los movimientos podría brindar una idea más precisa de la relación con las características estructurales de la melodía. Si bien estas categorías generales permiten una aproximación a la observación y al análisis del movimiento corporal en esta tarea, distan mucho de proporcionar una herramienta acabada de análisis. Muchos de los movimientos analizados pudieron ser incluidos en las categorías propuestas, pero la generalidad de las mismas no permite especular acerca del rol que podrían estar cumpliendo esos movimientos en la tarea de cantar a primera vista. La categoría otros incluyó una variedad importante de movimientos que deberían poder analizarse y clasificarse de manera independiente. Es posible que una parte importante de esos movimientos presenten alguna relación con la melodía y cumplan un papel importante para la resolución de la tarea. Por estas razones se considera necesario hallar nuevas categorías que posibiliten un análisis más puntual y detallado de los movimientos con el fin de buscar posibles vinculaciones con las estrategias cognitivas que los estudiantes emplean en tareas de lectura cantada a primera vista.

La observación de las partes involucradas en el movimiento y su posterior cuantificación, brinda información general que posibilita subdividir el movimiento corporal para un análisis 
más preciso. Asimismo, la posibilidad de observar cuáles son las partes del cuerpo mayormente involucradas en el movimiento permite hallar relaciones entre los movimientos efectuados por distintos sujetos, puntualizando en aquellas partes que participan del movimiento en todos los sujetos.

Los resultados mostraron que si bien los movimientos vinculados al ritmo y a la estructura métrica fueron desplegados por un porcentaje menor de sujetos, fueron mucho más persistente a través del tiempo, mientras que el movimiento vinculado a las alturas fue más generalizado pero permaneció menos tiempo. Además, los movimientos vinculados a las alturas parecieron ser realizados en momentos particulares de dificultad en la lectura. Esto podría sugerir que son desplegados con una finalidad específica, tal vez como un recurso para propiciar una mejor resolución de los problemas originados por los fragmentos que resultan más difíciles. Esto podría estar dando cuenta de un rol cognitivo o epistémico del movimiento corporal en tareas de cantar a primera vista. Sin embargo, es necesario continuar con la exploración de estos movimientos, como así también estudiar empíricamente su función en este tipo de tareas para poder establecer relaciones entre el movimiento corporal manifiesto y los procesos cognitivos desplegados.

Considerando que el movimiento de las manos estuvo presente en todos los participantes, que fue uno de los que presentó mayor permanencia a lo largo de la ejecución y mayor relación tanto con la altura como con el ritmo y la estructura métrica, resulta necesario focalizar en los movimientos de las manos con el fin de generar tipologías que puedan ser aplicadas al análisis de los movimientos en este tipo de tareas. Además, la variabilidad observada en estos movimientos permitirá construir un sistema de categorías lo suficientemente abarcador como para ser utilizado en movimientos más globales o con diferentes partes del cuerpo.

Este estudio exploratorio constituye el puntapié inicial para la observación y el análisis de los movimientos en tareas de cantar a primera vista, y como tal, dejó más interrogantes que certezas, pero señaló, de alguna manera, el camino por el cual continuar la exploración y el análisis en los estudios subsiguientes. 


\section{Estudio 2: Clasificación de los Gestos Manuales en la Tarea de Cantar a Primera Vista}

Como se señaló en el capítulo 1, el avance del estudio del rol del cuerpo en los procesos de significación musical, ha necesitado echar mano a los métodos de análisis de movimientos corporales aportados por otras disciplinas, como la lingüística, la sociología y la danza, entre otras. Uno de los sistemas de análisis de movimientos que mayor acuerdo ha encontrado entre los investigadores en música proviene de la danza, y fue propuesto por Rudolph Laban (1970). Muy sintéticamente, este sistema se basa en cuatro categorías que describen las cualidades internas de los movimientos: (i) cuerpo (analiza la parte del cuerpo que realiza el movimiento); (ii) espacio (refiere al comportamiento del cuerpo en los planos vertical, horizontal y sagital); (iii) forma (observa las posiciones del cuerpo y sus modificaciones durante los movimientos); y (iv) esfuerzo (refiere a las características sutiles de expresión e intención del movimiento).

Analizar los movimientos utilizando las categorías propuestas por Laban permite describir detalladamente los gestos corporales de los sujetos, pero dice poco acerca del rol de esos gestos en los procesos de significación musical. Es decir que permite dar lugar a la generación de categorías descriptivas pero no funcionales del gesto. Sin embargo, como se verá a lo largo de este estudio, las categorías que pueden estar vinculadas a la función de los gestos podrían estar identificadas, en algunos casos, con aspectos descriptivos en términos morfológicos. Por ejemplo, el establecimiento del vínculo entre un gesto y la melodía podría basarse en cierta equivalencia morfológica entre el movimiento corporal y el contorno melódico. Es decir que un movimiento melódico ascendente en la lectura podría corresponderse con un gesto ascendente de la mano, como formas equivalentes.

A partir de las observaciones realizadas, de los resultados obtenidos en el estudio 1 , y de la necesidad de hallar nuevas categorías que posibiliten un análisis más puntual y detallado de los movimientos, se propuso la realización de un segundo estudio con el fin de postular una tipología basada en relaciones que permitan (i) mapear los movimientos con rasgos estructurales, y (ii) establecer vinculaciones con las estrategias cognitivas que los estudiantes emplean para resolver tareas de lectura a primera vista. En este sentido, se acotó el estudio del movimiento al gesto manual observable en dicha tarea, a partir del marco teórico descripto en el capítulo 1 referente al gesto, sus definiciones y sus categorías provenientes de diferentes campos disciplinares. Más específicamente, se aplicó y se estimó la pertinencia para el estudio 
del gesto en la lectura a primera vista de las tipologías propuestas por Ekman y Fresen (1969), McNeill (1992), Delalande (1988), y Davidson (2001).

\section{Objetivos}

Analizar críticamente diferentes categorizaciones de gestos provenientes de distintos ámbitos disciplinares y estimar su pertinencia para el análisis del gesto manual en las tareas de lectura cantada a primera vista. Proponer una tipología alternativa que permita sistematizar los gestos de acuerdo con las particularidades de la tarea. Testear y ajustar la clasificación propuesta en con el fin de validarla para su posterior aplicación.

\section{Metodología}

El estudio constó básicamente de tres etapas, por lo que la metodología se describe de acuerdo a ellas. La primera consistió en la realización de un estudio experimental en el que los sujetos debían cantar una melodía a primera vista. Además durante esta etapa se seleccionó uno de los sujetos que participó de la prueba y se realizó una descripción detallada de cada uno de los movimientos de las manos de acuerdo con las categorías espacio y forma propuestas por Laban (1970). En la segunda etapa se realizaron análisis críticos de las categorizaciones propuestas en distintos contextos disciplinares para el estudio del gesto, se intentó aplicar alguna de ellas a los gestos observados en la lectura a primera vista y se diseñó una nueva tipología específica. En la tercera etapa, se testeó la tipología resultante por medio de su aplicación por parte de un panel de jueces expertos y se ajustaron las categorías en función de los resultados del testeo.

\section{Primera Etapa: Recolección de Datos}

\section{Sujetos}

Se realizó una prueba en la que participaron 15 estudiantes de música que habían finalizado el primer año correspondiente al ciclo de formación básica para las carreras de música de la Facultad de Bellas Artes de la UNLP. Al haber transitado un año en la formación musical profesional, los participantes se hallaban en condiciones de resolver la lectura propuesta y poseían estrategias para cantar a primera vista. Además, esto aseguraba tener una muestra homogénea en relación con el desarrollo de la habilidad. 


\section{Estímulo}

Se diseñó una melodía especialmente para la realización de la prueba considerando el nivel de desarrollo en la habilidad alcanzado por todos los participantes (ver figura 3.4). Para el diseño del estímulo se tuvo especial cuidado en la coherencia melódica (movimiento melódico, armonía subyacente, organización morfológica, etc.) con el fin de promover la generación de expectativas que favorezcan la lectura en función de los estudios abordados en el capítulo 2 , que señalan la relevancia de la buena continuidad melódica en la ejecución a primera vista (Ortmann, 1934; Lehmann y Kopiez, 2009; Segalerba, 2009). Sin embargo, se diseñó intencionalmente un giro melódico que generara una disrupción medida en la coherencia con el fin de promover su abordaje como un problema cognitivo de mayor dificultad y propiciar el despliegue de estrategias para su resolución (ver figura 3.4, compás 15).

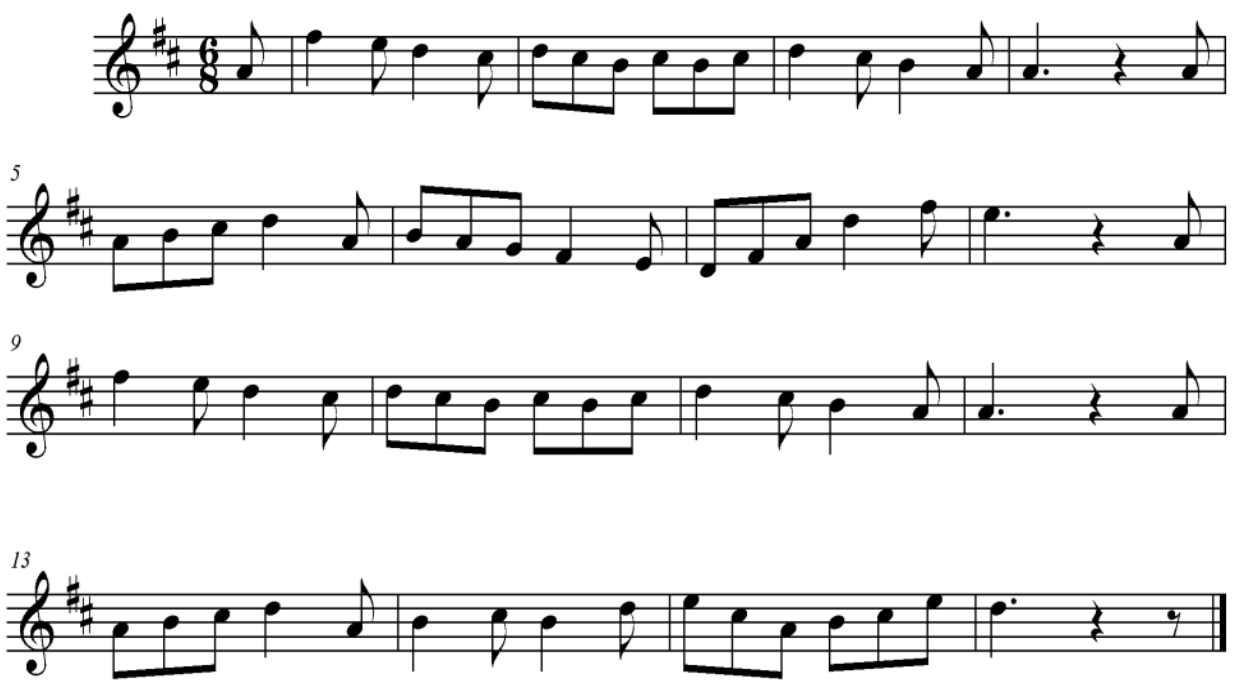

Figura 3.4. Melodía para lectura a primera vista elaborada para la realización de la prueba.

\section{Procedimiento}

La tarea consistió en leer a primera vista la melodía proyectada en una pantalla. Los sujetos debieron permanecer de pie frente a la pantalla durante la realización de la prueba y dispusieron de 4 minutos para ubicarse en la tonalidad y conocer la melodía antes de realizar la versión final. Considerando el efecto positivo del tiempo de preparación previo a la ejecución final hallado por Killian y Henry (2005), y presuponiendo, a partir de sus observaciones en cuanto a las estrategias desplegadas durante el lapso de preparación (ver capítulo 2), que los participantes podrían desplegar movimientos que les resulten relevantes para la ejecución de la melodía leída, se estableció un tiempo de 4 minutos de preparación 
para la lectura. Si bien en el estudio de los autores mencionados el lapso de preparación fue de 30 segundos, se decidió ampliar el lapso en función del nivel de desarrollo musical de los participantes como estudiantes iniciales de música, y de la práctica de lectura habitual que se les requiere en el ámbito académico en el que participan.

\section{Diseño}

Se dispusieron dos cámaras filmadoras fijas, ubicadas a 90 grados una de otra y a la altura de un plano medio del sujeto de pie, para realizar tomas de frente y de perfil con el fin de registrar todos los movimientos que los sujetos realizaban durante la lectura, y el sonido resultante de la ejecución. Se registró tanto el momento de preparación como la ejecución final de la melodía, con el fin de observar y comparar los movimientos realizados en ambas situaciones. Además, para no restringir el movimiento se proyectó la partitura en una pantalla a una distancia cómoda de lectura (2,5 metros).

\section{Selección y Descripción de los Movimientos}

Luego de realizar múltiples observaciones de los videos del test se seleccionó uno de ellos para realizar un análisis detallado. Esta selección se realizó de acuerdo a criterios a priori basados en la cantidad de movimientos realizados con las manos, la cantidad de gestos manuales diferentes, la recurrencia de gestos, y la identificación de posibles relaciones entre el gesto y el sonido. El análisis fue realizado utilizando las categorías Laban de espacio y forma, y se focalizó en las manos considerando las observaciones realizadas en el estudio exploratorio 1 relativas a la permanencia, variabilidad, relación con aspectos musicales y cantidad de participantes que realizaron tales movimientos. Las descripciones, tanto de los movimientos típicos desplegados, como de todos los movimientos realizados con las manos durante la ejecución del participante seleccionado se presentan en el anexo 1.

\section{Segunda Etapa: Análisis de las Tipologías}

Se realizaron análisis críticos de las categorizaciones de gestos propuestas por McNeill (1992), Ekman y Friesen (1969), Delalande (1988), y Davidson (2001; 2002), que fueron descriptas en el capítulo 1 de esta Tesis. El análisis consistió en testear las categorías que propone cada autor aplicándolas a los movimientos de las manos del sujeto seleccionado detallados en la primera etapa, y estimar la pertinencia de cada categoría para el análisis de los gestos manuales desplegados durante las tareas de lectura entonada a primera vista. Se diseñó una tipología específica acorde a las particularidades de la tarea y a la necesidad de considerar las relaciones entre los movimientos y la melodía leída. Además, se analizaron las definiciones y 
conceptos relativos al gesto explicados en el capítulo 1 con el fin de estimar la posibilidad de considerar gestos a los movimientos manuales desplegados en la tarea de cantar a primera vista.

\section{Tercera Etapa: Testeo de la Tipología Gestual Diseñada}

A partir de los análisis realizados y de los resultados obtenidos en la segunda etapa, y se segmentaron los videos de frente y de perfil del participante seleccionado. Considerando la definición de gesto propuesta en función de los conceptos analizados y de las particularidades de la tarea se marcaron todos los gestos manuales en ambas tomas de video. Luego, se le pidió a 4 jueces expertos que observaran los videos y clasificaran todos los gestos de acuerdo al sistema de categorías propuesto (ver protocolo para jueces en anexo 2). Finalmente se compararon todos los análisis cotejando los gestos incluidos en las diferentes categorías, y se realizó una estimación de la pertinencia de la tipología propuesta a partir del juicio de los expertos.

\section{Resultados}

\section{Análisis y Clasificación}

Algunas de las propuestas de McNeill (1992) resultan sumamente interesantes para el análisis del gesto manual en la lectura musical cantada. La idea de la existencia de una jerarquía kinésica, y de que el gesto es una unidad completa de sentido en sí mismo (ver capítulo1), permite establecer los límites del gesto de acuerdo al significado que expresan, y agruparlos en unidades gestuales en función de la detención del movimiento. Sin embargo, cuando se intentó aplicar estos conceptos para segmentar los gestos manuales del sujeto observado durante la realización de la tarea surgieron algunos inconvenientes. Lo que para McNeill sería un gesto, como por ejemplo señalar un punto en el espacio con el dedo índice, no podía segmentarse aquí como una unidad de sentido completo, debido a que su significado se completaba con los siguientes movimientos deícticos, que presentaban una variación espacial intencional en el plano vertical respecto del movimiento anterior. Las articulaciones de los sonidos ejecutados vocalmente en este pasaje se correspondían uno a uno con los movimientos de señalamiento, los cuales parecían representar el punteo de los grados de la escala, y las relaciones de ascensos y descensos melódicos. Así, solamente se podía comprender el sentido del gesto cuando se analizaba completo, observando las relaciones espaciales entre los señalamientos (ver figura 3.5). Esto permitía inferir una relación entre el movimiento de la mano y algunas características estructurales de la melodía, como el ritmo y 
el diseño melódico, que pasarían inadvertidas aplicando rigurosamente los criterios de McNeill. De este modo, se optó por definir al gesto como todo aquel movimiento o grupo de movimientos que conforma una unidad mínima de sentido completo, observando que no se pierdan las posibles vinculaciones con la estructura musical. Así, retomando el ejemplo anterior, un único gesto podría presentar varias fases de ataque (cada señalamiento), y esto permitiría segmentarlo en subgestos como un modo de facilitar su análisis.
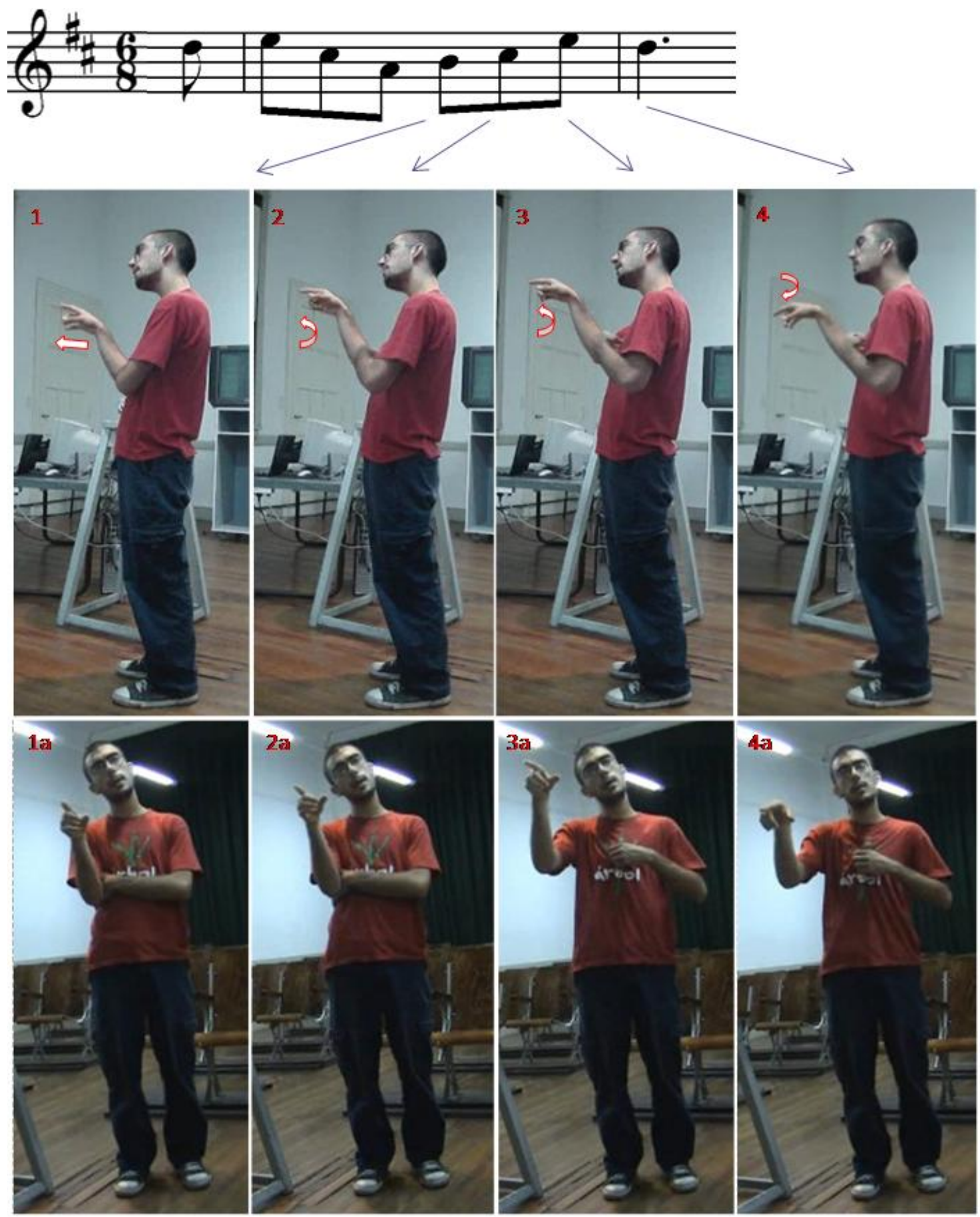

Figura 3.5. Fotogramas capturados de las tomas de perfil y de frente de los movimientos de señalamiento (gestos deícticos) vinculados al contorno melódico. Tomando cada señalamiento 
como un gesto deíctico separado se pierde el sentido completo de la relación espacial entre los cuatro señalamientos, que representa las relaciones de alturas del giro melódico. Las flechas representan el movimiento de la mano respecto de la posición anterior. Los fotogramas de frente se corresponden con los mismos momentos de los fotogramas de perfil.

De las cinco categorías de gestos propuestas por McNeill se considera que dos de ellas no resultan pertinentes para el análisis de los gestos manuales en la lectura entonada: gestos icónicos y gestos cohesivos. El análisis detallado de los movimientos de la mano en esta tarea mostró que estas categorías no dan cuenta cabalmente de ninguno de los gestos desplegados, como tampoco explican las posibles relaciones entre gestos y características musicales. Sin embargo, se observó con frecuencia la aparición de gestos que podrían incluirse en la categoría batidos, que generalmente estaban vinculados a la estructura métrica de la melodía leída. Asimismo, y como se mencionó anteriormente, los gestos deícticos se hallaron generalmente vinculados a la articulación de las notas. Sin embargo, cuando el sentido del gesto se completaba con los movimientos subsiguientes, la segmentación no se realizaba de acuerdo a cada movimiento deíctico, sino que se priorizaba el significado gestual completo, y al estar vinculado metafóricamente a las características de la estructura musical de la melodía, se consideraba un gesto metafórico. Es una vinculación metafórica porque no representa icónicamente el contenido musical, sino que, en el caso descripto, representa un movimiento melódico que en términos físicos está vinculado a relaciones entre las diferentes frecuencias de los sonidos cantados. Así, los señalamientos en el espacio con diferentes relaciones en el eje vertical constituyen una representación metafórica de esas relaciones de alturas en el giro melódico cantado.

De acuerdo con el alcance que se le dio al término gesto en este trabajo, un gesto metafórico podría estar compuesto por varios subgestos deícticos, en función de la unidad de significado del gesto, vinculado a las características de la estructura musical. Así, se considera apropiado tomar las categorías gestos deícticos (aquí vinculados a la articulación de las notas), batidos (vinculados con la estructura métrica) y gestos metafóricos (que permiten vincular metafóricamente los movimientos a los rasgos musicales) propuestas por McNeill, para analizar los gestos manuales en las tareas de lectura entonada a primera vista.

Las categorías propuestas por Ekman y Friesen (1969) pueden resultar muy útiles, como lo mostró Davidson (2001), para analizar los gestos producidos durante la ejecución vocal de una canción, en la que el gesto puede ilustrar los contenidos semánticos del texto, puede ayudar a coordinar con otros músicos, e incluso puede potenciar la comunicación entre el ejecutante y la audiencia. Sin embargo, no resultaron pertinentes para el estudio del gesto en la tarea de 
lectura entonada a primera vista, debido a que no hay un contenido semántico basado en palabras para comunicar, no hay otros músicos para coordinar, y no se establece la comunicación con otros sujetos porque la tarea se realiza individualmente y sin audiencia. Davidson propone la existencia de otro tipo de gestos durante la ejecución cantada, que son los gestos de exhibición, utilizados meramente para mostrarse o lucirse ante la audiencia. Al realizar la tarea sin público, esta es otra categoría claramente desestimable para la lectura cantada a primera vista. No obstante, tanto Ekman y Friesen como Davidson hablan de gestos adaptativos, que están orientados hacia el interior del sujeto y podrían exhibir características personales o estados internos. Luego de la observación detallada de los movimientos de las manos durante la tarea aquí estudiada, se considera pertinente utilizar esta categoría para clasificar algunas de las acciones que fueron realizadas, como por ejemplo, rascarse, tocarse la cabeza, acomodarse la ropa, etc.

Con respecto a la categorización propuesta por Delalande para el análisis de los movimientos en una ejecución musical, resulta evidente que todos los gestos estudiados en este trabajo estarían incluidos en la categoría de gestos de acompañamiento, ya que la ejecución es producida vocalmente. De esta manera, es indudable que esta categorización no resulta pertinente para el estudio de los gestos manuales en esta tarea.

Hasta aquí se han analizado las tipologías propuestas por distintos autores y se han hallado cuatro categorías que fueron consideradas pertinentes para el análisis del gesto manual en la lectura a primera vista, a saber: gestos adaptativos, batidos, gestos deícticos y gestos metafóricos. Sin embargo, estas categorías no dan cuenta de todos los movimientos que se observaron en el análisis descriptivo detallado de la primera etapa (ver anexo 1). Por ejemplo, se observaron gestos similares a otros que estaban claramente vinculados a aspectos musicales, pero que aparecían en momentos en que no se producía sonido vocal, por lo cual no se podía estimar la relación con tales componentes de forma directa (por ejemplo, batidos antes de comenzar la lectura). Además, si bien la categoría de gestos metafóricos vincula algunos movimientos a las características musicales de la melodía, es una categoría demasiado abarcadora, por lo que se considera necesario subdividirla de acuerdo al rasgo musical al que se vinculan, a fin de favorecer el análisis de estos vínculos. En este sentido, podrían encontrarse algunos gestos metafóricos que estén dando cuenta del diseño melódico (por ejemplo, señalamientos de puntos sucesivos representando las relaciones de altura), otros que estén representando la forma musical (por ejemplo, marcaciones de cierres de frases, bajando la mano o cerrándola, en los puntos de articulación formal), etc. Por estas razones, se esbozó una categorización alternativa (esquematizada en la tabla 3.1) incorporando las categorías que 
fueron estimadas pertinentes, e incluyendo nuevas categorías a partir de las necesidades derivadas del análisis descriptivo inicial.

\begin{tabular}{|c|c|c|c|}
\hline \multirow{8}{*}{ Gestos } & \multirow{6}{*}{$\begin{array}{l}\text { Gestos que acompañan la } \\
\text { emisión de sonido vocal }\end{array}$} & \multirow{5}{*}{$\begin{array}{c}\text { Directamente } \\
\text { vinculados a aspectos } \\
\text { musicales } \\
\text { (metafóricos) }\end{array}$} & $\begin{array}{l}\text { Vinculados al contorno melódico } \\
\text { (deícticos o no deícticos) }\end{array}$ \\
\hline & & & $\begin{array}{l}\text { Vinculados a la estructura } \\
\text { métrica (batidos) }\end{array}$ \\
\hline & & & Vinculados al ritmo \\
\hline & & & Vinculados a la expresión \\
\hline & & & Vinculados a la forma \\
\hline & & $\begin{array}{c}\text { Adaptativos } \\
\text { durante la ejecución }\end{array}$ & \\
\hline & \multirow{2}{*}{$\begin{array}{l}\text { Gestos sin emisión } \\
\text { de sonido vocal }\end{array}$} & Preparatorios & \\
\hline & & $\begin{array}{l}\text { Adaptativos sin sonido } \\
\text { vocal }\end{array}$ & \\
\hline
\end{tabular}

Tabla 3.1. Categorización preliminar propuesta para el estudio del gesto manual en las tareas de lectura musical entonada a primera vista.

La clasificación inicial de los movimientos en gestos que acompañan la emisión de sonido vocal y gestos sin emisión de sonido vocal obedece a la necesidad de distinguir los gestos que podrían ser vinculados más explícitamente a ciertas características de la estructura musical de aquellos que no. La primera alude a todos los movimientos que el sujeto realiza mientras canta; y la segunda, a aquellos producidos en ausencia de sonido vocal.

Los gestos adaptativos, entendidos como movimientos orientados internamente que ayudan a la regulación interna, podrían aparecer tanto durante la emisión de sonido vocal como en momentos de silencio, es por ello que forman parte de ambas categorías.

Los gestos directamente vinculados a aspectos musicales (o metafóricos) refieren a todos aquellos movimientos que representan metafóricamente algún rasgo musical, y por lo tanto, puede advertirse una relación entre el gesto y la estructura musical de la melodía leída. Para poder establecer este tipo de relaciones es necesario que los gestos sean desplegados al mismo tiempo que la ejecución vocal de la melodía. A su vez, estos gestos se pueden clasificar de acuerdo al aspecto musical con el que se vinculan en: vinculados a las alturas (por ejemplo, señalar puntos sucesivos en el espacio, cada vez más abajo, mientras se canta un giro melódico descendente); vinculados a la estructura métrica (o batidos, por ejemplo, mover una mano hacia arriba y hacia abajo varias veces coincidiendo con algún nivel de pulso de la estructura 
métrica de la melodía); vinculados al ritmo (por ejemplo, golpear la pierna coincidiendo con las articulaciones del canto); vinculados a la expresión (por ejemplo, movimientos continuos en partes cantadas legato); y vinculados a la forma (por ejemplo, movimientos que marcan puntos de articulación formal). Los gestos que se vinculan a las alturas pueden ser tanto deícticos, en los que las relaciones entre alturas se representan a través del señalamiento de puntos en el espacio, como no deícticos, en los que el vínculo puede establecerse por otro tipo de movimientos, como por ejemplo, cambios de posición de la mano.

Los gestos preparatorios son muy similares a los gestos que se vinculan a algún aspecto musical, pero que al presentarse sin emisión de sonido vocal no puede establecerse una relación directa con dichos aspectos. Sin embargo, estos gestos podrían estar favoreciendo la realización correcta de la tarea, cumpliendo un rol preparatorio para la ejecución vocal de la lectura, y en este sentido, podrían estar vinculados indirectamente a los rasgos musicales de la melodía.

La categorización propuesta intenta abarcar la totalidad de los gestos observados durante el análisis detallado inicial, y su organización prioriza las posibles relaciones entre los gestos y los rasgos estructurales de la melodía.

\section{Testeo de la Tipología Propuesta}

De acuerdo con las observaciones de los jueces se ajustó metodológicamente el análisis desestimando los movimientos que eran realizados con las manos detrás de la espalda. Estos movimientos presentaban una gran dificultad para ser clasificados, tanto por su brevedad como poca amplitud. Además, solo eran tomados parcialmente por la cámara de perfil, por lo que se disponía de una imagen no muy precisa para clasificarlos. Considerando estas dificultades y que solamente representaban el 1,7\% del total de movimientos se decidió desestimarlos.

Para analizar el grado de acuerdo entre los jueces se utilizó el coeficiente Kappa de Cohen, y se interpretaron sus valores de acuerdo a la valoración del estadístico propuesto por Landis y Koch (1977).

Como puede observarse en la tabla 3.2, el acuerdo entre pares de jueces resultó de moderado a considerable. El promedio total del coeficiente Kappa fue de 0,63, por lo que el grado de acuerdo interjueces al testear la tipología propuesta para clasificar los gestos desplegados al cantar a primera vista resultó considerable. De este modo, es posible decir que este sistema de 
categorías resulta aplicable para el estudio de los gestos manuales desplegados en las tareas de lectura a primera vista.

\begin{tabular}{|l|l|}
\hline Jueces & Kappa \\
\hline $\mathbf{1 * 2}$ & 0,601 \\
\hline $\mathbf{1 * 3}$ & 0,605 \\
\hline $\mathbf{1 * 4}$ & 0,805 \\
\hline $\mathbf{2 * 3}$ & 0,516 \\
\hline $\mathbf{2 * 4}$ & 0,653 \\
\hline $\mathbf{3 * 4}$ & 0,606 \\
\hline
\end{tabular}

Tabla 3.2. Grado de acuerdo interjueces estimado con el coeficiente Kappa de Cohen e interpretado con la valoración de Landis y Koch (1977). Valores entre 0,41 y 0,6 indican un acuerdo moderado, y valores entre 0,61 y 0,8 acuerdo considerable.

\section{Discusión}

Este trabajo propuso la realización de un análisis crítico de categorizaciones de gestos provenientes de distintos contextos disciplinares, a fin de estimar su pertinencia para el análisis del gesto manual en las tareas de lectura cantada a primera vista. En este sentido, se analizaron cuatro categorizaciones gestuales: dos provenientes del ámbito de la lingüística y el estudio de la comunicación no verbal (McNeill, y Ekman y Friesen), una tercera referente al campo de la ejecución musical instrumental (Delalande), y finalmente, una propuesta para el estudio de los gestos en la ejecución musical vocal (Davidson). Sin embargo, es evidente que no se ha pretendido abarcar la totalidad de los estudios referentes a los gestos en los ámbitos mencionados, sino más bien, hallar algunas categorías que posibiliten el análisis de los gestos manuales es este tipo de tarea, que por su naturaleza, no permite aplicar íntegramente ninguna de las tipologías estudiadas. En este sentido, surgió la necesidad de hallar nuevas categorías que posibiliten un análisis más acabado de los gestos. Así, se propuso una categorización preliminar que fue diseñada a partir del análisis de las tipologías de gestos mencionadas, y del análisis de los gestos que fueron observados durante la realización de tareas de cantar a primera vista. Además, se intentó poner en primer plano las posibles vinculaciones entre el gesto y las características musicales estructurales de la melodía. En este sentido, las categorías propuestas se basan en la posibilidad de establecer estos vínculos, con el fin de hallar, en instancias posteriores, relaciones entre los gestos y las estrategias cognitivas 
desplegadas por los sujetos para la resolución de la tarea. El testeo con jueces expertos de esta tipología arrojó un acuerdo considerable, que permite validarla como instrumento de análisis y de clasificación gestual.

Esta propuesta, como aporte al estudio del rol del cuerpo en las tareas de cantar a primera vista, brinda la posibilidad de analizar diferentes gestos a partir de categorías que los vinculan con las características de la estructura musical de la melodía objeto de la lectura. Poner el foco en esas relaciones podría ser la clave para analizar y entender los procesos cognitivos implicados en la habilidad de cantar a primera vista, pues ellas podrían revelar o formar parte del pensamiento musical en el que se basa la tarea. En este sentido, los vínculos entre el movimiento corporal y la música ejecutada a partir de la lectura será la base del estudio experimental que será presentado en el capítulo subsiguiente. 


\section{Capítulo 4}

\section{Etapa Experimental}

\section{Estudio 3: El Gesto Corporal como Acción Epistémica}

En la etapa exploratoria descripta en el capítulo 3, se observó que una gran parte de los movimientos realizados por los participantes cuando cantaban a primera vista parecían estar vinculados temporal y morfológicamente a rasgos estructurales de la melodía, principalmente a la estructura métrica y al contorno melódico. Por un lado, los movimientos vinculados a la estructura métrica aparecían como batidos de algún nivel de pulsación, generalmente del tiempo, y en tal sentido, parecían estar apoyando la configuración de la estructura métrica durante, o incluso antes de comenzada la ejecución. Por otro lado, los movimientos que se observaban vinculados al contorno melódico se presentaban como señalamientos manuales en el espacio, y parecían representar el punteo de las notas cantadas en simultaneidad con el gesto respetando, en diferente medida los ascensos y descensos de altura. Algunos de estos movimientos solían aparecer en fragmentos que parecían resultar más difíciles de resolver, puesto que coincidían con momentos en los que los estudiantes detenían la ejecución, volvían a comenzar, ralentizaban, etc. Así, se pensó que era posible que movimientos de este tipo fueran desplegados por los estudiantes de música para ayudarse a resolver las lecturas cantadas a primera vista, y en tal sentido, estuvieran cumpliendo una función epistémica, es decir, mejorando los procesos cognitivos desplegados y reduciendo la carga cognitiva que implicaba resolver este tipo de tareas. Como se mencionó en el capítulo 1, el concepto de acción epistémica fue propuesto por Kirsh y Maglio (1994) para referirse a todas aquellas acciones que son realizadas en el mundo físico con el fin de mejorar aspectos de la cognición. Este tipo de acciones favorecerían una reducción de la memoria utilizada, del número de pasos mentales y de la posibilidad de error en el proceso mental. De este modo, las ideas de Kirsh y Maglio postulan la existencia de un fuerte vínculo entre la cognición y la interacción corporal con el mundo circundante, y en este sentido, apoyan la teoría de mente extendida delineada por Andy Clark y David Chalmers (1998). De acuerdo con esta teoría, la mente humana trasciende los límites del cerebro y se extiende hacia el mundo externo, incorporando 
elementos del entorno físico y social a los procesos cognitivos a partir de la interacción corporal. Este externalismo activo implica la acción de los componentes del mundo externo en la cognición humana, que incide tanto en el organismo como en su conducta. Estas teorías apoyan la idea de que la interacción corporal con el entorno físico y social está íntimamente vinculada a la cognición.

A partir de los resultados obtenidos en los estudios exploratorios presentados en el capítulo 3, en relación con los gestos observados, descriptos y clasificados durante tareas de cantar a primera vista, se propuso la realización de un estudio experimental para analizar la posibilidad de que ciertos gestos vinculados a la estructura musical de la melodía sean realizados con una finalidad cognitiva, y en tal sentido, puedan ser considerados como acciones epistémicas. En función de las características descriptas en los párrafos precedentes, se focalizó en los gestos vinculados al contorno melódico y a la estructura métrica, debido a que tanto sus rasgos propios como el modo en el que se parecían relacionarse temporal y morfológicamente con la melodía permitían suponer una finalidad cognitiva en su realización. Si esto fuera así, es decir, si ciertos gestos desplegados al cantar a primera vista cumplieran una función epistémica para la resolución de la tarea, entonces, la restricción del movimiento corporal habría provocado un perjuicio en el desempeño, o mejor dicho, habría impedido la formación de recursos cognitivos externos que hubieran favorecido una mejor resolución de la lectura. A partir de este razonamiento, se consideró necesario comparar el desempeño al realizar los gestos descriptos con pautas restrictivas (ausencia voluntaria de movimiento) y con pautas libres de movimiento.

\section{Objetivo}

Este estudio se propone analizar la incidencia del movimiento corporal manifiesto (i) libre, (ii) pautado en vinculación con la estructura métrica y el contorno melódico, y (iii) restringido, en el desempeño en tareas de lectura cantada a primera vista. Para tal fin, se pretende observar si las pautas corporalmente restrictivas perjudican el desempeño y, en contraposición, si el movimiento, sea libre o pautado no restrictivo, favorece la resolución de la tarea. Esto permitirá entender a los gestos vinculados temporal y morfológicamente con la estructura métrica y con el contorno de la melodía leída como acciones epistémicas que mejoran los procesos cognitivos desplegados para resolver la tarea. 


\section{Método}

\section{Sujetos}

Participaron de la prueba 15 estudiantes de música. Al momento de la realización de la prueba, los estudiantes habían aprobado el examen de lectura a primera vista de la asignatura Educación Auditiva 2, lo que aseguraba un conocimiento del procedimiento de resolución de la tarea, y permitía conocer la dificultad adecuada de las melodías que ellos podían abordar a primera vista.

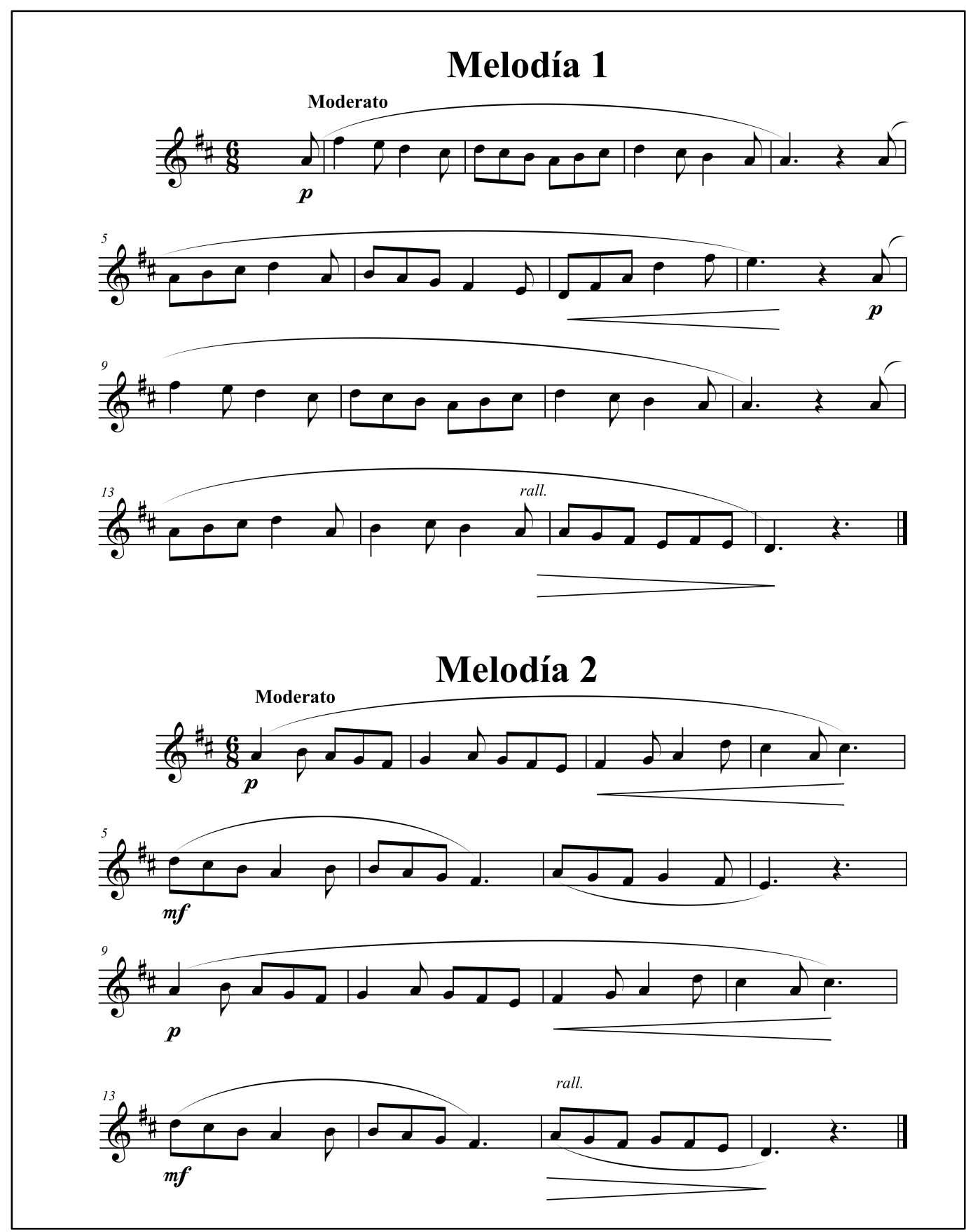

Figura 4.1. Melodías 1 y 2, utilizadas como estímulos para la realización de la prueba. 


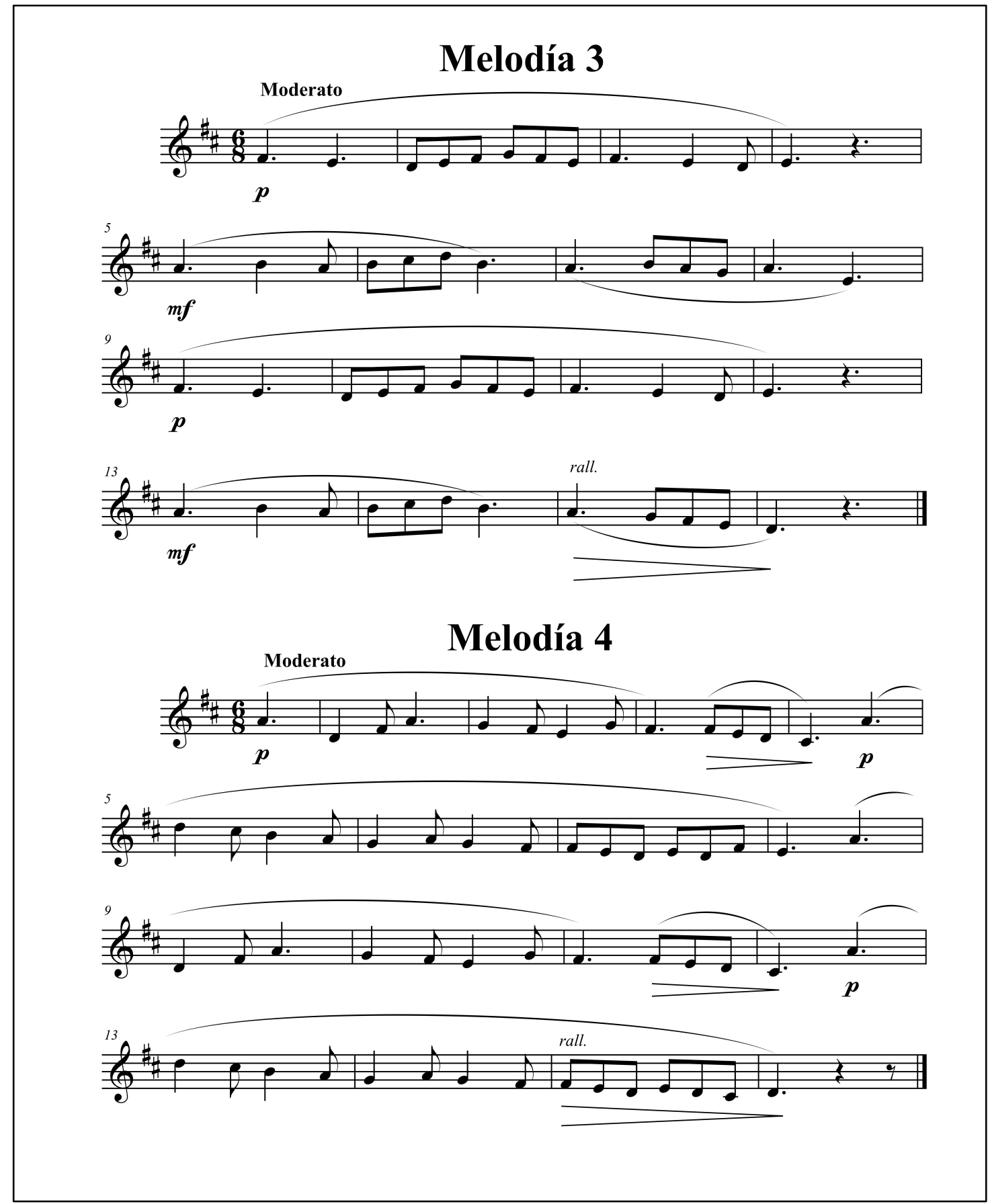

Figura 4.2. Melodías 3 y 4, utilizadas como estímulos para la realización de la prueba.

\section{Aparatos}

Se utilizaron dos cámaras filmadoras para registrar la imagen y el sonido de cada una de las ejecuciones, realizando tomas de frente y de perfil del sujeto durante la realización de la tarea. Para la extracción, edición y procesamiento del audio de las ejecuciones se utilizó el software Sound Forge 9.0. 


\section{Diseño}

El diseño constó de 4 condiciones experimentales: (i) movimiento libre; (ii) movimiento restringido; (iii) movimientos vinculados al contorno melódico; y (iv) movimientos vinculados a la estructura métrica. Los estímulos y las condiciones fueron aleatorizadas para todos los sujetos con el fin de minimizar la incidencia de un orden particular, de aprendizaje durante el experimento y de posibles diferencias en la dificultad de los estímulos, de modo tal que cada sujeto leía las 4 melodías, cada una en una condición diferente. Este diseño permite comparar las ejecuciones y observar las diferencias en el desempeño de acuerdo a la condición de movimiento corporal en que fue realizada cada ejecución.

Para el análisis del desempeño, se recurrió a la evaluación de un panel de expertos formado por 8 docentes de las asignaturas Educación Auditiva 1 y 2, con amplia experiencia en evaluaciones de desempeños en tareas de este tipo. Los jueces evaluaron el audio de la segunda versión de todas las ejecuciones en un orden aleatorio, sin conocer la condición en la que se realizó la lectura, y de acuerdo a 5 categorías: (i) evaluación global; (ii) ritmo; (iii) afinación; (iv) fidelidad; (v) expresión (ver protocolo entregado a los jueces en el anexo 3). Todas estas categorías son de uso común en la práctica pedagógica musical habitual, y por lo tanto resultaron familiares para los jueces, a excepción de la categoría fidelidad, que fuera oportunamente explicada y que refiere a cuánto se ajusta la ejecución al modelo de la partitura leída. La inclusión de esta categoría obedeció a la necesidad de capturar en la evaluación las sustituciones diatónicas, es decir, aquellas notas que aun estando afinadas y formando parte del contexto armónico local no se correspondían con las notas plasmadas en la partitura leída.

\section{Procedimiento}

La tarea consistió en leer a primera vista las cuatro melodías dos veces seguidas, cada una de ellas en una condición diferente. Los sujetos se hallaban parados frente a una pantalla en la cual se proyectaba la partitura de cada una de las melodías, y antes de comenzar la ejecución recibían la consigna de forma oral y disponían de unos segundos para "acomodarse" en la tonalidad. Las consignas para las 4 condiciones experimentales fueron las siguientes:

- condición (i): lea cantando a primera vista la siguiente melodía sin restricciones ni pautas corporales;

- condición (ii): lea cantando a primera vista la siguiente melodía sin realizar movimientos corporales durante toda la ejecución; 
- condición (iii): lea cantando a primera vista la siguiente melodía realizando únicamente movimientos manuales que reflejen el contorno melódico durante toda la ejecución;

- condición (iv): lea cantando a primera vista la siguiente melodía marcando con la mano, un pulso de la estructura métrica durante toda la ejecución.

\section{Resultados y Discusión}

En primer lugar se realizó un análisis del acuerdo entre jueces aplicando el coeficiente de correlación $\mathbf{r}$ de Pearson, en relación a las evaluaciones efectuadas para cada variable. La media de los coeficientes interjueces fue 0,72 siendo $p<0,01$. En tal sentido, se podría asumir que existe un acuerdo considerable entre los jueces en función de sus evaluaciones en general.

En segundo lugar, se aplicó un análisis de correlaciones para establecer si existía relación entre las variables, o indicadores de evaluación del desempeño en la lectura: (i) evaluación global; (ii) ritmo; (iii) afinación; (iv) fidelidad y (v) expresión. Los resultados mostraron que todas estas variables se encontraban fuertemente asociadas, siendo evaluación global y fidelidad las que presentaron la mayor correlación, mientras que afinación y ritmo mostraron el índice de correlación más bajo (ver tabla 4.1).

\begin{tabular}{|c|c|c|c|c|c|}
\hline & Global & Ritmo & Afinación & Fidelidad & Expresión \\
\hline Global & 1 & $878^{* *}$ & ,973 & , $980^{* *}$ & ,920** \\
\hline Ritmo & $878^{* *}$ & 1 &, $794^{* *}$ & $836^{* *}$ &, $868^{* *}$ \\
\hline Afinación & $973^{* *}$ & ,794 ${ }^{* *}$ & 1 & ,951 & $913^{* *}$ \\
\hline Fidelidad & $980^{* *}$ & $836^{* *}$ & $951^{* *}$ & 1 & $865^{* *}$ \\
\hline Expresión & $920^{* *}$ & $868^{* *}$ &, $913^{* *}$ & $865^{* *}$ & 1 \\
\hline
\end{tabular}

Tabla 4.1. Resultados de las correlaciones entre las 5 variables utilizadas para evaluar el desempeño en la lectura a primera vista. Se resaltan los valores de mayor y menor correlación.

**. La correlación es significativa al nivel 0,01 (bilateral).

Estas variables, pensadas como categorías elaboradas para evaluar y medir los desempeños en la lectura a primera vista, apuntaban a capturar las posibles diferencias en los resultados musicales, de acuerdo a la condición de movimiento pautada para cada ejecución. Sin embargo, la fuerte asociación encontrada en el análisis de correlaciones plantea el interrogante de qué es lo que realmente están midiendo estas categorías, y en tal sentido, si 
resultan útiles como indicadores de desempeño en la lectura a primera vista. El alto grado de asociación podría ser entendido básicamente de dos modos. Por un lado, podría suponerse que los aspectos musicales que las variables pretenden capturar se encuentran, en efecto, altamente asociadas en este tipo de tareas. De este modo, se podría pensar que la ejecución será mejor evaluada globalmente cuanto mayor sea la fidelidad al modelo de la partitura leída, y que si es más fiel también será rítmicamente más ajustada, más afinada e incluso más expresiva. Por otro lado, también se podría especular con que la separación de la evaluación global de ejecuciones a primera vista en categorías asociadas a aspectos musicales particulares resulta forzada, y en tal sentido, podría generar en el evaluador la necesidad de justificar su percepción global de la ejecución en cada categoría que debe puntuar, dando como resultado puntajes similares para todas las categorías y para la evaluación global del desempeño.

Teniendo en cuenta el grado de asociación hallado entre variables, se realizó un análisis de regresión lineal por pasos tomando a la evaluación global como variable dependiente para observar en qué medida las variables ritmo, afinación, fidelidad y expresión pueden predecir a los valores correspondientes a la evaluación global. Los resultados de este análisis mostraron que el modelo calculado que mejor predice a la variable evaluación global es el que excluye del cálculo a la expresión (ver modelo 5 en tabla 4.2).

\begin{tabular}{|l|r|r|r|r|}
\hline Modelo & \multicolumn{1}{c}{ R } & \multicolumn{1}{r|}{$\begin{array}{r}\text { R cuadrado } \\
\text { corregida }\end{array}$} & \multicolumn{2}{c|}{$\begin{array}{r}\text { R cuadrado estimación } \\
\text { la }\end{array}$} \\
\hline 1 &, $980^{\mathrm{a}}$ &, 960 &, 959 &, 25820 \\
\hline 2 &, $990^{\mathrm{b}}$ &, 981 &, 980 &, 23446 \\
\hline 3 &, $992^{\mathrm{c}}$ &, 984 &, 984 &, 19170 \\
\hline 4 &, $995^{\mathrm{d}}$ &, 990 &, 989 &, 19185 \\
\hline 5 &, $995^{\mathrm{e}}$ &, 990 &, 989 & \\
\hline
\end{tabular}

Tabla 4.2. Resultados del análisis de regresión lineal por pasos, tomando a la evaluación global como variable dependiente. Las variables predictoras (constante) de acuerdo a cada modelo fueron: 1) Fidelidad; 2) Fidelidad, Expresión; 3) Fidelidad, Expresión, Afinación; 4) Fidelidad, Expresión, Afinación, Ritmo; 5) Fidelidad, Afinación, Ritmo.

Resulta interesante observar que el modelo 4, que incluye a la variable expresión, presentó los mismos valores para $\mathrm{R}$ y $\mathrm{R}$ cuadrado que el modelo 5 . En este sentido, es probable que el 
modo en que es evaluada la expresión en este tipo de tareas no tenga incidencia en el puntaje asignado al desempeño en forma global.

En tercer lugar, y teniendo en cuenta el resultado del análisis de correlación interjueces que mostró un acuerdo considerable, se consideró la media de las evaluaciones para cada variable en cada condición, y se aplicó un ANOVA para medidas repetidas en un diseño 4 por 5, tomando como factores las CONDICIONES experimentales ( 4 niveles) y las VARIABLES testeadas ( 5 niveles). Los resultados mostraron diferencias significativas para el factor VARIABLE, (F ${ }_{4}$ $\left.{ }_{56}\right]=15,334$ y $\left.p<0,01\right)$, mientras que para el factor CONDICIÓN las diferencias fueron NS. Contrariamente a lo esperado, no se observaron diferencias significativas para la interacción VARIABLE*CONDICIÓN. Sin embargo, los resultados mostraron algunas tendencias sumamente interesantes que permiten proyectar diferencias significativas hacia una muestra mayor.

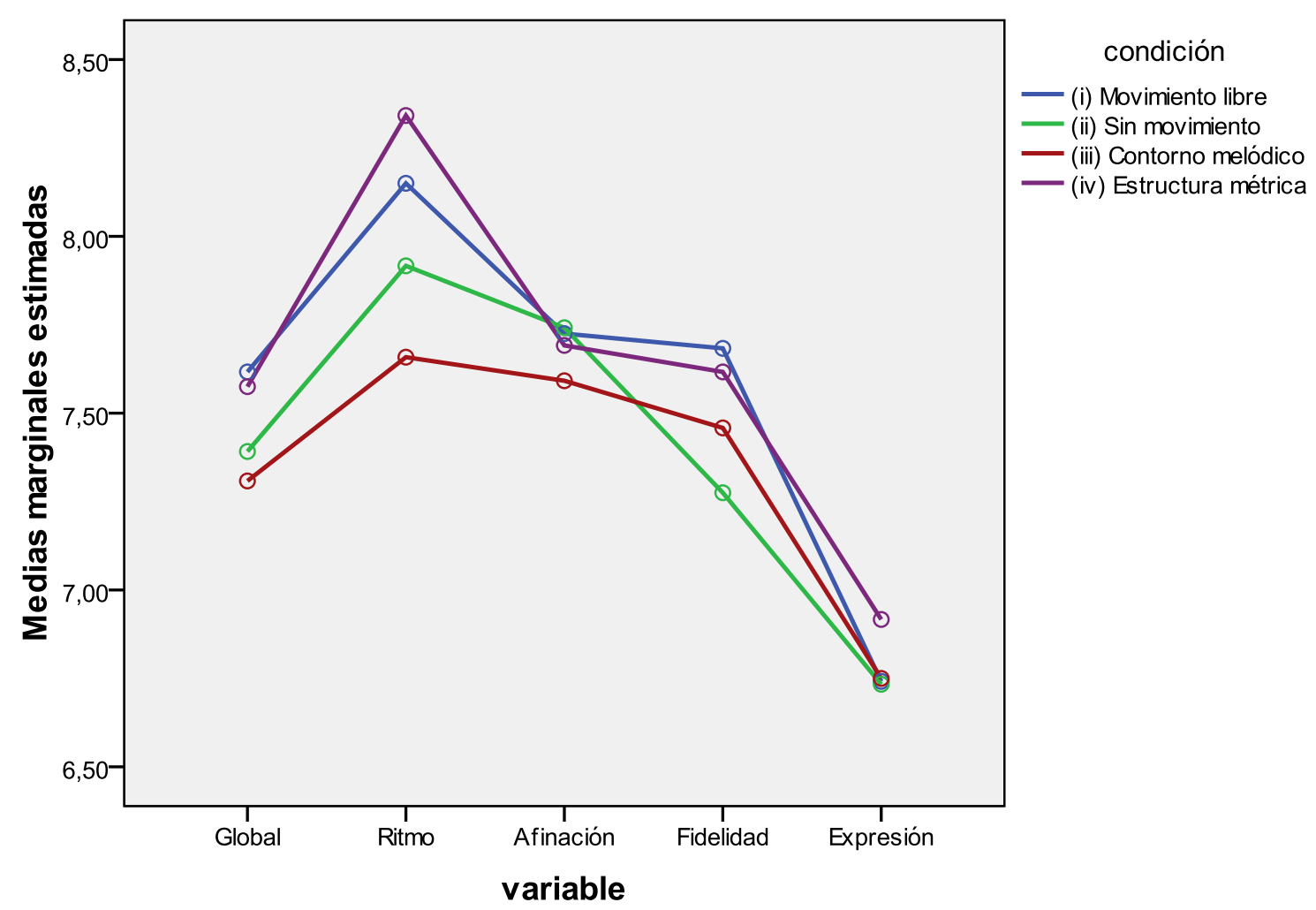

Figura 4.3. Gráfico de medias marginales estimadas variable*condición.

Como puede observarse en la figura 4.3, la variable expresión fue la que presentó los puntajes más bajos para todas las condiciones. Incluso, resulta llamativo que en tres de las condiciones los puntajes correspondientes a los promedios de expresión hayan sido prácticamente iguales. Sin embargo, esta aparente homogeneidad de la variable se desvanece cuando se analiza más en detalle cómo se distribuyen sus valores. Las medidas de dispersión mostraron que, a pesar de presentar una media similar en todas las condiciones, la expresión fue la variable con el 
rango más amplio de valores y con la desviación estándar más elevada, y por tanto, con el mayor índice de dispersión (ver tabla 4.3).

Estos valores de las medidas de dispersión para la variable expresión podrían estar asociados a su naturaleza profundamente subjetiva, y en tal sentido, a las múltiples y variadas visiones que aluden a este concepto tan escurridizo. Así, es posible suponer que los jueces miembros del panel de expertos no evalúen lo mismo cuando puntúan la expresión de una ejecución a primera vista, y por ende, esta variable no resulta confiable a la hora de buscar diferencias en los desempeños en función de las condiciones experimentales testeadas en este estudio.

\begin{tabular}{|r|r|r|r|}
\hline Variable & \multicolumn{1}{c|}{ Media } & \multicolumn{1}{c|}{$\begin{array}{l}\text { Media } \\
\text { Rango }\end{array}$} & \multicolumn{2}{c|}{$\begin{array}{c}\text { Media Desvándar } \\
\text { Global }\end{array}$} \\
\cline { 2 - 4 } Ritmo & 7,47 & 4,40 & 1,21 \\
\hline Afinación & 7,02 & 5,27 & 1,43 \\
\hline Fidelidad & 7,69 & 4,73 & 1,27 \\
\cline { 2 - 4 } & 6,51 & 4,87 & 1,40 \\
\hline Expresión & 6,79 & 6,07 & 1,55 \\
\hline
\end{tabular}

Tabla 4.3. Medias de las medidas de dispersión, rango y desviación estándar para las cinco variables.

Los desempeños en la condición (i) - movimiento libre - presentan los valores más altos para las diferentes variables, excepto en ritmo y expresión, que muestran los mayores puntajes en la condición (iv) en la cual se realizaron movimientos vinculados a la estructura métrica. Es destacable que el valor de la variable ritmo en la condición (iv) es el más alto del promedio de evaluaciones y presenta diferencias considerables con las otras tres condiciones. Esto podría deberse a que el compromiso corporal explicito que involucra moverse marcando un nivel métrico, refuerza los aspectos temporales de la ejecución musical, y de este modo, favorece tanto la continuidad como el ajuste rítmico de la ejecución. Del mismo modo, en el estudio exploratorio 1 descripto en el capítulo 3, se encontró que la mayor parte del tiempo los participantes realizaron movimientos espontáneos vinculados con la estructura métrica de la melodía leída. Esto podría estar dando cuenta de que este tipo de movimientos acompaña la lectura musical a primera vista de forma natural, es decir, sin demandar un esfuerzo cognitivo 
extra para mantener el movimiento durante la ejecución. Más aun, la marcación espontánea de pulsos podría estar formando parte de la experiencia musical que significa cantar a primera vista, y en tal sentido, podría ser entendida como una acción epistémica que mejora los procesos cognitivos necesarios para resolver la tarea (Kirsh y Maglio, 1994). Por tal motivo, se puede colegir que los movimientos vinculados con la estructura métrica no son restrictivos. Esto es, tales movimientos no estarían haciendo uso de recursos cognitivos extra, sino que, por el contrario estarían aportando recursos cognitivos (corporizados) al sistema. De este modo la condición (iv) es más afín a la (i) en el sentido de que permitiría al sujeto descargar en el entorno (cuerpo en el entorno) parte de la demanda cognitiva de la tarea, que a la (iii) que estaría consumiendo recursos cognitivos que debieran ser utilizados para la resolución de la tarea. Limitar este tipo de movimientos podría coartar la experiencia musical y perjudicar el desempeño en la lectura cantada a primera vista.

Resulta interesante observar que la condición (iii) en la que se efectuaron movimientos vinculados al contorno melódico, está por debajo de todas las demás condiciones en todas las variables, excepto en la variable fidelidad, en la que se produce un cruce con la condición (ii) de movimiento restringido (ver figura 4.3). El más bajo nivel de desempeño observado en esta condición podría estar asociado al carácter altamente restrictivo del movimiento pautado. Desplegar este movimiento durante toda la ejecución conlleva una demanda cognitiva extra que aumenta la complejidad propia de la tarea de lectura a primera vista, y por tanto, consume recursos que no estarán disponibles para resolver de forma eficaz la tarea en sí misma. Aun cuando la restricción corporal impuesta en esta condición perjudique el desempeño, el movimiento corporal vinculado al contorno melódico de la melodía ejecutada podría estar favoreciendo la conciencia de la escala y del movimiento melódico plasmado en la partitura, permitiéndole al sujeto tener un mayor control de la emisión en el marco del contexto escalístico particular y un monitoreo del ajuste con lo escrito a través del mapeo entre el movimiento de la mano y el dibujo del contorno melódico en la partitura. De esta manera, se estaría compensando, al menos en parte, el carácter restrictivo del movimiento. Esto podría estar explicando el cruce entre las condiciones (ii) y (iii) observado en la variable fidelidad.

La variable afinación mostró otro resultado interesante que merece ser mencionado; el puntaje más alto para esta variable, aunque la diferencia sea acotada, se observó en la condición (ii) en la que se le pedía a los sujetos que lean las melodías sin realizar movimientos corporales (ver figura 4.3). Llamativamente, esta condición sumamente restrictiva permanecía, junto con la condición (iii), con puntajes muy bajos para el resto de las variables. En un primer 
análisis podría suponerse que cuando los sujetos están quietos afinan más ajustadamente. Sin embargo, este resultado también podría explicarse poniendo el foco en el desarrollo musical que habían alcanzado los sujetos al momento de su participación en la prueba. Conviene recordar que eran estudiantes que estaban en un nivel inicial de la formación musical profesional, y que por tanto, estaban transitando una etapa en la que, en general, comenzaban a tener conciencia de la emisión y de la búsqueda de la afinación en este tipo de tareas que plantean la necesidad de generar un contexto armónico tonal sin contar con un soporte armónico instrumental explícito. En tal sentido, es posible que la preocupación por cantar afinadamente genere en ellos una especie de inmovilidad, por lo que, aun cuando mantenerse quieto voluntariamente perjudique el desempeño en las demás variables testeadas, podría no incidir negativamente en la afinación.

Notablemente, los valores correspondientes a las medias de la variable fidelidad son muy similares a los de la evaluación global. La única diferencia considerable en los valores de estas dos variables se encuentra en la caída del puntaje de fidelidad en la condición de movimiento restringido, y el ascenso en la condición de contorno melódico, observados en el cruce de valores mencionado en los párrafos precedentes. Esta similitud está en sintonía con la fuerte correlación hallada entre estas variables.

Teniendo en cuenta el grado de restricción corporal que imponía cada condición, se decidió colapsar las condiciones restrictivas por un lado - (ii) sin movimiento y (iii) señalamiento del contorno melódico - y las no restrictivas por el otro - (i) movimiento libre y (iv) movimiento vinculado a la estructura métrica - promediando los puntajes asignados por los jueces. La unificación de las condiciones (i) y (iv) obedece a que, como ya se mencionó, la marcación de un pulso durante la lectura a primera vista parece ser un movimiento natural que forma parte de la experiencia musical y que podría ser entendido como una acción epistémica, y por lo tanto, la imposición de este movimiento no genera dispersión ni fuertes restricciones corporales. Los datos obtenidos al realizar este procedimiento fueron analizados aplicando un ANOVA para medidas repetidas con un diseño $2 * 5$, tomando como factor 1 las CONDICIONES colapsadas ( 2 niveles) y como factor 2 las VARIABLES testeadas ( 5 niveles). El factor VARIABLE, al igual que en el análisis previo, mostró diferencias significativas siendo $F[4-56]=15,351$ y $p<0,01$. Los resultados no mostraron diferencias significativas para el factor CONDICIÓN, pero se observó una significación marginal para la interacción VARIABLE*CONDICIÓN $(F[4-1]=2,964 ; p<0,05)$. Este valor resulta sumamente importante teniendo en cuenta el número acotado de casos (ver figura 4.4). 


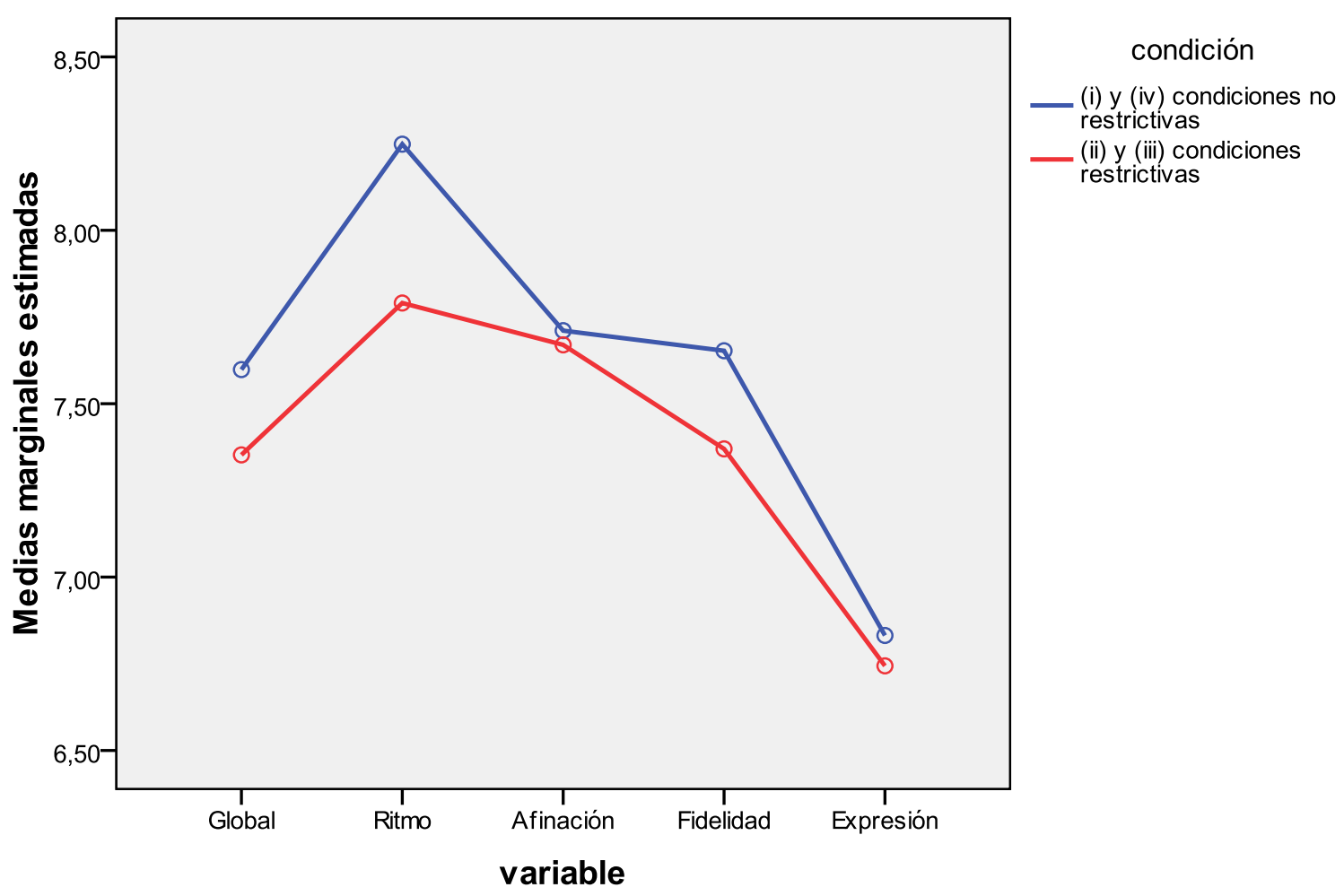

Figura 4.4. Gráfico de medias marginales estimadas variable*condición, colapsando las condiciones no restrictivas (i) y (iv); y las restrictivas (ii) y (iii).

La condición que emerge de colapsar las condiciones restrictivas presentó, como podría esperarse, los valores más bajos para todos los indicadores de desempeño. Tanto la autorrestricción corporal, como el sostén de movimientos complejos durante toda la ejecución parecen estar atentando en contra de la experiencia corporal espontánea del sujeto frente a la tarea de lectura cantada a primera vista, y en tal sentido, perjudicando el desempeño en todos los aspectos musicales evaluados en este estudio. Sin embargo, una vez más se observó que la variable afinación no presentó grandes diferencias entre las condiciones, lo que permitiría suponer que esta variable no se comportaría igual a las demás en diferentes situaciones corporales. Parece ser que la afinación no estaría tan vinculada, al menos en el nivel de desarrollo del canto en el que se encontraban los sujetos que participaron de la prueba, a las condiciones corporales que fueron aplicadas en este estudio.

\section{Conclusiones}

Este estudio se propuso analizar la incidencia del movimiento corporal explícito libre, pautado y restringido en el desempeño en tareas de lectura cantada a primera vista. Los resultados obtenidos sugieren que el desempeño medido en vinculación con diferentes aspectos 
musicales, varía de acuerdo al tipo de restricción corporal con el que se realiza la tarea. En este sentido, los movimientos vinculados a la estructura métrica como la marcación del tiempo musical, parecen estar funcionando como un soporte métrico temporal que favorece los aspectos temporales de la ejecución, como la configuración de la estructura métrica y el ajuste rítmico. En tal sentido, se puede decir que este tipo de movimientos estaría cumpliendo una función epistémica durante la ejecución de la lectura a primera vista, es decir, mejorando aquellos aspectos cognitivos necesarios para resolver la tarea. Sin embargo, aun no es posible afirmar lo mismo respecto de los movimientos vinculados al contorno melódico, porque su complejidad y la dificultad que implica sostener este tipo de acciones corporales a lo largo de la ejecución parecen demandar una carga cognitiva mayor que complejiza la tarea y perjudica el desempeño. La quironimia implica una representación convencionalizada atravesada por la escritura musical, en la cual se establecen relaciones espaciales en el eje vertical (abajo-arriba) para representar las relaciones de altura (grave-agudo). Esta noción requiere mayores niveles de conocimiento y enculturación que simplemente realizar movimientos que responden a un pulso subyacente. Teniendo en cuenta las observaciones efectuadas en los estudios exploratorios previos reportados en el capítulo 3 se considera apropiado poner el foco en los momentos en los que este movimientos aparece espontáneamente, es decir, en los fragmentos melódicos que presentan mayor dificultad para su lectura. Parece ser allí, el lugar en donde este tipo de movimientos cumplen una función epistémica en la interacción corporal con el entorno.

Resulta interesante observar cómo los jueces expertos, acostumbrados a evaluar ejecuciones de este tipo, puntúan globalmente la ejecución prácticamente igual a la fidelidad con el modelo. Es posible que esto esté vinculado al sesgo teórico-pedagógico que impone la noción de réplica como ideal a alcanzar en la ejecución, y que permanece fuertemente arraigado en la educación musical. Conviene recordar que los jueces eran profesores de educación auditiva, y que la lectura cantada a primera vista forma parte de los contenidos a enseñar y a evaluar en esta asignatura, por lo que tenían amplia experiencia en evaluar en términos pedagógicos los desempeños de este tipo. El sesgo al que se hace referencia aquí forma parte de la práctica habitual de enseñanza musical en el ámbito profesional, esto justamente es lo que distingue al panel de expertos formado por docentes de otros grupos de profesionales que podrían evaluar estos desempeños desde otros puntos de vista afines a la disciplina a la que pertenezcan.

La fuerte asociación encontrada entre los indicadores de desempeño testeados parece estar dando cuenta de que el desempeño en la ejecución de tareas de lectura cantada a primera vista podría percibirse de forma holística. Como ya se mencionó, intentar desagregar el 
desempeño en actuaciones parciales para su evaluación resulta forzado y podría generar en el evaluador la necesidad de justificar su evaluación global con puntajes similares en las otras categorías. Aun cuando esta explicación pueda tener algún correlato con las evaluaciones de lecturas musicales en la práctica pedagógica habitual y, en tal sentido, se considere necesario replantear la evaluación categorial para la lectura cantada a primera vista, los indicadores elaborados resultan útiles para este estudio porque la naturaleza de los movimientos pautados para las diferentes condiciones experimentales se asocian más a uno u otro aspecto musical. Así, las diferencias observadas en los puntajes asignados por el panel de expertos a cada categoría en función de la pauta de movimiento de cada condición aportan datos importantes acerca de la función del movimiento corporal en relación a esa categoría en particular, como se señaló en los párrafos precedentes.

El modo en que la variable expresión se asocia con las otras variables testeadas, da cuenta de la dificultad que presenta para ser evaluada, y de su naturaleza profundamente subjetiva. Si bien no resultó completamente desvinculada de las demás, presentó la mayor dispersión y no mostró incidencia en la predicción de la evaluación global. En este sentido, y vinculado al sesgo pedagógico mencionado anteriormente, el docente que evalúa desempeños en lecturas a primera vista suele poner el foco en aspectos que tal vez estén menos vinculados a la expresión, como por ejemplo, en la fidelidad con el modelo plasmado en la partitura. Es posible que esto esté asociado a la idea implícita en la educación musical de que una ejecución a primera vista no puede ser expresiva, al menos no antes de tener resueltos con precisión los aspectos musicales estructurales, es decir, básicamente las notas y el ritmo. Más allá de los resultados de este estudio y desde una visión crítica de esta idea, podría resultar interesante intentar entenderlo exactamente al revés: tal vez sean los aspectos expresivos los que le otorguen sentido a la lectura para el ejecutante, y quizás se valga de ese sentido expresivo para construir la ejecución y resolver los aspectos estructurales.

Las condiciones experimentales incluidas en este estudio responden a la observación de los movimientos corporales más recurrentes en los estudios exploratorios previos (ver capítulo 3). Sin embargo, a diferencia de la marcación de un pulso, los movimientos de señalamiento del contorno no aparecieron sostenidamente durante toda la ejecución, sino sólo en lugares puntuales del discurso musical, asociados a dificultades de afinación o fidelidad con el modelo de la partitura. En esta restricción del tiempo del uso de la acción podría radicar su carácter de epistémica, es decir, aun cuando la quironimia sostenida a lo largo de la ejecución perjudicaría el desempeño, su utilización espontánea de acuerdo a las necesidades cognitivas del sujeto para resolver ciertas dificultades vinculadas al ajuste de alturas podría mejorar el desempeño 
en este tipo de tareas. Los movimientos vinculados tanto al contorno melódico como a la estructura métrica podrían ser entendidos como gestos convencionalizados aprendidos por observación e imitación. 


\section{Estudio 4: Expresión y Movimiento en la Lectura Cantada a Primera Vista}

A partir de los resultados obtenidos en el estudio 3, en relación con la dificultad para la evaluación y la complejidad de los datos del indicador expresión en las diferentes condiciones experimentales, surgió la necesidad de indagar el modo en que se vincula la expresión de la ejecución cantada a primera vista con los movimientos desplegados durante la realización de la tarea.

Los estudios sobre el movimiento en la ejecución musical reconocen tipos gestuales cuya existencia se vincula preponderantemente a los aspectos expresivos y comunicacionales de la performance. La expresión adquiere así un estatus corporizado. Sin embargo es poco lo que se sabe acerca de la vinculación entre los atributos de dicho componente sonoro y del movimiento en cuanto a la elaboración de la expresión en la performance.

Shifres (2009) exploró las vinculaciones entre los movimientos implícitos de una cantante y los atributos expresivos de su ejecución cantada. El objetivo fue identificar indicios de modelado corporal de la interpretación expresiva a lo largo de una serie de ensayos de una pieza musical. Particularmente observó los rasgos morfológicos y topológicos del movimiento (Gallagher, 2005) en vinculación con el contenido musical de la pieza cantada. Los primeros se refieren a la forma del movimiento considerando su trayectoria en relación a la oposición del cuerpo y el espacio que lo circunda (Laban, 1970). Los segundos aluden a la localización específica del movimiento tanto en términos del espacio (arriba, abajo, adelante, atrás, etc.) como del cuerpo que lo realiza (aludiendo a la parte del cuerpo involucrada). De este modo Shifres pudo observar que ciertos rasgos morfokinéticos (por ejemplo la relación expansión-contracción) se conservaban en relación a momentos claves del discurso musical, aunque sus características topokinéticas variaran. Por ejemplo, la morfología extensión-contracción estuvo siempre asociada a la ejecución de la nota culminante de un pasaje. Sin embargo las características topokinéticas en esos puntos fueron diferentes. Por ejemplo, la extensión en el primer ensayo fue de los brazos en relación al tronco, mientras que en el segundo ensayo fue del ángulo de giro del tronco, respecto de la posición de reposo, en un movimiento de torsión. Esto dio lugar a hipotetizar que la expresión del pasaje era sentida por la cantante a través del registro corporal de esos atributos gestuales. Ciertas cualidades del sonido emitido se vinculaban entonces sistemáticamente con esas características del movimiento. Pero también, además de las cualidades del movimiento, la preponderancia de los aspectos morfológicos por sobre los 
topológicos parece darle cierto carácter cuantitativo (se podría decir algo así como "cuánto se mueve el cuerpo") al registro interno y subliminal del movimiento que el cantante siente, significa y reproduce. Interesantemente Shifres observó también que algunos rasgos permanecían a lo largo de los ensayos al tiempo que nuevos detalles se iban incorporando. De esta manera, el movimiento se iba esculpiendo a medida que la idea expresiva se iba consolidando. Así, en la ejecución cantada tendría lugar una serie de movimientos que sin ser responsables de la producción mecánica del sonido se suceden como consecuencia de una intencionalidad que no es específica de esos movimientos en sí. Tales movimientos son ejecuciones preconcientes y sub-personales que el cantante aplica con una intencionalidad que no focaliza en ellos mismos, sino que se refiere a un modo particular expresivo del contenido musical. Es posible decir que el ejecutante ejerce la fuerza, la dirección y la trayectoria necesarias para "mover" la nota correspondiente con la expresión dramática aspirada (Trevarthen y Schogler, 2007; Johnson, 2007). El significado expresivo emergería del modo en el que el cuerpo va configurando (sintiendo) las cualidades dinámicas de la realidad musical que se va configurando.

La idea de un movimiento que no focaliza en sí mismo sino en cómo ajustan sus propias cualidades a las cualidades del entorno que reflejan remite a las nociones de Entonamiento y Formas Dinámicas de la Vitalidad de Daniel Stern $(1985,2010)$. La primera refiere a un tipo particular de imitación que no atiende a las características topológicas sino más bien a las morfológicas del modelo que se imita (la cualidad expresiva), y que es crucial en la comunicación preverbal (en la temprana infancia). La segunda alude a "fenómenos psicológicos y subjetivos que emergen del encuentro con eventos dinámicos" (Stern, 2010, p.7), es decir con eventos que ven modificados sus atributos a lo largo del tiempo. Estos fenómenos son propiedades emergentes de una gestalt constituida por las experiencias de movimiento, fuerza, tiempo, espacio e intención con aquellos eventos y se aplican (i) al mundo inanimado, en tanto es observado; (ii) a las relaciones interpersonales en tanto son vividas, y (iii) a los productos de la cultura en tanto son experimentados. "Este parece ser el modo en el que la mente fue diseñada para capturar los sucesos dinámicos." (Ibíd, p. 7)

Existe abundante evidencia anecdótica e importantes avances tanto teóricos (Salgado Correia, 1999; Cox, 2001) como empíricos (Leman, 2008) para suponer que el significado expresivo se compone corporalmente no simplemente como "adosado" a un armazón estructural previo, sino que el sentido musical es también el resultado del esfuerzo corporal en vinculación a la demanda (tanto cognitiva como física) de la propia ejecución. 
En vinculación con estas ideas, los resultados obtenidos en el estudio 3, descripto en el apartado anterior, mostraron que el movimiento vinculado a la estructura métrica parece favorecer los desempeños, especialmente en los aspectos temporales vinculados con el ajuste rítmico y métrico. Por otra parte, las condiciones más restrictivas corporalmente - sin movimiento y señalamiento del contorno melódico - fueron las que presentaron los puntajes más bajos en todas las categorías testeadas. Así, parece haber una diferencia entre el uso espontáneo del movimiento corporal y la realización de movimientos impuestos, que aunque conserven las mismas características topokinéticas y morfokinéticas que los espontáneos, carecen de significación para los estudiantes y se convierten en una carga cognitiva extra que perjudica el desempeño. Es posible que no solamente el significado expresivo sea progresivamente configurado corporalmente sino también los aspectos más estructurales de la ejecución. Ahora bien, ¿cuál es la relación de este modelado con el aprendizaje musical? ¿En qué medida esa configuración corporal es el resultado de esa intencionalidad musical y no al revés, la intencionalidad musical (como consecuencia de la comprensión musical) como emergiendo del impulso kinético?

\section{Objetivos}

El estudio se propone analizar las vinculaciones entre las descripciones de los atributos expresivos de dinámicas y rubato durante la ejecución de melodías cantadas leídas a primera vista y algunas características del movimiento corporal observado en el transcurso de esas ejecuciones. Debido a la importancia relativa de características morfokinéticas en el modelado expresivo identificado en los trabajos anteriores que conduce a considerar la importancia de cierto aspecto cuantitativo del movimiento para el registro mental de dicho modelado expresivo se estudia la cualidad de cantidad de movimiento (QoM quantity of motion).

Asimismo se exploran las relaciones entre los componentes expresivos (sonoros y kinéticos) con las particularidades estructurales de la obra musical.

\section{Método}

\section{Sujetos}

2 sujetos fueron seleccionados de una muestra de 15 estudiantes iniciales de música que habían participado del estudio anterior (ver estudio 3 en este capítulo) cantando una melodía tonal leída a primera vista. El audio de las ejecuciones de la muestra original fue evaluado por un panel de expertos en relación a diversos aspectos de la ejecución, entre ellos la 
expresividad. De los 15 participantes del estudio anterior, se seleccionaron aquellos que fueron considerados por el panel como más y menos expresivos, respectivamente, y se analizaron únicamente sus ejecuciones incluidas en la condición de movimiento libre.

\section{Estímulos}

Dos melodías diferentes con características musicales similares (forma, compás, valores rítmicos, saltos melódicos, etc.) con el fin de minimizar la incidencia de diferencias estructurales en las ejecuciones (ver figura 4.1: melodía 2; y figura 4.2: melodía 3).

\section{Aparatos}

Las ejecuciones fueron tomadas por dos cámaras de video ubicadas a 90 grados para realizar tomas de frente y de perfil, y para capturar el audio de la ejecución.

Los análisis de sonido y del movimiento fueron realizados con asistencia de software (i) para la elaboración de los perfiles de timing y para el análisis de la regulación temporal se utilizó el software de edición de sonido Sound Studio 3, midiendo todos los intervalos de tiempo entre ataques sucesivos de la melodía con los que se elaboraron las representaciones gráficas del rubato empleado; (ii) para el análisis de la intensidad y calidad del sonido se utilizaron las funciones respectivas del software Praat (Boersma y Weenik, 2001); para el análisis de las imágenes tomadas se utilizó software de análisis de movimiento (VideoAnalisys) para la función cantidad de movimiento.

\section{Procedimiento}

Los sujetos se colocaban de pie frente a una partitura gigante proyectada en una pantalla que tenían que leer a primera vista. Disponían de unos segundos para observar el compás, acomodarse en la tonalidad, y encontrar un registro vocal cómodo; luego debían cantar la melodía completa dos veces seguidas.

\section{Diseño}

Debido a que los casos seleccionados están tomados de un estudio anterior, los sujetos ejecutan diferentes melodías (de acuerdo al diseño de dicho estudio, véase estudio 3 en este capítulo) 


\section{Resultados y Discusión}

Los datos fueron recogidos a partir de la aplicación de un microanálisis. Básicamente el microanálisis consiste en observar minuciosamente un evento de muy limitada duración, y describir sus atributos en su evolución temporal en términos de fracciones de segundos. De este modo se puede estudiar los cambios en los comportamientos rescatando su naturaleza dinámica (como proceso) (Valsiner, 2006).

Las bandas sonoras de los videos fueron analizadas identificando los ataques (onsets) de cada una de las notas cantadas y calculando el tiempo entre ataques sucesivos. Esos valores de intervalos de tiempo entre ataques ( $\mathrm{IOI}$, inter onset intervals) fueron comparados con los valores de duración nominal estipulados por las respectivas partituras. Se calcularon las proporciones de desviación de cada sonido, y con estos valores de desviación temporal se confeccionaron gráficos denominados "perfiles de timing" (Repp, 1998). Estos perfiles de timing dan cuenta de los alargamientos y acortamientos relativos de las notas cantadas respecto de la duración nominal. De este modo los puntos indicados por encima del eje horizontal principal (en los casos aquí presentados, el valor 1) implican que dichas notas eran más largas que sus valores nominales respectivos, y los puntos por debajo de ese eje representan notas más cortas.

La función de cantidad de movimiento ha sido utilizada tanto en investigaciones en el campo como en producciones artísticas como un atributo del movimiento que puede ser vinculado psicológicamente a atributos sonoros tales como la intensidad. "La cantidad de movimiento está basada en las variaciones en la forma de la silueta. Se puede considerar una medida general de la cantidad de movimiento detectado, involucrando velocidad y fuerza" (Leman, 2008, p. 179). Ha sido utilizada aquí como un indicador holístico del movimiento, y probablemente del movimiento sentido por el agente sin atender a los detalles cualitativos de localización, trayectoria y dirección del movimiento.

A partir de los datos obtenidos del procesamiento da las funciones de QoM (quantity of motion) del analizador de imagen, y de Intensity y Spectrum del analizador de voz, se confeccionaron gráficos que se superpusieron. Los resultados se presentan aquí como descripciones de dichos gráficos.

Se comparan los datos obtenidos a lo largo de las dos ejecuciones del sujeto considerado más expresivo (sujeto A) con el objeto de identificar diferencias y similitudes que puedan dar cuenta de una elaboración de la expresión. Asimismo se comparan los datos de esas 
ejecuciones con la ejecución final del sujeto considerado menos expresivo (sujeto B), con el objeto de contrastar los atributos analizados.

La figura 4.5 muestra los valores de QoM (panel superior) y de Intensidad, en amarillo, sobre el espectrograma (panel inferior) correspondientes a la primera ejecución del sujeto A. La parte sombreada corresponde al tiempo que implicó una ejecución fallida (canta otra nota y luego de un par de notas advierte el error y se corrige) del comienzo de la frase 4 , que es retomada finalmente con éxito.

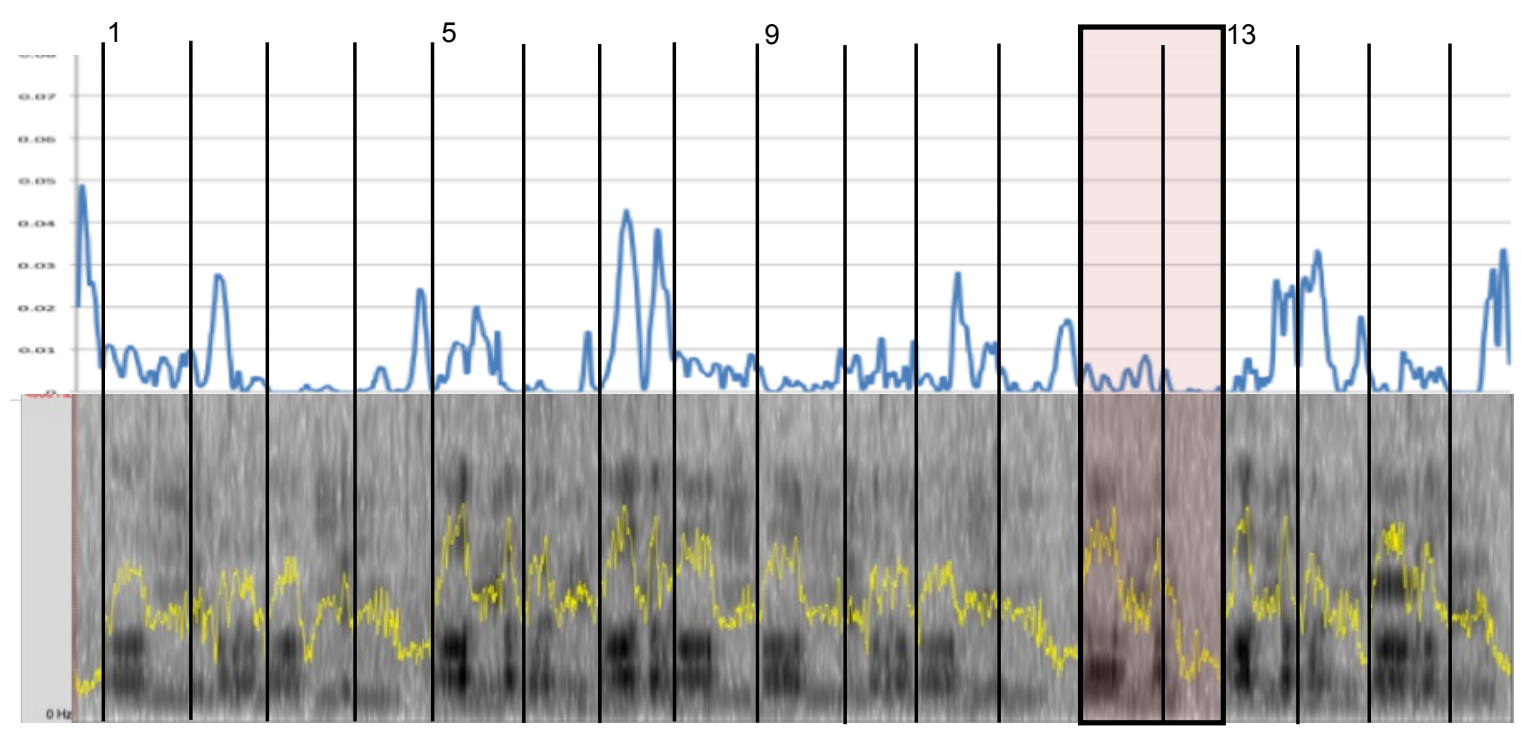

Figura 4.5. Cantidad de movimiento (panel superior), espectrograma e intensidad (panel

inferior) de la ejecución 1 del Sujeto A. Los números indican los compases de acuerdo a la partitura.

Los movimientos más ostensibles que son los que se aprecian a simple vista en el gráfico de la figura 4.5 se vinculan básicamente a:

- Marcaciones formales. Obsérvese, la similitud del compás 4 y el compás 12, el movimiento como marcador de la frase. Coincide con el diminuendo de final de frase. Esta marcación tiene una función autorregulatoria ${ }^{8}$ como parte de la preparación para la frase que sigue a continuación.

- Contingencias de la ejecución. Por ejemplo en el compás 11, el movimiento observado se vincula a la respiración: el sujeto no respiró antes,

\footnotetext{
8 La función autorregulatoria de los movimientos es entendida aquí como reuniendo algunas características de las categorías de Davidson (2001) relativas a los gestos adaptativos (en tanto son dirigidos hacia el propio individuo) y de gestos regulatorios (en tanto que se realizan para coordinar y ajustar la ejecución). Específicamente son movimientos que estabilizan el estado de equilibrio interno y externo del ejecutante necesario para la consecución de la ejecución y de tal modo regulan la propia ejecución individual.
} 
aparentemente por no tener aún la conciencia acabada de la extensión de la frase (recuérdese que se trata de una ejecución a primera vista), y se encuentra en ese punto ya sin aire pero sabiendo que la frase continúa, realiza movimientos más enfáticos para llegar a tiempo con la respiración (la primera vez no llega a tiempo y se le alarga el compás).

- Marcaciones regulares. Existe una cantidad de movimiento de base como consecuencia de la marcación del tiempo que hace en varios compases (por ejemplo en el 10, en el 15).

- Retroalimentación. El movimiento que hace entre 13 y 14 tiene que ver con la afirmación de que "ahora sí" está haciendo lo correcto, luego de su intento anterior fallido. Este movimiento es de retroalimentación (feedback), y también autorregulatorio porque sobre esa reafirmación se dispone a continuar.

Como se ve todos estos movimientos regulan la actividad de ejecución. En tal sentido pueden ser considerados como autorregulatorios. No obstante es importante diferenciar los que tienen que ver con la estructura de la música y los que tienen que ver con la impronta de la ejecución.

Sin embargo, el movimiento del compás 7, parece no cumplir con ninguna de esas funciones. Resulta aquí interesante comparar con la curva de intensidad (que a su vez se vincula con la calidad sonora manifestada en el espectrograma con los tonos más negros) con la que se observa una notable correspondencia: el pico de mayor cantidad de movimiento coincide con un pico de intensidad, y ambas curvas marcan la articulación de los dos sonidos largos del compás. Puede entenderse como un gesto expresivo. La descripción del movimiento nos dice que tiene lugar un balanceo de izquierda a derecha marcando los dos tiempos del compás. Es la primera vez que utiliza claramente ese plano de movimiento, y el gesto es amplio y expansivo.

La segunda ejecución presenta un perfil de movimiento diferente, no tan vinculado a las vicisitudes de la ejecución (figura 4.6). En primer lugar los movimientos de finales de las frases permanecen, aunque es mucho más pronunciado el de la frase 3. El perfil de timing (figura 4.7) revela que se trata de la nota más prolongada. Así, es posible hipotetizar que a partir de la primera ejecución el movimiento realizado en ese momento lo va habilitando para prolongar la nota (obsérvese que en la ejecución 1 esa nota está cantada muy a tempo, mientras que en la ejecución 2 es alargada en la frase 1 y más aun en la frase 3). Es interesante notar cómo al tiempo que alarga más, disminuye la intensidad. De este modo, se ve una elaboración del 
retardando de final de frase, con la disminución de la intensidad, en conjunción con el movimiento.

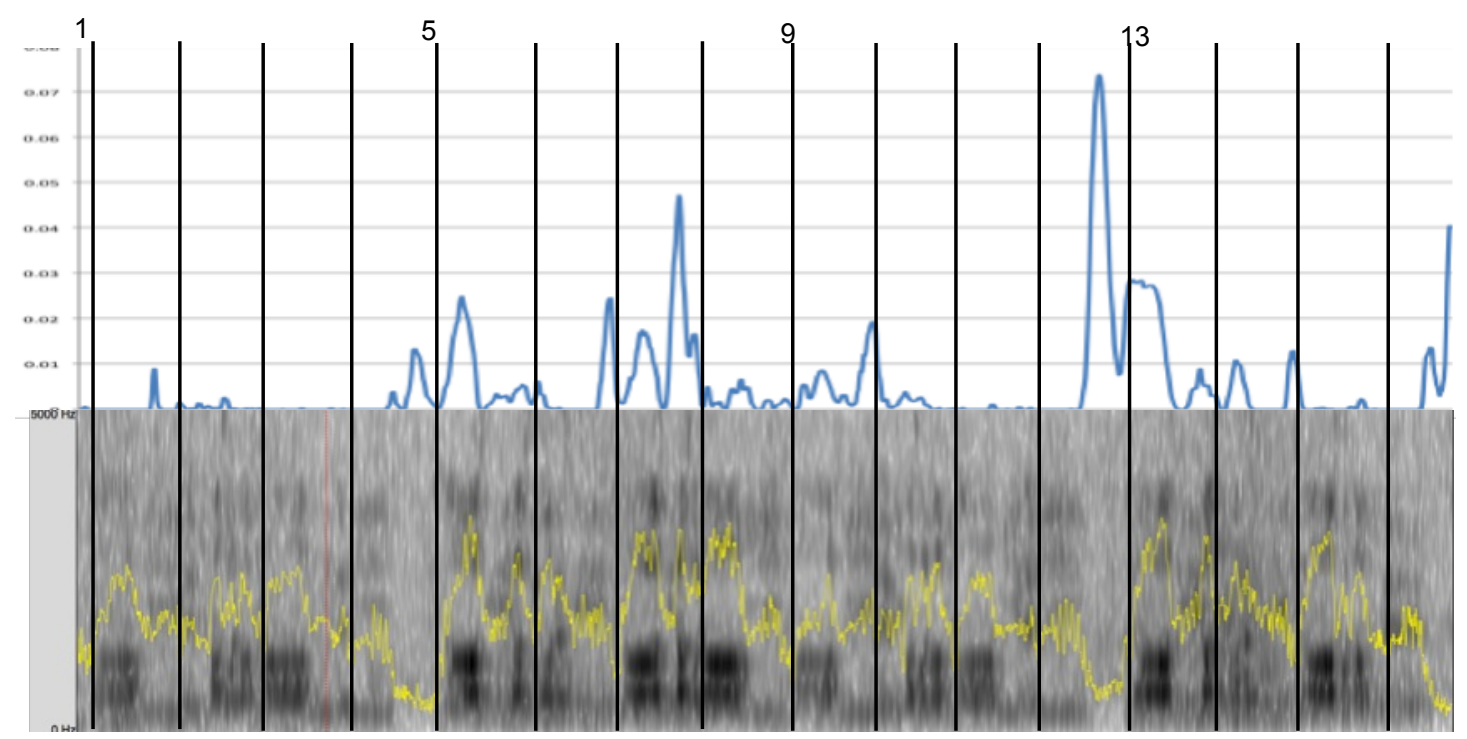

Figura 4.6. Cantidad de movimiento (panel superior), espectrograma e intensidad (panel inferior) de la ejecución 2 del Sujeto A. Los números indican los compases de acuerdo a la partitura.

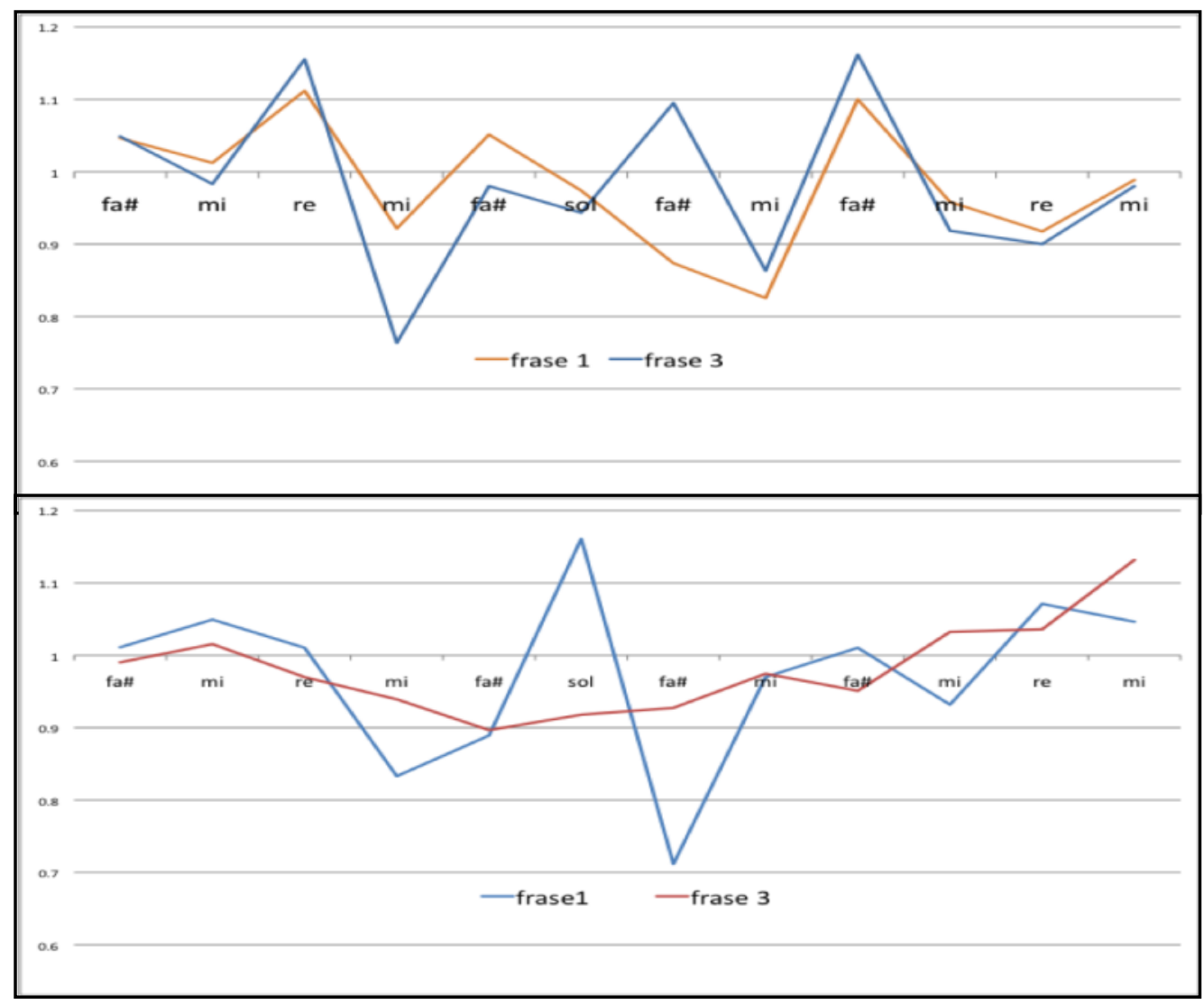

Figura 4.7. Perfiles de timing de las frases 1 y 3 de la ejecución 1 (panel superior) y 2 (panel inferior) del sujeto $A$. 
El ritardando del final de la frase 3 es a su vez el punto culminante de cantidad de movimiento (compás 12), a partir de ahí, la cantidad de movimiento va descendiendo en una suerte de diminuendo de movimiento hasta el final. Esto contrasta con el final de la frase 2 en la que el movimiento general continúa, en acuerdo al mantenimiento de la tensión armónica (antecedente). De esta manera, el perfil de la cantidad de movimiento refleja mejor la relación de tensión-relajación de toda la melodía. Esto tiene un correlato con la colocación de la voz (nótese las secciones más oscuras en el espectrograma)

En el compás 1 hay un pequeño pico que es reflejado también en el compás 9 (ambos compases iguales). Ambos momentos tienen que ver con movimientos autorregulatorios de los brazos. Aunque los movimientos son diferentes es sugestiva la necesidad de mover los brazos que el sujeto tiene en ese momento en ambas frases.

Es evidente que en esta segunda ejecución el sujeto tiene un mayor dominio de la estructura musical y por eso puede controlar mejor esos gestos autorregulatorios. Esto se corresponde con un mayor control de las variables expresivas de dinámicas y timing. Obsérvese por ejemplo la similitud en los perfiles de dinámicas para las frases 1 y 3 (compás 1 a 4 y 9 a 12 respectivamente), o la vinculación del perfil dinámico con la relación armónica de tensión y relajación: los compases 7 y 8 están ejecutados con más fuerza mientras que los compases 15 y 16 muestran claramente un diminuendo.

La figura 4.7 también permite considerar más en detalle la vinculación entre el timing y la descripción de los movimientos. Considérese el segundo compás de cada frase, en el que todos los valores son de corchea (agrupadas en dos tiempos ternarios). La primera ejecución (frase 1 ejecución 1) el movimiento consiste en un suave movimiento de la cabeza, marcando los dos tiempos del compás. Al "cabecear" como impulso al segundo tiempo, impulsa las corcheas que siguen que se van acortando progresivamente. Al repetir la frase (frase 3 ejecución 1) el movimiento cambia: por un lado se contabiliza mayor cantidad de movimiento (ver figura 4.6) y además es topokinética y morfokinéticamente diferente, no es la cabeza balanceándose sino la mano derecha chasqueando los dedos. Este cambio coincide con una organización del fraseo (timing) cada dos corcheas, en lugar de cada tres (obsérvese la secuencia largo-corto en la figura 4.5). En cierto modo, la irrupción del gesto de marcación del tiempo, quiebra la unidad de las 6 corcheas (y paradójicamente las distribuye de a dos).

En la segunda ejecución (figura 4.6 compases 2 y 10, figura 4.7 panel inferior) el sujeto se queda prácticamente quieto con un pequeñísimo movimiento de cabeza. Se podría decir que vuelve a llevar el movimiento a la cabeza como en la primera ejecución luego de trasladarlo a 
la mano en la ejecución anterior. Pero ahora impulsa el primer tiempo "cabeceando" (hacia abajo) y en el segundo tiempo hacia arriba (es decir marca claramente los dos tiempo), en un vaivén con la cabeza (muy sutil), con dos golpecitos de cabeza (uno hacia abajo y otro hacia arriba). Aquí, en consecuencia, el fraseo se organiza claramente de a tres (figura 4.7, panel inferior, frase 1). En la repetición (frase 3), el vaivén de la cabeza se elabora a través de suavizar notablemente el cabeceo hacia arriba, y enfatizar el cabeceo hacia abajo, girando un poco la cabeza hacia su derecha. Se ve la coincidencia entre el cambio y la elaboración del rasgo morfokinético, con el cambio en la organización del fraseo en un único arco (paralelizando el arco que hace con la cabeza).

Examinando el gráfico de la figura 4.5 en comparación con el gráfico de la figura 4.6 y tomando cada frase como un todo, se observa que de las cuatro frases la 2 es la que presenta un perfil de QoM más parecido entre ambas ejecuciones. Los gráficos de la figura 4.8 muestran esa similitud más de cerca.
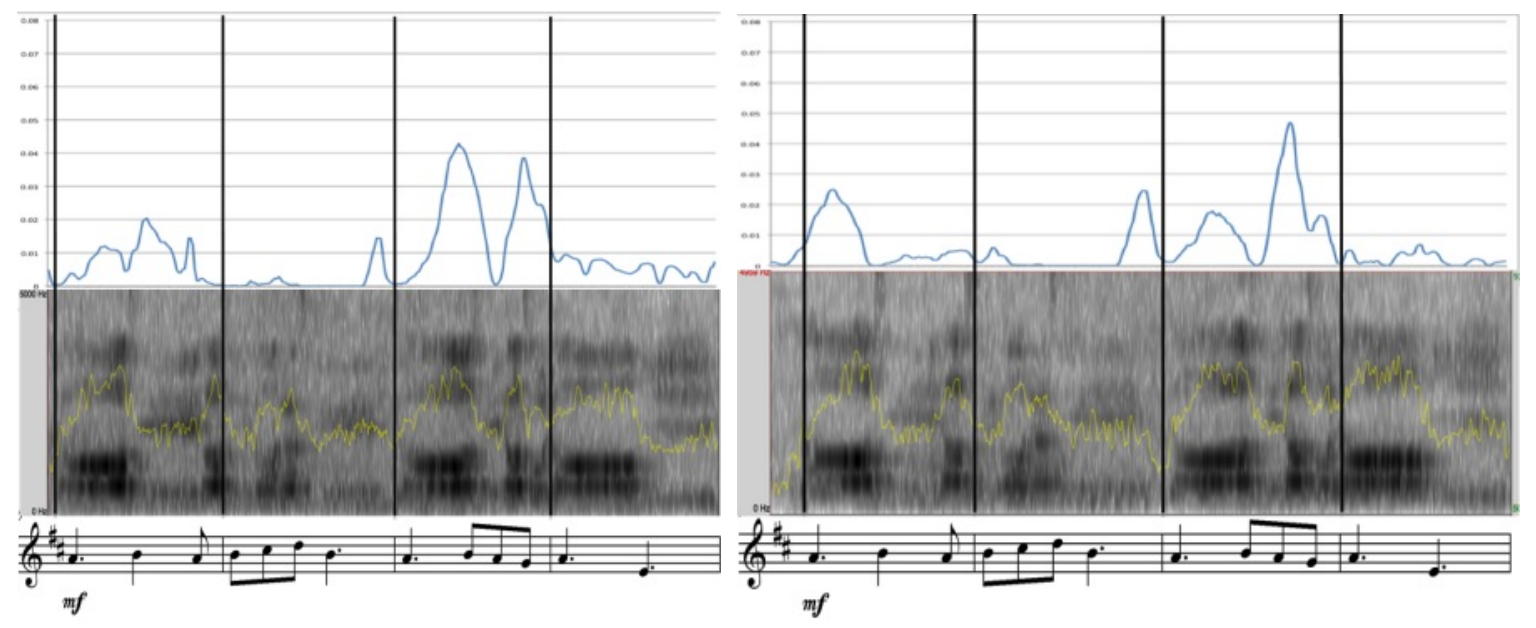

Figura 4.8. Cantidad de movimiento, intensidad y espectro para la frase 2 de las ejecuciones 1

(panel izquierdo) y 2 (panel derecho) del sujeto $A$.

Lo contrario ocurre en la frase 3: los perfiles de QoM son muy diferentes entre ambas ejecuciones, como lo muestran los gráficos de la figura 4.9. Al examinar los perfiles de timing se puede también observar una gran similitud en la frase 2 y una gran diferencia en la frase 3 (figura 4.10). Para medir esta observación se realizó un cálculo de correlación por frases entre los perfiles de desviación temporal de las dos ejecuciones. Como se observa en la tabla 4.4, la única correlación significativa fue la de la frase 2, mientras que la correlación más baja fue la de la frase 3. Es posible aventurar que la concepción de timing más estable, estaría vinculada entonces a un patrón de QoM más estable también. 

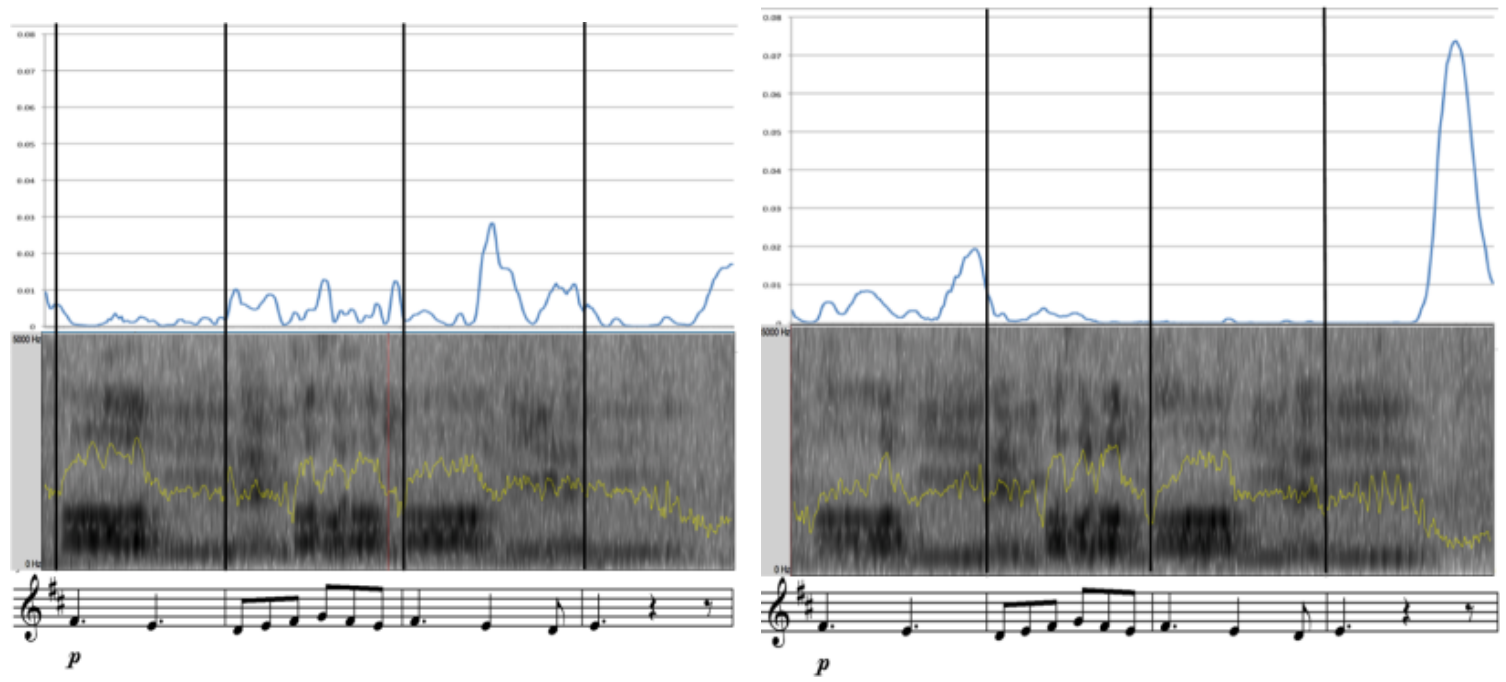

Figura 4.9. Cantidad de movimiento, intensidad y espectro para la frase 3 de las ejecuciones 1 (panel izquierdo) y 2 (panel derecho) del sujeto $A$.

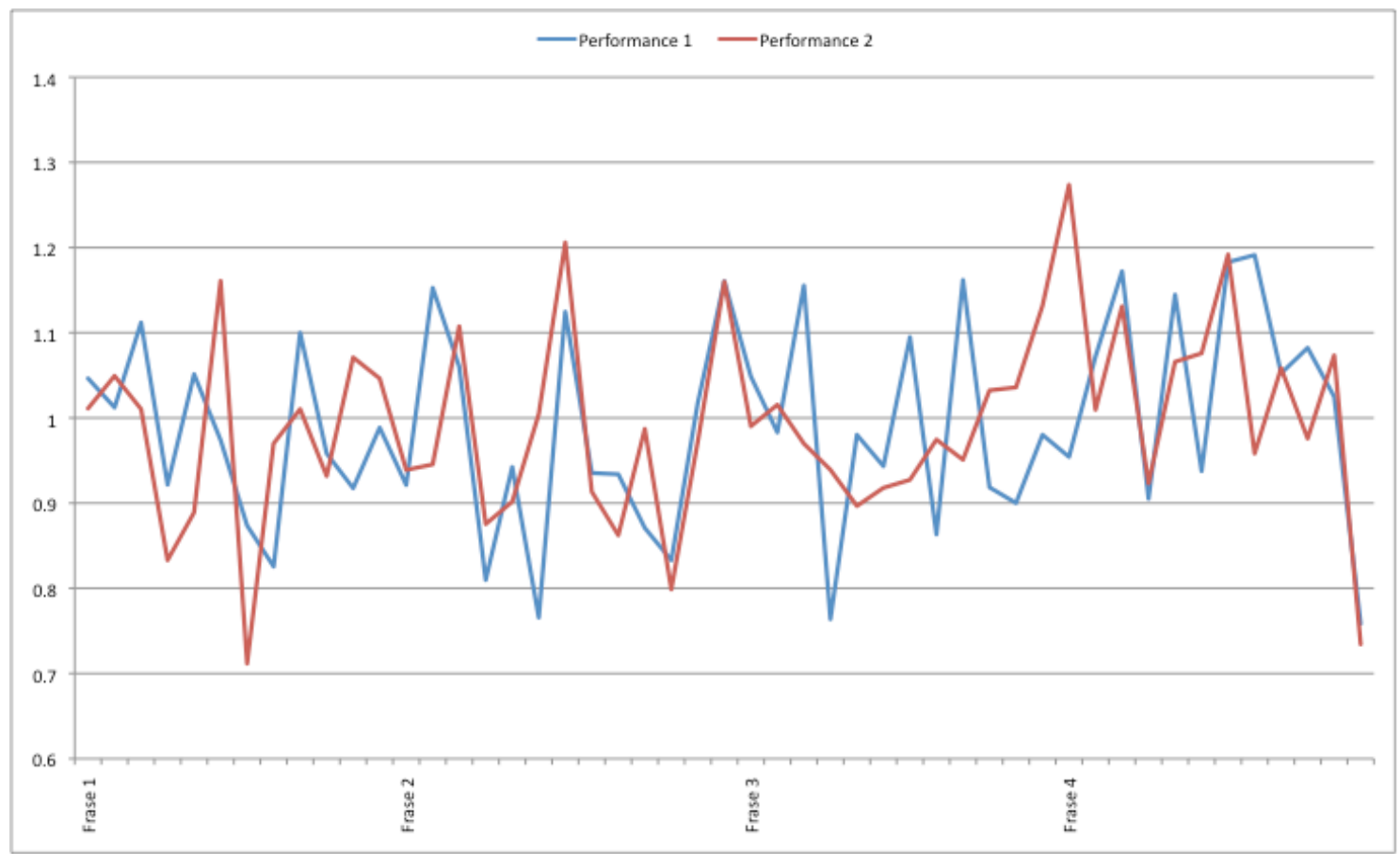

Figura 4.10. Perfiles de timing de las dos ejecuciones del sujeto $A$.

\begin{tabular}{|c|c|c|}
\hline Frase & $\begin{array}{c}\text { Coeficiente de } \\
\text { Pearson }\end{array}$ & $\begin{array}{c}\text { Nivel de } \\
\text { Significación }\end{array}$ \\
\hline $\mathbf{1}$ & .338 & .283 \\
\hline $\mathbf{2}$ & .641 & .018 \\
\hline $\mathbf{3}$ & -.098 & .761 \\
\hline $\mathbf{4}$ & .494 & .103 \\
\hline
\end{tabular}

Tabla 4.4. Correlaciones de los desviaciones expresivas de timing de las dos ejecuciones, por frases. 
Finalmente se comparan los perfiles de los parámetros medidos del sujeto $\mathrm{A}$ con los correspondientes a la segunda ejecución del sujeto B (figura 4.11). Se observa que tanto la QoM como el perfil de intensidad y la cualidad presentan un patrón de alta regularidad. La observación del video permite apreciar que el movimiento está básicamente concentrado en el brazo. El sujeto realiza una marcación de compás en tres tiempos (tomando la corchea como tiempo). La consecuencia más importante de esto es que el sujeto construye su ejecución nota por nota, sin atención a la estructura de la frase. Paradójicamente, ni siquiera el compás puede configurar por esta razón de modo que a menudo altera los valores de duración como ocurre en el compás 6 (obsérvese que dura menos).

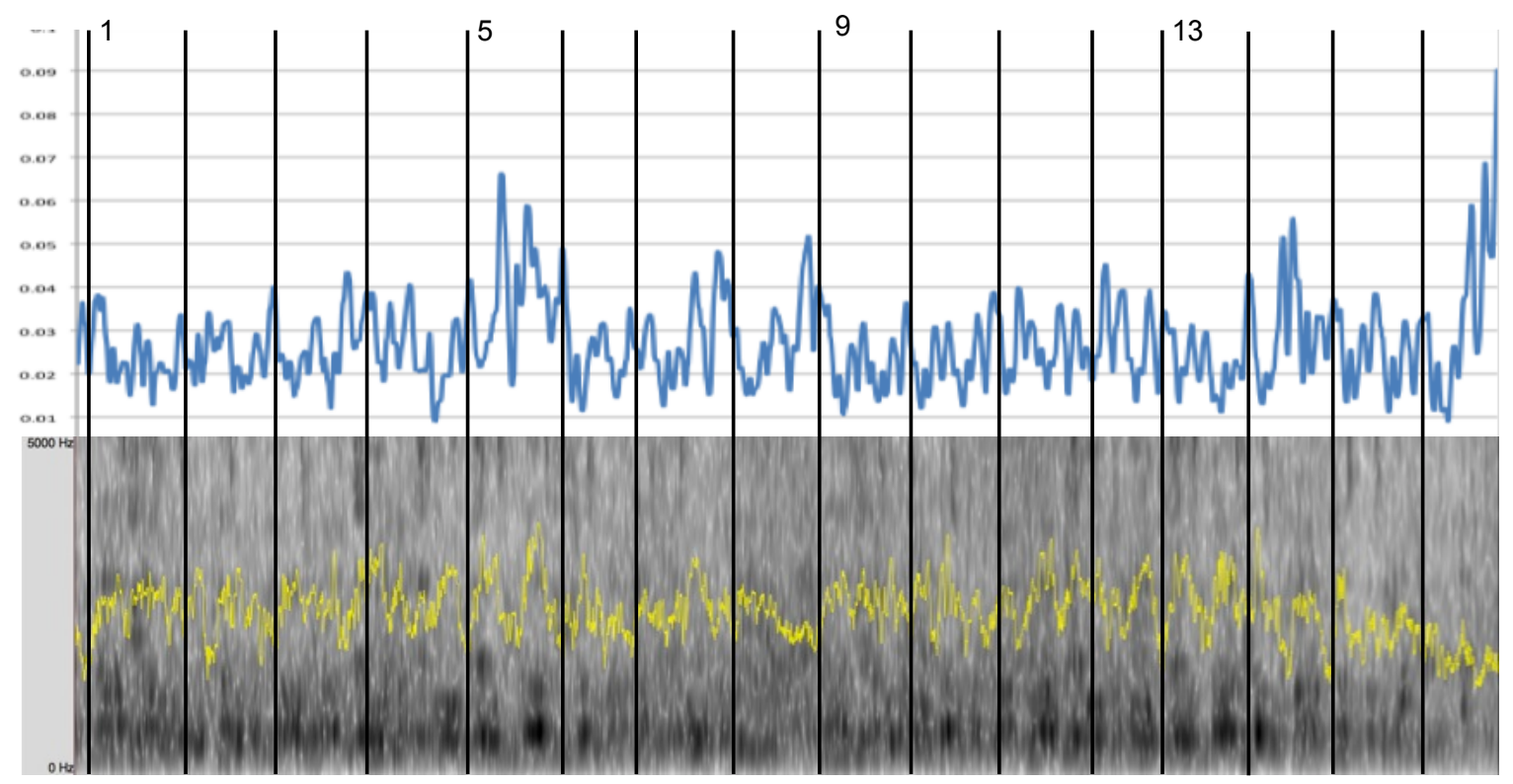

Figura 4.11. Cantidad de movimiento (panel superior), espectrograma e intensidad (panel

inferior) de la ejecución 2 del Sujeto $B$ (menos expresivo). Los números indican los compases de acuerdo a la partitura

\section{A Modo de Conclusión}

Este estudio se propuso analizar las vinculaciones entre las descripciones de los atributos expresivos de dinámicas y rubato durante la ejecución de melodías cantadas a primera vista y algunas características del movimiento corporal observado en el transcurso de esas ejecuciones. En tal sentido, se encontró que el sujeto que logró hacer una ejecución a primera vista expresiva, realizó movimientos que se vinculan tanto con características estructurales de la melodía (por ejemplo, la forma) como de su propia interpretación (por ejemplo, las variaciones de intensidad). Además las características topokinéticas y morfokinéticas se vincularon con el modo en el que se realiza el fraseo, agrupando los sonidos en relación con el timing en frases cada vez más largas a medida que va tomando conciencia de las frases. En 
este sentido, siguiendo la idea de Schögler y Trevarthen (2007) el movimiento parecía empujar las notas. Esto podría estar dando cuenta de que los movimientos se vinculan con el modo de elaborar la ejecución vocal, y en tal sentido, no son una imagen especular de las estructuras musicales ejecutadas sino que revelan un particular modo de sentir y de construir significado. Pero además se pudieron apreciar diferencias importantes de la primera a la segunda ejecución del sujeto. La primera presenta muchas más situaciones en las que el sujeto busca estabilizarse a través de movimientos autorregulatorios. Parecería que estos le permiten ir acomodándose a las contingencias de la ejecución, conforme esta transcurre, habida cuenta de que es su primera ejecución de la pieza, y por lo tanto no tiene un registro corporal de la misma: la está conociendo. La segunda ejecución es notablemente diferente en lo que respecta a cantidad de movimiento, que a su vez está más asociado a estructuras musicales más abarcadoras, tales como las relaciones de tensión y relajación que organizan el discurso como un todo (como antecedente-consecuente). Esta orientación más holística del movimiento parece adecuarse al perfil dinámico y agógico. Así, movimiento, tiempo, fuerza (energía sonora) y espacio, aparecen enlazados en una totalidad que se ajusta a la estructura de la pieza (intención): la gestalt dinámica (de la que habla Stern, 2010) se hace ostensible en la ejecución.

Por otra parte, los movimientos constantes y repetitivos que realizó el sujeto menos expresivo estaban siempre vinculados a la estructura métrica, y en general se limitaban a la marcación de un pulso (la división del tiempo) a modo de guía métrico-rítmica para no perder continuidad. En este sentido, el movimiento parecía buscar un apoyo cognitivo, llevando a cabo una función epistémica, en tanto puede contribuir a la resolución de la tarea permitiendo al sujeto guiar su ejecución, en términos temporales, a partir de la exteriorización de ese pulso (movimiento autorregulatorio). Sin embargo, y aunque la ejecución era en efecto continua, se tornaba atomizada (nota a nota), y en tal sentido, el movimiento parecía estar interfiriendo en la concepción global de la melodía, fragmentando la ejecución e impidiendo la construcción de significado a partir de ella (como lo hace el sujeto $A$ a lo largo de sus dos ejecuciones). De este modo, el movimiento carece de función semiótica y en consecuencia, por tratarse de una tarea cuya naturaleza expresiva emerge inexorablemente de la construcción de significado, pierde su función epistémica ya que no logra descargar la alta demanda cognitiva.

Así, el movimiento corporal podría ser considerado como una acción epistémica cuando surge de modo verdaderamente espontáneo en el sujeto, y no cuando forma parte de una imposición pedagógica que le es ajena y que no resulta significativa en su experiencia. En este sentido, la recurrencia de estrategias pedagógicas corporales podría tener un efecto positivo 
en la construcción de significados, cuando los estudiantes logran establecer un vínculo entre el movimiento estereotipado propio de este tipo de estrategias y el modo particular en el que experimenta la música. Pero también puede resultar perjudicial cuando el movimiento se torna una imposición desvinculada de la experiencia del estudiante, y genera una carga cognitiva extra a la que demanda la tarea musical, fomentando la atomicidad en la ejecución y perjudicando la comprensión holística de la música. 



\section{Capítulo 5}

\section{Conclusiones}

Esta Tesis se propuso explorar y analizar los movimientos realizados durante tareas de lectura cantada a primera vista en orden a determinar la existencia de vinculaciones temporales y morfológicas con aspectos musicales de las melodías leídas, y destacar los aspectos claves de la asociación entre estos movimientos manifiestos y el desempeño musical relativo a este tipo de tareas con particular relevancia para modelizar los procesos psicológicos implicados. Estos objetivos apuntaron a comprobar la hipótesis que recorrió toda esta Tesis de que los movimientos manifiestos desplegados en tareas de lectura cantada a primera vista que se vinculan temporal y morfológicamente con aspectos musicales poseen una función epistémica, actuando como un anclaje corporal externo y reduciendo la carga cognitiva que la tarea demanda.

Para tal fin se desarrolló en primer término un recorrido teórico que abordó los conceptos básicos de la cognición postulados por la Ciencia Cognitiva Clásica, señaló algunas críticas mencionando las limitaciones que esta concepción clásica presenta al intentar explicar la formación de sentido en la experiencia humana, y presentó las ideas más relevantes de las Ciencias Cognitivas de Segunda Generación focalizando en la Cognición Musical Corporizada como marco teórico general de esta tesis.

La idea clásica de mente refiere a una entidad etérea encargada de la realización de operaciones simbólicas, que ocurren en una caja negra. En este contexto, la cognición es un proceso que implica la entrada de información a través de los sentidos (input), el procesamiento mental de la información percibida a través de las operaciones simbólicas con representaciones mentales, y la salida (output) de la información procesada, como respuesta, generalmente involucrando la acción corporal del sujeto. En este modelo, el cuerpo se limita a recibir la información sensorial, a ser el soporte material del proceso mental y a realizar la acción de salida del procesamiento de la información. Resulta interesante el hecho de que algunos investigadores, partiendo de esta visión clásica, comenzaran a pensar en otro tipo de participación de la acción corporal en la cognición. Tal es el caso de Kirsh y Maglio (1994), quienes postularon el concepto de acción epistémica para referirse a todas aquellas acciones 
que los sujetos realizan con el fin de mejorar aspectos de la cognición. Son acciones realizadas en el mundo externo para favorecer los procesos del mundo interno, y en este sentido, la perspectiva adoptada por estos autores avanza hacia una idea de cognición que excede el marco clásico. El cuerpo, como ejecutor de las acciones epistémicas es visto como colaborador externo en el proceso cognitivo, pero no como parte del mismo.

Como alternativa a la visión clásica, se desarrollaron fuertemente en las últimas 3 décadas las Ciencias Cognitivas de Segunda Generación, que si bien comprenden un grupo de disciplinas heterogéneo y un cuerpo teórico con variados matices, todos los enfoques que se incluyen en él le otorgan una gran importancia al cuerpo y al entorno en la cognición, particularmente cuando la entendemos como la formación de significados acerca de la experiencia humana (ver por ejemplo Gibson, 1979; Lakoff y Johnson, 1980; Varela, 1988; Clark, 1999, 2008; Nöe, 2004; Gibbs, 2006; Johnson, 2007; Calvo y Gomila, 2008; Chemero, 2009). Esta corriente de pensamiento planteó la necesidad de revisar el modelo clásico de la cognición, destacando un cuerpo que no se limita a ser un sustento material de la mente abstracta, sino como parte, junto con el entorno, del propio proceso cognitivo.

La Cognición Musical Corporizada, como parte de este cuerpo teórico, se basa en la idea de que nuestra comprensión de la música responde al modo en que la experimentamos a través del cuerpo y la mente como un todo unificado e indivisible. De este modo, los estudios acerca de la comprensión musical tanto desde la audición como desde la ejecución, comenzaron a poner el foco en el cuerpo y en el movimiento para intentar entender el modo en el que se forman los significados musicales (ver por ejemplo Clarke, 2005; Johnson, 2007; Calvo y Gomila, 2008; Leman, 2008).

La investigación en el campo de la cognición musical corporizada se nutrió de las definiciones y de los conceptos relativos al gesto corporal, provenientes desde diferentes disciplinas. Tradicionalmente definido como el "movimiento del rostro, de las manos o de otras partes del cuerpo con que se expresan diversos afectos del ánimo" (Diccionario de la Real Academia Española, 2012), el gesto ha sido abordado y clasificado de múltiples modos. Entre las tipologías gestuales más reconocidas se encuentran las delineadas por Ekman y Friesen (1969), y McNeill (1992) provenientes del ámbito de la lingüística y de la comunicación interpersonal que dieron lugar, en el contexto de la ejecución musical, al desarrollo de tipologías gestuales específicas (ver por ejemplo, Davidson, 2001). Sin embargo, la derivación de los estudios de gesto en pragmática al campo de la ejecución musical resultó insuficiente, pues no logró capturar la riqueza y complejidad de las relaciones entre gesto y música. Así, el estudio de los 
gestos desplegados en tareas de lectura a primera vista requiere una tipología específica, que considere las características propias de la tarea.

El recorrido teórico que planteó la tesis también abordó el estado del arte en investigaciones sobre la habilidad de cantar a primera vista. Principalmente se consideraron los estudios que analizaron los aspectos cognitivos implicados en la habilidad, y se señalaron las limitaciones en materia del análisis corporal y de los movimientos desplegados durante la realización de la tarea. Cantar a primera vista, es una tarea de ejecución musical de alta demanda cognitiva que implica una serie de habilidades complejas, entre las que se encuentran (i) la decodificación de los símbolos del sistema de escritura, (ii) la construcción de una representación mental en tiempo real de la música plasmada en la partitura basada en las expectativas que el lector genera en función de sus conocimientos previos, (iii) la interpretación como proceso de significación, (iv) la construcción del marco métrico temporal, del centro tonal y de las condiciones de estabilidad de las alturas, (v) el emparejamiento de las representaciones auditivas con el resultado sonoro a través de la retroalimentación auditiva, y (vi) el control de la emisión vocal y la ejecución ajustada.

Para alcanzar los objetivos de la Tesis y validar la hipótesis postulada se diseñó y se desarrolló una serie de estudios empíricos sustentados en el marco teórico expuesto en el capítulo 1 y considerando el estado del arte descripto en el capítulo 2, que exploraron los movimientos desplegados en tareas de cantar a primera vista, los clasificaron, y analizaron la posibilidad de considerarlos como acciones epistémicas que mejoran los procesos cognitivos implicados en la habilidad.

De acuerdo con la evidencia anecdótica que dio origen a esta Tesis, los estudiantes de música realizan una amplia gama de movimientos corporales manifiestos cuando cantan a primera vista, muchos de los cuales parecen estar vinculados a rasgos de la melodía leída, principalmente al contorno melódico (o a las alturas), a la estructura métrica y al ritmo. Los resultados obtenidos en la etapa exploratoria confirmaron esta evidencia y mostraron que los movimientos vinculados a las alturas aparecen en casi todos los sujetos (91\%), aunque solamente durante el $25 \%$ del tiempo total de las ejecuciones. El análisis detallado de este tipo de movimientos en relación con la resultante sonora de la ejecución mostró que eran realizados principalmente con las manos y en momentos de mayor dificultad en la lectura, lo que permitió suponer una función epistémica de estos movimientos. Por su parte, los movimientos vinculados a la estructura métrica y al ritmo fueron realizados por una cantidad menor de sujetos (73\%), pero permanecieron durante mucho más tiempo (73\%) en relación con el señalamiento de alturas. Estos movimientos, principalmente la marcación de 
pulsaciones con las manos y con los pies, era sostenida por los sujetos a lo largo de gran parte de la ejecución, y en algunos casos, durante la totalidad de la misma.

Resulta sorprendente que al ser tan ostensible la realización de movimientos durante este tipo de tareas, los estudios que han abordado la habilidad no hayan reparado en ellos y en su posible participación en el desempeño en la lectura. Como se mencionó en el capítulo 2, la participación del cuerpo en este tipo de tareas se ha abordado en las investigaciones aquí descriptas básicamente de modos: (i) como traducción cinestésica desde el código de escritura musical (ver Fine et al., 2006); y (ii) como estrategia corporal exitosa basada en la realización de gestos convencionales con las manos en el lapso de preparación para la lectura y en la posterior ejecución (ver Killian y Henry, 2005). Estos gestos utilizados como estrategias para la resolución de la tarea se vinculan claramente con la estructura tonal de la melodía leída porque representan la función tonal de cada una de las alturas cantadas, en base a la relación entre gesto y grado de la escala planteada por método del do móvil (ver capítulo 2). Sin embargo, nada se dice en estos estudios acerca del modo en que determinado tipo de movimiento convencionalmente asociado a la melodía, se convierte en una estrategia de resolución para los participantes. En primer término, parece existir una razón contextual para esta limitación explicativa que deviene de las publicaciones internacionales a las que se tiene acceso (principalmente de Estados Unidos y del Reino Unido). Los estudios publicados que abordan la habilidad de cantar a primera vista se desarrollan generalmente en contextos con características diferentes a las que presentan los ámbitos académicos en los que se aplicaron los estudios reportados en esta Tesis. Esta diferencia se hace evidente, por ejemplo, en el amplio desarrollo que ha tenido el método del do móvil en países como Estados Unidos, (ver Kuehne, 2010) y, en contraposición, el escaso impacto en los ámbitos académicos latinos. Como se mencionó en el capítulo 2, este método establece una relación directa y rígida entre el movimiento corporal convencional (realizado con las manos) y la función tonal de la nota cantada. Es probable que la realización de estos movimientos convencionales implique una disminución en la realización de otros movimientos más idiosincráticos o espontáneos por parte del lector. En consecuencia el investigador, al juzgar que los movimientos son conocidos, convencionales y con una función específica definida por el método pedagógico (representar la función tonal de cada nota cantada), podría subestimar la participación del movimiento corporal en la formación de significados musicales en este tipo de tareas de lectura.

En segundo término, resulta evidente que las investigaciones abordadas aquí se sustentan en una concepción clásica de cognición, en la cual los procesos cognitivos son desplegados internamente en la mente, y en cuyo contexto el movimiento corporal manifiesto puede 
significar una respuesta a la información recibida por los sentidos, pero no puede tener una función cognitiva en sí mismo. En este sentido, los estudios en lectura cantada a primera vista comparten la limitación explicativa de la Ciencia Cognitiva Clásica en relación con la ausencia del cuerpo en la formación de significados acerca de la experiencia humana.

El segundo estudio de la etapa exploratoria describió y analizó los movimientos manifiestos en tareas de cantar a primera vista a la luz de las definiciones, conceptos y categorías relativas al gesto que provenían de diferentes ámbitos disciplinares. Observando las particularidades de la tarea, resultó necesario redefinir el concepto de gesto con el fin de considerar, preservar y destacar las relaciones entre el movimiento corporal y las características de la melodía. Conviene recordar aquí que las definiciones tradicionales de gesto mencionadas en el capítulo 2 aluden al movimiento que acompaña el habla, mientras que es esta Tesis el término refiere a los movimientos corporales que acompañan la ejecución de una melodía cantada a primera vista. En este contexto se definió gesto como todo aquel movimiento o grupo de movimientos que conforma una unidad mínima de sentido completo, observando que no se pierdan las posibles vinculaciones con la estructura musical. Si bien esta definición captura uno de los rasgos distintivos del gesto de acuerdo con las diferentes concepciones estudiadas, a saber, la conformación de una unidad de sentido, evade intencionalmente el otro punto relevante incluido en las definiciones más tradicionales: la expresión de significado (ver por ejemplo McNeill, 1992; Cadoz y Wanderley, 2000; Diccionario de la Real Academia Española, 2012). La razón para esta elusión intencional es justamente la particularidad de la tarea. En el contexto académico pedagógico en el que se realizaron los estudios que forman parte de esta Tesis que fue descripto en la introducción y en el capítulo 2, la tarea de cantar a primera vista se aborda como una habilidad a desarrollar en las materias que se ocupan del desarrollo del oído musical (Educación Auditiva, Audioperceptiva, Lenguaje Musical, etc.). Aquí el estudiante no está realizando una ejecución elaborada dirigida a una audiencia como en la tarea analizada por los estudios que abordan el gesto desde la ejecución instrumental (Delalande, 1988; Cadoz y Wanderley, 2000), o vocal (Davidson, 2001), sino que está resolviendo una tarea de alta demanda cognitiva que implica una ejecución vocal ajustada individual, y por momentos, en solitario (en general, durante el tiempo de preparación para la lectura el estudiante se encuentra solo, y es uno de los momentos en donde se ha observado una gran cantidad de gestos corporales). La ejecución final se realiza en compañía del docente evaluador, que claramente no conforma una audiencia para que el estudiante ejecute una obra y exprese corporalmente el significado de la música, sino más bien es un juez del ajuste de su desempeño vocal. En este sentido, se puede sugerir que el movimiento desplegado está 
dirigido hacia el propio ejecutante, y no hacia una audiencia como una expresión del significado musical que el ejecutante elabora. Una vez más, esta dirección auto-orientada permite suponer una función epistémica del gesto, es decir, permite pensar en gestos realizados con el fin de mejorar los procesos cognitivos implicados en la resolución de la tarea. Sin embargo, esta idea de gesto no expresivo (en el sentido de la comunicación), conlleva la factibilidad de una crítica de base: si no es expresivo, es decir, si no tiene uno de los rasgos más distintivos del gesto, tal vez no es un gesto. En tal caso, no correspondería nombrar un movimiento cuya intención no sea comunicativa como gesto. No obstante, esta crítica puede ser discutida básicamente desde dos frentes. En primer lugar, como se mencionó en el capítulo 1, tanto la definición como las tipologías gestuales varían de acuerdo al ámbito disciplinar en el que se aplican. No es lo mismo el concepto de gesto en la comunicación interpersonal (McNeill, 1992; Ekman y Friesen, 1969), que en la ejecución musical (Delalande, 1988; Cadoz y Wanderley, 2000; Davidson, 2001) o que en la interacción hombre-máquina (Kurtenbach y Hulteen, 1990). Cada una de las definiciones dadas de gesto preserva ciertos rasgos, elude otros e incluye nuevos en función de las particularidades de la tarea que se está estudiando. Además, algunas categorías gestuales pueden parecer contradictorias incluso con la definición de gesto dada por los mismos autores que proponen tales categorías. Por ejemplo, la categoría de gestos adaptativos postulada por Ekman y Friesen (1969) que luego fuera aplicada a la ejecución musical vocal por Davidson (2001), refiere a los gestos realizados con una orientación interna, es decir, que son desplegados con una finalidad de regulación interna, para calmar los nervios, relajarse, etc. (ver capítulo 1). Como puede apreciarse, esta es una categoría que no considera el gesto desde la expresión de sentido, sino más bien, como desempeñando una función psicológica propia del individuo que lo realiza. En este sentido, representa una contradicción con una definición de gesto vinculada excluyentemente a la función comunicacional. Al presentar tantas variantes conceptuales, categoriales, etc., sumado a su aplicación interdisciplinaria, el estudio del gesto resulta epistemológicamente conflictivo en las diferentes disciplinas que se ocupan de su abordaje. Sin embargo, esta interdisciplinariedad y este eclecticismo teórico es justamente lo que enriquece el campo de estudio del gesto, pues en cada contexto, es factible captar los conceptos teóricos y definiciones, las categorías analíticas y las herramientas de análisis en general desarrolladas en diferentes disciplinas, que resulten más relevantes de acuerdo al ámbito y a la actividad humana que se esté estudiando.

Este razonamiento se vincula con la segunda respuesta a la posible crítica de la definición de gesto adoptada aquí, ya que es justamente la posibilidad de considerar gestos a los 
movimientos desplegados en tareas de cantar a primera vista la que abre el camino a la aplicación de conceptos, ideas y categorías que resultan sumamente interesantes para el estudio del movimiento como variable en el desarrollo de esta habilidad. Particularmente, en esta Tesis la idea de gesto permitió observar, reconocer y segmentar unidades de sentido del movimiento en vinculación con la unidad de sentido musical. Es decir que la relación congruente entre la aparente unidad gestual (determinada por detenciones, cambios en el tipo de la forma gestual, etc.) y la unidad de sentido musical (motivo o frase melódica), es concordante con la idea de que el gesto está definido por una unidad de sentido completo.

Ahora bien, ¿cómo es posible establecer estas vinculaciones entre el movimiento corporal y los atributos musicales?, y en ese sentido, ¿cuáles son las características tanto del movimiento como de la música leída que revelan esta congruencia? En primer lugar, y como ya se mencionó, la relación es temporal, porque el movimiento coincide temporalmente con un atributo musical particular, como por ejemplo un pulso. Es decir, si existe una correspondencia temporal directa entre el movimiento de batido de una parte del cuerpo y las pulsaciones isócronas de algún nivel métrico de la estructura musical, es posible decir que tal movimiento está vinculado a la estructura métrica de la melodía que se está leyendo. En segundo lugar, la correspondencia también es morfológica, porque la forma de un gesto puede corresponderse con la forma de representar ciertos rasgos formales de la música, como por ejemplo, el arco que agrupa un motivo melódico o frase representado con alguna parte del cuerpo, generalmente la mano o la cabeza. En tercer lugar, también es posible establecer un vínculo entre el movimiento y la música en términos topológicos, es decir, en el modo de ubicar en el espacio los movimientos en relación con la disposición espacial metafórica de algún aspecto de la melodía. La relación topológica más fácilmente observable es la quironimia, entendida como la representación espacial del punteo de los grados de la escala realizada con movimientos de la mano en el eje vertical. Estas relaciones espaciales implican la representación metafórica del atributo 'altura' en el eje vertical, en el cual agudo es representado arriba y grave abajo, en concordancia con el modo en que es representado este atributo en el sistema de escritura musical convencional.

Las congruencias observadas confirman la asunción de una relación directa entre el movimiento corporal y la música basada en la conformación de unidades de sentido. Del mismo modo, la utilización y elaboración de los conceptos vinculados al gesto posibilitó tomar categorías ya desarrolladas y aplicarlas a los movimientos manifiestos observados y utilizar las herramientas de análisis de aquellas disciplinas dedicadas al estudio de este complejo 
concepto, con el fin de diseñar nuevas categorías que contemplaran los movimientos que no podían ser incluidos en las categorías existentes (ver estudio 2 en el capítulo 3 ).

Sin embargo, y como se deja entrever en estos párrafos, el estudio del gesto resulta sumamente complejo, pues la multiplicidad de enfoques genera también ambigüedades, conflictos y contradicciones teóricas que no son posibles de resolver sin un debate profundo interdisciplinario que eche luz sobre las ideas que acompañan a este campo de estudio. Actualmente, una solución plausible parece ser la postura ecléctica autodefinida en cada contexto de estudio, como ya se mencionó, de acuerdo a las particularidades de la tarea estudiada tal como se intentó realizar en esta Tesis. En este sentido, el gesto no debería ser entendido como un dominio de conocimiento independiente que se vincula a otros, como el lenguaje o la música, a través de cualidades comunes (temporales, morfológicas, etc.), sino más bien como una manifestación propia de cada uno de esos dominios. Intentar entenderlo de manera aislada como si se tratara de un lenguaje en sí mismo, para luego relacionarlo con un ámbito de la experiencia humana alejaría al mismo gesto del contexto en el que se realiza, y por lo tanto conspiraría contra la comprensión holística de la experiencia en cuestión. No es posible pensar el gesto si no se entiende en relación a su modo de existencia particular, que en este caso es la música. De este modo, la música no es hecha únicamente de sonidos sino que los gestos son también sus constituyentes (véase Mithen, 2006; Stern, 2010; Tropea, Shifres y Massarini, en prensa).

A partir de toda la evidencia recolectada en los estudios iniciales, se diseñó y se aplicó un estudio experimental para testear la naturaleza epistémica de las acciones corporales desplegadas en la tarea de leer cantando una melodía a primera vista. Se buscó analizar la incidencia del movimiento libre y restringido (con diferentes pautas de restricción) en la melodía leída a primera vista. Para el experimento, los movimientos se pautaron en vinculación al contorno melódico y a la estructura métrica -por ser aquellos que aparecieron más asiduamente (tanto en cantidad de participantes que los realizaron como en permanencia temporal) de manera espontánea durante las ejecuciones registradas en los estudios exploratorios (ver estudios 1 y 2 en el capítulo 3)-, se dejaron libres -esto es, de realización espontánea de los sujetos-, o se impidieron totalmente. Los resultados mostraron que la restricción del movimiento, ya sea por vinculación a un atributo estructural de la melodía o por impedimento total, perjudica el desempeño en este tipo de tareas, mientras que las condiciones menos restrictivas de movimientos lo favorecen. Estos resultados sugieren una validación, al menos parcial, de la hipótesis que se postula en esta Tesis. Como se mencionó en el capítulo 4, los gestos vinculados a la estructura métrica parecen estar funcionando como un 
marco métrico temporal que favorece los aspectos temporales de la ejecución leída. Esto se observó en las medias de los puntajes obtenidos para el indicador ritmo en las diferentes condiciones, que mostró el promedio más alto para la condición de movimientos vinculados a la estructura métrica. De este modo, siguiendo a Kirsh y Maglio (1994) se puede decir que este tipo de movimientos que se vinculan temporal y morfológicamente a un rasgo musical estructural, como es la estructura métrica, funcionan como acciones epistémicas que mejoran aspectos de los procesos cognitivos necesarios para resolver la tarea, principalmente, aquellos vinculados con la temporalidad (configuración de la estructura métrica y ajuste rítmico). Sin embargo, considerando el marco de las Ciencias Cognitivas de Segunda Generación (ver capítulo 1), estos movimientos podrían no sólo ser una acción externa que mejora el proceso cognitivo interno, sino una parte del proceso cognitivo mismo que permite configurar la estructura métrica para luego ajustar las articulaciones rítmicas a ese marco temporal. Es decir, que el lector a primera vista no mejora su modo de pensar la melodía para resolver los problemas que la tarea implica a través del movimiento corporal, sino que piensa con el movimiento, generando recursos cognitivos que de otro modo no estarían disponibles. Tal como señalan Gomila y Calvo (2008) la cognición es de naturaleza corporizada y está embebida en el entorno; para entenderla, es necesario tomarla como un sistema que incluye al cuerpo y al entorno. Esta idea amplía el concepto de acción epistémica acuñado por Kirsh y Maglio (1994), porque las considera como acciones que forman parte de los procesos cognitivos empleados para resolver tareas de lectura cantada a primera vista, y no solamente como una acción mejoradora de algún aspecto de la cognición. De acuerdo a la idea ampliada de acción epistémica postulada en esta Tesis, la división entre lo externo (la acción corporal) y lo interno (el proceso cognitivo o mental) que proviene de una visión clásica de la cognición, pierde sentido. No es lo externo lo que mejora lo interno, sino más bien, es todo un sistema cognitivo que implica procesos que se realizan tanto dentro como fuera del cerebro, del cual el movimiento corporal es una parte fundamental. Esta idea también cuestiona el concepto de gesto propuesto por Leman (2010) como articulador de la mediación que realiza el movimiento corporal entre el mundo físico y el mundo mental. Si el gesto vinculado a la estructura métrica configura el marco temporal para la ejecución leída a primera vista, se considera más apropiado entenderlo como una parte del mundo mental, es decir, como un proceso cognitivo en sí mismo, y no como un articulador de una mediación entre dos mundos bien definidos que, en función de este razonamiento, no parecen estar tan separados.

Esta idea está ligada a la Teoría de la Mente Extendida delineada por Clark y Chalmers (1998; Clark, 1997, 2008), en la cual la mente trasciende los límites del cerebro e incorpora al cuerpo 
y a los elementos del entorno en el proceso mental (ver capítulo 1). Sin embargo, los resultados del estudio experimental descripto en el capítulo 4, si bien avalan al movimiento corporal como parte del proceso cognitivo, no brindan evidencias, dada la naturaleza del estudio, para sostener también la participación del entorno.

Contrariamente a lo esperado, los gestos vinculados al contorno melódico perjudicaron el desempeño prácticamente para todos los indicadores medidos. Esto podría vincularse con que sostener la pauta corporal propuesta, es decir, desplegar gestos vinculados al contorno melódico durante toda la ejecución, consume recursos cognitivos que no estarían disponibles para ser utilizados en la realización de la tarea. Los resultados de los estudios iniciales habían mostrado que este tipo de movimientos manifiestos estaban presentes en una gran mayoría de los participantes aunque durante un tiempo acotado, muy por debajo de los movimientos vinculados a la estructura métrica. Como ya se mencionó, al analizar más en detalle los momentos en que este tipo de movimientos era desplegado, se encontró que aparecía acompañando la ejecución de giros melódicos que resultaban difíciles para los estudiantes, hecho que se hacía evidente en detenciones, reiteraciones, errores y correcciones. Esto permite suponer que la función cognitiva del gesto está vinculada al nivel de la espontaneidad con la que se realiza. Así, cuando el gesto vinculado al contorno melódico es desplegado de manera espontánea en momentos en los que resultan necesarios para los lectores, podría estar cumpliendo el rol de soporte cognitivo o epistémico en los términos definidos en los párrafos precedentes. Pero sostener un gesto tan complejo, que implica una representación convencionalizada atravesada por la escritura musical, durante toda una ejecución no resulta para nada espontáneo. Es más bien una tarea que genera mayor dificultad para la lectura, puesto que una parte de los recursos cognitivos disponibles tiene que estar respondiendo constantemente al emparejamiento entre la forma del movimiento, basada en las relaciones espaciales de la mano en el eje vertical y el contorno melódico. Para que un gesto sea realizado de manera espontánea durante una ejecución musical a primera vista, debe ser significativo para quien lo realiza. Es decir, que el lector tiene que haber construido las relaciones de significación entre su experiencia con la música, o más precisamente, con los rasgos musicales con los que se vincula el gesto, y las características del movimiento. Tal vez, esta sea la razón por la cual Killian y Henry (2005) encontraron que los gestos con las manos basados en el método del do móvil resultaban estrategias exitosas para los lectores más expertos. Al desarrollar la habilidad de cantar a primera vista a partir de este método, fueron construyendo relaciones significativas entre el gesto y el rasgo musical que el gesto representaba, en este caso, la función tonal de la altura cantada. Luego, al realizar tareas de 
cantar a primera vista la apelación espontánea al gesto es parte de la estrategia cognitiva misma que se despliega para resolver la tarea. Sin embargo, sostener este tipo de gestos complejos de un modo no espontáneo sino impuesto, no resulta significativo para el lector no entrenado de ese modo, y consume recursos cognitivos en vez de generarlos, lo que actúa inexorablemente en perjuicio del desempeño. En este sentido, la realización de movimientos que pueden cumplir una función epistémica en determinadas situaciones (cuando son espontáneos y presentan una relación morfológica y temporal con la melodía que resulta significativa para quien los despliega) pueden volverse restrictivos corporalmente implicando una mayor demanda cognitiva y dificultando el desarrollo de la habilidad en otras situaciones (cuando son impuestos y no resultan significativos para el propio ejecutante).

En tal sentido, es posible aceptar que algunos de estos movimientos cumplen, al menos en algunas situaciones, una función epistémica (en los términos propuestos en esta Tesis), formando parte de los procesos cognitivos implicados en la resolución de la tarea, potenciando la experiencia musical y favoreciendo el desempeño, siempre que exista un entrenamiento ad hoc que favorezca la apropiación de tales movimientos propiciando el involucramiento corporal en el contexto de la experiencia musical que implica leer melodías a primera vista. Sin embargo, pensar una derivación didáctica de esto no debería conducir directamente a realizar movimientos corporales manifiestos como un entrenamiento deportivo para la adquisición del lenguaje musical en la clase de música, sino de atender a los movimientos espontáneos, admitir el despliegue de movimiento libre de acuerdo a las necesidades de la comprensión musical de los estudiantes y propiciar el establecimiento de relaciones significativas entre el gesto y los conceptos musicales que permiten una comprensión de la melodía, con el fin de favorecer el desarrollo de la habilidad de cantar a primera vista.

Los resultados del estudio 3 también mostraron una gran dispersión (mayor rango y mayor desviación estándar) en los puntajes que los jueces le asignaron a la variable expresión. En tal sentido, de todas las variables evaluadas en dicho estudio (ajuste global, ritmo, afinación, fidelidad y expresión), la expresión, además de mostrar los puntajes más bajos, fue la que presentó mayor variabilidad de criterios para su calificación. Partiendo de estas observaciones, se consideró necesario avanzar en el estudio de las relaciones sonoro-kinéticas poniendo el foco en los atributos expresivos de la resultante sonora en vinculación con ciertos aspectos globales del movimiento corporal. Siguiendo esta idea, se analizaron las vinculaciones entre las descripciones de los atributos expresivos de dinámica y rubato y la cantidad de movimiento corporal como componente kinético de las ejecuciones cantadas a primera vista (ver estudio 4 en el capítulo 4). Además, se describieron los movimientos que resultaron de interés de 
acuerdo al análisis de los picos y valles de dicha magnitud. Para realizar este análisis se seleccionaron los participantes del estudio 3 que habían recibido los puntajes extremos en la variable expresión, es decir, el participante más expresivo y el menos expresivo de acuerdo a la calificación de los jueces, y se tomaron sus ejecuciones con movimiento libre. Los resultados mostraron una clara diferencia en el modo en que se organizó la ejecución de la melodía en términos de la expresión del sentido musical elaborado en vinculación con el movimiento corporal en uno y otro caso. Esto pudo observarse en el análisis de la curva de cantidad de movimiento, la posterior descripción de los mismos y su relación con los componentes expresivos de la resultante sonora.

El movimiento corporal del participante que realizó una ejecución expresiva presentaba características topokinéticas y morfokinéticas claramente vinculadas con el fraseo melódico, es decir con el modo de agrupar los sonidos en relación con el timing de acuerdo a su significación de la melodía. De esta manera, el movimiento aparece como parte del modo en el que el lector significa la música y la interpreta expresivamente. No es una representación externa auxiliar o accesoria de los procesos desplegados para leer a primera vista, sino parte intrínseca del modo particular de construir significados en este tipo de tareas. Del mismo modo, la elaboración del movimiento observada en la segunda ejecución del participante, (recuérdese que en la primera ejecución desplegó principalmente movimientos autorregulatorios, mientras que en la segunda los movimientos fueron más holísticos, presentando relaciones morfológicas y estructurales más globales y asociados a los perfiles dinámico y agógico) muestra una vez más que la construcción expresiva de la ejecución musical no es únicamente sonora, sino también, y muy fuertemente, corporal.

Por otro lado, el movimiento corporal del participante que realizó la ejecución menos expresiva de acuerdo al panel de expertos, fue regular, constante y se vinculó principalmente con la marcación de un pulso métrico. Como se mencionó anteriormente, este tipo de movimientos serían parte de la configuración de los aspectos temporales de la ejecución, y en tal sentido, derivarían en una ejecución más continua, y precisa en términos rítmicos. Si bien se observó continuidad en la ejecución, la marcación métrica constante se correspondió, en este caso, con una atomización del discurso musical. Resulta interesante analizar lo que ocurrió aquí: por un lado, una ejecución continua y rítmicamente precisa vinculada a movimientos corporales constantes y repetitivos de marcación de batidos; pero por otro lado y al mismo tiempo, un discurso musical atomizado, nota a nota, carente de fluidez y de sentido holístico de la estructura musical. El movimiento, por sus características topológicas y morfológicas, parece estar favoreciendo un aspecto de la ejecución, pero al mismo tiempo, 
perjudicando una comprensión más holística de la melodía, y en consecuencia, interfiriendo en la construcción del significado musical. Esta diferencia entre las ejecuciones de los participantes, en la relación entre el movimiento corporal y la resultante sonora en términos expresivos, da cuenta, una vez más, del vínculo estrecho y significativo que existe entre el cuerpo y el modo particular de sentir, construir significado musical y expresarlo en la ejecución.

Pero, ¿es posible hablar de expresión, en términos del manejo de los atributos expresivos para comunicar la interpretación de la estructura musical, en la lectura a primera vista? Como ya se mencionó, desde el punto de vista de la construcción de sentido para la configuración de la tarea de descodificación en la lectura, resulta difícil de sostener que la expresión es un agregado a una estructura musical preexistente, o dicho de otro modo, que los ejecutantes necesiten resolver las notas y los ritmos para luego trabajar sobre los atributos expresivos que permitan agregarle algo expresión. De ser así, leer a primera vista sería una tarea, por definición, carente de expresión. Sin embargo, tanto los desarrollos teóricos de diferentes autores (ver por ejemplo, Salgado Correia, 1999; Cox, 2001) como la evidencia empírica recogida en esta Tesis (ver estudios 3 y 4 en el capítulo 4), sustentan la idea de que el sentido expresivo es una construcción corporizada en vinculación a la demanda de la propia ejecución. Así, no sólo se puede hablar de expresión musical en la lectura a primera vista, sino que también se puede pensar en una participación activa y necesaria del cuerpo y el gesto tanto en los procesos de significación musical a partir de la lectura como en la expresión de tales significados. Si bien esto puede parecer contradictorio con la definición de gesto adoptada en esta Tesis, en la cual la intención comunicativa no es condición necesaria para que un movimiento sea considerado gesto, no es así. Básicamente, porque la elusión de la comunicación como condición necesaria resuelve el problema de la necesidad de que exista un interlocutor a quien se le expresen los significados, en relación con la gran cantidad de gestos observados durante momentos de lectura en solitario (ver estudio 2 en capítulo 3 ). Esto no significa que no hay expresión (en términos de elaboración corporal expresiva del sentido musical) en los gestos desplegados durante esos momentos, sino que no hace falta que se establezca una comunicación expresiva para que un determinado movimiento corporal sea considerado gesto.

Finalmente, los resultados obtenidos en esta Tesis apoyan la idea de que la construcción de significados musicales está íntimamente ligada a la interacción corporal con el medio musical, y brindan una alternativa al modo clásico de entender la participación del cuerpo en las tareas de lectura a primera vista. De este modo, el cuerpo no es solamente una base material para los 
procesos cognitivos desplegados para resolver la tarea, o para la representación del proceso interno, sino más bien es el proceso cognitivo mismo. El movimiento corporal es parte de la construcción de los significados musicales en los que se basa la habilidad de leer a primera vista. En tal sentido, no debiera ser pensado como una estrategia exitosa para resolver la tarea, sino como el modo en que se siente la música, se construye el significado relativo a ella y se expresa ese significado. 


\section{Referencias}

Banton, L. J. (1995) 'The Role of Visual and Auditory Feedback During the Sight-Reading of Music', Psychology of Music 23(1): 3-16.

Boersma, P. y Weenink, D (2001) PRAAT, a system for doing phonetics by computer, Glot International 5(9/10), pp. 341-345.

Callejas Leiva, D. y Jacquier, M. de la P. (2011). Observaciones a estudios de la experiencia musical que implican a la teoría de la metáfora. En A. Pereira Ghiena, P. Jacquier, M. Valles y M. Martínez (Eds.) Musicalidad Humana: Debates Actuales en Evolución, Desarrollo y Cognición e Implicancias Socio-Culturales. Buenos Aires: SACCoM, pp. 4960.

Chemero, A. (2009). Radical Embodied Cognitive Science. Cambridge: MIT Press.

Clark, A. (1999). Estar ahí. Cerebro, Cuerpo y Mundo en la Nueva Ciencia Cognitiva. Barcelona: Paidos.

Clark, A. (2008). Embodiment and explanation. En P. Calvo y T. Gomila (Ed.) Handbook of Cognitive Science. An Embodied Approach. San Diego: Elsiever Ltd, pp. 41-58.

Clark, A. y Chalmers, D. (1998). The Extended Mind. En http://consc.net/papers/extended.html (Página consultada el 20-02-2010).

Clarke, E. (2005). Ways of Listening: An Ecological Approach to the Perception of Musical Meaning. Oxford: Oxford University Press.

Colles H. C./Ward Jones, P. y Rainbow, B. (2001). "Curwen" The New Grove Dictionary of Music and Musicians ( $2^{\circ}$ Edición). Oxford University Press.

Cox, A. (2001). The mimetic hypothesis and embodied musical meaning. Musicæ Scientiæ, 5 2, 195-212.

Damasio, A. (1999). The Feeling of What Happens: Body, Emotion and the Making of Consciousness. Vintage, London.

Davidson, J. W. (2001). The role of the body in the production and perception of solo vocal performance: A case study of Annie Lennox. Musicæ Scientiæ, 2 (V), pp. 235-256.

Delalande, F. (1988). La gestique de Gould; éléments pour une sémiologie du geste musical. En L. Courteau (Ed.), Glenn Gould pluriel. Montréal: Guertin G.

Ekman, P. y Friesen, W. V. (1969). The repertoire of nonverbal behavioral categories: origins, usage, and coding. Semiotica, 1, pp. 49-98. 
Ekman, P. y Friesen, W. V. (1969). The repertoire of nonverbal behavioral categories: origins, usage, and coding. Semiotica, 1, pp. 49-98.

Fine, P., Berry, A., y Rosner, B. (2006). The effect of pattern recognition and tonal predictability on sight-singing ability. Psychology of Music 34, 431-447.

Fodor, J. y Pylyshyn, Z. (1988). Connectionism and Cognitive Architecture .Cognition , 28 , 3 71.

Fodor, J. (2009). Where is the Mind? London Review of Books, 31 (3), 13-15.

Gallagher, S. (2005). How the Body Shapes the Mind. Oxford: Clarendon Press.

Gibbs Jr., R. (2006). Embodiment and Cognitive Science. Cambridge: Cambridge University Press.

Gibson, J. (1979). The Ecological Approach to Visual Perception. Hillsdale, NJ: Lawrence Erlbaum.

Gomila, T. y Calvo, P. (2008). Directions for an Embodied Cognitive Science: Toward an Integrated Approach. En P. Calvo y T. Gomila (Eds.) Handbook of Cognitive Science: An Embodied Approach. San Diego: Elsevier, pp. 1-25.

Jander, O. (2001). " Solfeggio [solfège]" The New Grove Dictionary of Music and Musicians ( $2^{\circ}$ Edición). Oxford University Press.

Johnson, M. (2007). The Meaning of the Body. Aesthetics of human understanding. Chicago: The University of Chicago Press.

Johnson, M. y Larson, S. (2003). "Something in the way she moves": metaphors of musical motion. Metaphor and Symbol, 18(2), 63-84.

Kandel, E. R.; Schwartz, J. H. y Jessell, T. M. (2001). Principios de la neurociencia. McGraw Hill. Interamericana.

Karpinski, G. S. (2000). Aural Skills Acquisition: The Development of Listening, Reading, and Performing Skills in College-Level Musicians. Oxford: Oxford University Press.

Killian, J. N. y Henry, M. L. (2005). A comparison of successful and unsuccessful strategies in individual sight-singing preparation and performance. Journal of Research in Music Education, 53, 51-65.

Kirsh D. (1995). Complementary Strategies: Why we use our hands when we think. En J.D. Moore y J.F. Lehman (Eds.), Proceedings of the Seventeenth Annual Conference of the Cognitive Science Society. Hillsdale, NJ: Lawrence Erlbaum.

Kirsh, D. (2009). Interaction, External Representations and Sense Making. En N. A. Taatgen y H. van Rijn (Eds.), Proceedings of the 31st Annual Conference of the Cognitive Science Society (pp. 1103-1108). Austin, TX: Cognitive Science Society.

Kirsh, D. y Maglio, P. (1994). On distinguishing epistemic from pragmatic action. Cognitive Science 18, pp. 513-549. 
Kohn, D y Eitan, Z. (2009) Musical Parameters and Chidren's Movement Responses. En Proceedings of the 7th Triennial Conference of European Society for the Cognitive Sciences of Music (ESCOM 2009) Jyväskylä, Finland.

Kornicke, L. E. (1995). An exploratory study of individual difference variables in piano sightreading achievement. Quarterly Journal of Music Teaching and Learning , 6 (1), 5679.

Kuehne, J. M. (2010). Sight-Singing: Ten Years of Published Research. Applications of Research in Music Education, 29:7, pp. 7-14.

Kurtenbach, G. y Hulteen, E. A. (1990). "Gestures in Human-Computer Communication." In B. Laurel, ed. The Art of Human-Computer Interface Design. Addison Wesley. pp. 309317.

Laban, R. (1970 [1989]). Danza Educativa Moderna. México: Paidós.

Lakoff, G. (1990). The invariance hypothesis: is abstract reason based on image-schemas? Cognitive Linguistics, 1(1), 39-74.

Lakoff, G. (1993). The contemporary theory of metaphor. En A. Ortony (Ed.) Metaphor and thought. New York: Cambridge University Press.

Lakoff, G. y Johnson, M. (1980). Metaphors We Live By [Metáforas de la vida cotidiana (C. González Marín, trad.). Madrid: Ediciones Cátedra, 1998]. Chicago: University of Chicago.

Lakoff, G. y Johnson, M. (1999). Philosophy in the flesh. The embodied mind and its challenge to Western Thought. New York: Basic Books.

Lehmann, A.C. and McArthur V. (2002) 'Sight-Reading', in R. Parncutt and G.E. McPherson (eds) The Science and Psychology of Music Performance: Creative Strategies for Teaching and Learning, pp. 135-50. Oxford: Oxford University Press.

Lehmann, A.C. y Kopiez, R. (2009). Signt-Reading. In S. Hallam, I. Cross \& M. Thaut (Eds.) (2009). The Oxford handbook of music psychology (pp. 344-351). Oxford: Oxford University Press.

Lehmann, C.A. and Ericsson, K.A. (1993) 'Sight-Reading Ability of Expert Pianists in the Context of Piano Accompanying', Psychomusicology 12: 182-95.

Lehmann, C.A. and Ericsson, K.A. (1996) 'Performance without Preparation: Structure and Acquisition of Expert Sight-Reading and Accompanying Performance', Psychomusicology 15: 1-29.

Leman, M. (2008). Embodied Music Cognition and Mediation Technology. Cambridge: the MIT Press.

Leman, M. (2010). Music, gesture, and the formation of embodied meaning. En R. Godoy y M. Leman (eds.). Musical gestures. Sound, movement and gestures. Londres: Routledge, pp. 126-153. 
Lerdahl, F. y Jackendoff, R. (1983). A generative Theory of Tonal Music [Teoría generativa de la música (J. González-Castelao, trad.). Madrid: Ed. Akal, 2003]. Massachusetts: MIT Press.

López Cano, R. (2005). Los cuerpos y la música. Introducción al dossier Música, Cuerpo y Cognición. Revista Transcultural de Música, 9, en http://www.sibetrans.com/trans/trans9/cano2.htm (página consultada el 22/08/2010)

López Cano, R. (2009). Música, cuerpo, mente extendida y experiencia artística. La gesticulación de Keith Jarret en su Tokio Encore '84. En P. Asís y S. Dutto (Comp.) La Experiencia Artística y la Cognición Musical. Villa María: UNVM.

Maglio, P. y Kirsh, D. (1996). Epistemic action increases with skill. En Proceedings of the Eighteenth Annual Conference of the Cognitive Science Society, pp. 391-396, Mahwah, NJ. LEA.

Maglio, P. y Wenger, M. J. (2000). Two views are better than one: Epistemic actions may prime. En Proceedings of the Twenty-second Annual Conference of the Cognitive Science Society, Mahwah, NJ. Erlbaum.

Marc Leman y Rolf Godøy (2010). Why Study Musical Gestures?. En R. Godoy y M. Leman (eds.). Musical gestures. Sound, movement and gestures. Londres: Routledge, pp. 311.

Martínez Manrique, F. (1999). Prólogo: Del conexionismo a la mente corpórea y embebida. En A. Clark Estar ahí. Cerebro, Cuerpo y Mundo en la Nueva Ciencia Cognitiva. Barcelona: Paidos.

Martínez, I. (2005). La audición imaginativa y el pensamiento metafórico en la música. En F. Shifres (Ed.) Actas de las I Jornadas de Educación Auditiva. La Plata: CEA Ediciones, pp. 47-72.

Mauleón, C. (2008). Las Bases Psicológicas de la Interpretación en el Canto. Tesis de doctorado inédita. Universidad de París X - Nanterre.

McNeill, D. (1992). Hand and Mind. What gestures reveal about thought. Chicago y Londres: The University of Chicago Press.

Menary, R. (Ed.). (2010). The Extended Mind. Cambridge: MIT Press.

Mithen, S. (1996) The Prehistory of the Mind: A search for the origins of art, religion and science. London: Thames and Hudson (trad. cast. de M. J. Aubet: Arqueología de la mente: Orígenes del arte, de la religión y de la ciencia. Barcelona: Crítica. 1998).

Neth, H. y Payne, S. J. (2001). Addition as interactive problem solving. En J.D. Moore, y K. Stenning (Eds.), Proceedings of the Twenty-third Annual Conference of the Cognitive Science Society (pp. 698-703). Mahwah, NJ: Lawrence Erlbaum.

Neth, H., y Payne, S. J. (2002). Thinking by Doing? Epistemic Actions in the Tower of Hanoi. En W.D. Gray and C.D. Schunn (Eds.), Proceedings of the Twenty-Fourth Annual Conference of the Cognitive Science Society (pp. 691-696). Mahwah, NJ: Lawrence Erlbaum. 
Noë, A. (2004). Action in Perception. Cambridge: MIT Press.

Peñalba, A. (2005). El cuerpo en la música a través de la teoría de la metáfora de Johnson: Análisis crítico y aplicación a la música. TRANS Revista Transcultural de Música, 9, s/p.

Rayner, K. and Pollatsek, A. (1997) 'Eye Movements, the Eye-Hand Span, and the Perceptual Span During Sight-Reading of Music', Current Directions in Psychological Science 6(2): 49-53.

Real Academia Española. (2012). Diccionario de la lengua española (22.a ed.). Consultado en http://www.rae.es/rae.html

Repp, B. H. (1998d). A microcosm of musical expression. I. Quantitative analysis of pianists' timing in the initial measures of Chopin's Etude in E major. Journal of the Acoustical Society of America, 104 (2), 1085-1100.

Rizzolatti, G.; Fogassi, L. y Gallese, V. (2007). Neuronas espejo. En Investigación y Ciencia, N. 364. Barcelona, pp. 14-21.

Salgado Correia, J. (1999). Embodied Meaning: All Languages are Ethnic.... Psychology of Music, 27, 96-101.

Schögler, B. y Trevarthen, C. (2007) To sing and dance together. En S. Bråten (Ed.) On Being Moved. From Mirror Neurons to Empathy. Amsterdam: John Benjamins Publishing Company, pp. 281-302.

Shifres, F. (2007). Poniéndole el cuerpo a la Música. Cognición corporeizada, movimiento, música y significado. Actas de las III Jornadas de Investigación Artísticas y Proyectuales.

Shifres, F. (2009) Movement and the Practice of Meaning in Song. En Jukka Louhivuori, Tuomas Eerola, Suvi Saarikallio, Tommi Humberg y Päivi-Sisko Eerola (Editores). Proceeding of the 7th Triennial Conference of European Society for the Cognitive Sciences of Music (ESCOM 2009). Jyväskylä, Finlandia. Pp, 495-502.

Sloboda, J. A. (1974). The eye-hand span. An approach to the study of sight reading. Psychology of Music , 2, 4-10.

Stern, D. (1985). The interpersonal world of the infant. New York: Basic Books.

Stern, D. (2010). Forms of vitality. Exploring dynamic experience in Psychology, the Arts, Psychoterapy and Development. Oxford: Oxford University Press.

Tropea, A.; Shifres, F. y Massarini, A. (en prensa). El origen de la musicalidad humana. Alcances y limitaciones de las explicaciones evolutivas. En S. Español (Ed.). Musicalidad humana. Una exploración interdisciplinaria. Buenos Aires: Paidós.

Valsiner, J. (2006). Developmental Epistemology and implications for methodology. En W. Damon y R. Lerner (Eds.) Handbook of Child Psychology. Vol 1. Theoretical Models of Human Development. Nueva York: John Wiley and Sons, pp. 165-209. 
Varela, F. (1988). Connaître: Les Sciences Cognitives, Tendances et Perspectives [Conocer : Las Ciencias Cognitivas, Tendencias y Perspectivas. Cartografía de las Ideas Actuales (C. Gardini, trad.). Barcelona: Ed. Gedisa, 2005]. Paris: Editions du Seuil.

Ward, D. y Burns, E. (1978) 'Singing without Auditory Feedback', Journal of Research in Singing 1: 24-44.

Waters, A. J.; Townsend, E. y Underwood, G. (1998). Expertise in musical sight-reading: a study of pianists. British Journal of Psychology , $89,123-149$.

Zbikowsky, L. (1997). Conceptual models and cross-domain mapping: new perspectives on theories of music and hierarchy. Journal of Music Theory, 41(2), 193-225. 
Anexos 


\section{Anexo 1}

\section{Descripción de los movimientos típicos desplegados con las manos por el participante seleccionado en el estudio 2}

M1 (movimiento1): cierra el pulgar hacia la palma (cierre de pulgar)

M2: señala (o representa) un punto en el espacio (con un dedo, con varios, con la palma, o con el movimiento de la mano en general)

- Sm2.a (Submovimiento 2.a.): hacia adelante y abajo, con la mano semicerrada, a la altura del pecho.

- sm2.b.: hacia arriba y adelante con el dedo índice mayormente estirado, a la altura del pecho.

- sm2.c.: cierra los dedos índice y pulgar en forma de pinza, con la palma hacia arriba a una altura entre el pecho y la cintura.

- sm2.d.: hacia adelante y abajo con la palma hacia arriba, dedos semicerrados, índice y pulgar en pinza, abriendo levemente los dedos cuando señala

- sm2.e.: hacia atrás y a la izquierda rotando la mano sobre el eje del codo, con la mano cerrada.

- Sm2.f.: señala sucesivamente 2 puntos hacia abajo describiendo una trayectoria circular en el plano sagital/vertical, hacia abajo y atrás con la mano semiabierta.

- Sm2.g.: hacia adelante, con los dedos mayor y pulgar en pinza, anular y meñique semi cerrados, e índice levemente más estirados que los demás señalando hacia adelante.

- Sm2.h.: con la palma hacia arriba, a la altura del pecho, dedos semi arrollados, señala hacia adelante y con el dedo índice.

- Sm2.i.: con la palma hacia arriba, a la altura del pecho, dedos semi arrollados, señala hacia atrás y con el dedo índice.

- Sm2.j.: Con la palma hacia arriba, dedos cerrados, señala con la mano hacia abajo y atrás (con o sin rotación de muñeca).

- Sm2.k.: mueve la mano hacia su propio cuerpo, a la altura del hombro hasta quedar con la palma de cara hacia atrás y estira los dedos hacia arriba, haciendo un pequeño movimiento hacia adelante.

- Sm2.I.: mueve la mano su cuerpo y luego hacia adelante, a la altura del hombro, con la palma hacia atrás, mientras arrolla ligeramente los dedos;

M3: Coloca la mano izquierda tomándose el costado derecho del cuerpo y la derecha sobre el codo izquierdo (cruce de brazos incompleto)

M4: con movimientos hacia adelante y hacia atrás del dedo índice roza la uña del pulgar (manos detrás de la espalda)

M5: movimiento ascendente y descendente con chasquido en el descenso. 


\section{Descripción de todos los movimientos de las manos desplegados por el participante seleccionado en el estudio 2}

1. 0:00 a 0:04. Mantiene las manos juntas detrás de la espalda, con la cara dorsal contra el cuerpo, sin moverlas.

2. 0:04. Cierra la mano derecha (manos detrás de la espalda)

3. 0:04 a 0:06. Mueve el pulgar de la mano derecha con la mano cerrada rozándose las uñas de los otros dedos de la misma mano. Plano horizontal. (manos detrás de la espalda)

4. 0:32. Abre la mano derecha y coloca la cara dorsal de esa mano sobre la palma de la mano izquierda, y la toma con ella. (manos detrás de la espalda)

5. 0:39 a 0:40. Mueve el pulgar de la mano derecha hasta que toma contacto con la palma. (m1) Luego lo separa levemente, lo vuelve a juntar y a separar (manos detrás de la espalda)

6. 0:40 a 0:42. Mueve levemente los dedos de la mano derecha (aparentemente todos menos el pulgar) y el meñique de la izquierda separándolo de los dedos de la mano derecha y volviéndolo a juntar como acomodando la posición de la mano izquierda agarrando la derecha. (manos detrás de la espalda)

7. 0:43 a 0:44. Mueve el meñique de la mano izquierda separándolo de los dedos de la mano derecha y volviéndolo a juntar. (manos detrás de la espalda)

8. 0:47. Mueve el meñique de la mano izquierda como si fuera a separarlo de los dedos de la derecha pero no se separa, sigue en contacto. (manos detrás de la espalda)

9. 0:52. Cierra el pulgar de la mano derecha hacia la palma (m1). (manos detrás de la espalda)

10. 0:54. Separa el pulgar de la mano derecha de la palma. Vuelve a la posición previa al movimiento anterior. (manos detrás de la espalda)

11. 0:58. Cierra el meñique de la mano izquierda levemente hacia la palma presionando los dedos de la mano derecha y lo abre. (manos detrás de la espalda)

12. 1:00 a 1:06. Cierra lentamente los dedos de la mano izquierda hacia la palma comenzando por el meñique, apretando los dedos de la derecha. Luego los vuelve a abrir y a cerrar con mayor velocidad. (manos detrás de la espalda) 
13. 1:07 a 1:09. Mano izquierda. La separa de la derecha y la lleva hacia adelante del cuerpo, y se toma la remera a la altura del pecho, la estira levemente hacia adelante y luego la suelta.

14. 1:07 a 1:09. Mano derecha. 2 Momentos: (i) la separa de la izquierda y la lleva adelante del cuerpo a la altura del pecho, y señala un punto en el espacio con la mano semi cerrada, hacia adelante y abajo (planos vertical y sagital) (sm2.a); y (ii) retrae un poco la mano y señala otro punto hacia arriba y adelante, ahora con el dedo índice mayormente estirado (planos vertical y sagital) (sm2.b).

15. 1:09 a 1:10. Desplaza la mano izquierda hacia el costado derecho del cuerpo y con la mano derecha se toma el codo izquierdo, como un cruce de brazos incompleto (m3). Luego mantiene los brazos en esa posición (plano horizontal, vertical y sagital)

16. 1:11 a 1:15. Mano derecha. 5 momentos: (i) suelta el codo izquierdo y desplaza la mano hacia adelante, señalando un punto en el espacio similar al sm2.b, pero girando la mano levemente hacia la izquierda hasta quedar con la palma casi hacia arriba; (ii) cierra el índice y el pulgar en forma de pinza y gira un poco más la mano hacia la izquierda (sm2.c); (iii) realiza un movimiento corto en trayectoria pero veloz hacia adelante girando un poco más la mano hasta quedar con la palma totalmente apuntando hacia arriba, a la vez que abre levemente los dedos de la mano, pero sin despegar el índice del pulgar (sm2.d); (iv) desplaza la mano hacia atrás y hacia la izquierda a medida que la rota hacia la izquierda sobre el codo y luego la detiene levemente (sm2.e); (v) iniciando en la posición anterior vuelve a realizar el sm2.e. plano sagital mayormente

17. 1:15 a 1:16. Mueve la mano derecha hasta volver a la posición de cruce de brazos incompleto $(\mathrm{m} 3)$

18. 1:17 a 1:20. Mano derecha. 4 momentos: (i) suelta el codo izquierdo y desplaza la mano hacia adelante y abajo a la altura de la cintura con los dedos semi cerrados (sm2.a más abajo); (ii) sm2.b pero con los dedos índice y pulgar en pinza, y abre los otros levemente cuando señala; (iii) señala sucesivamente 2 puntos hacia abajo describiendo una trayectoria circular (una circunferencia y media) en el plano sagital/vertical, hacia abajo y atrás con la mano semiabierta (sm2.f.); (iv) sm2.b pero con pulgar estirado hacia arriba. (planos vertical y sagital) 
19. 1:20 a 1:22. Mano derecha. Se frota la cabeza con la palma comenzando en la parte frontal superior y finalizando en la occipital (nuca). (planos sagital y vertical)

20. 1:17 a 1:21. Mano izquierda. Se toma la remera a la atura de la cintura, la estira y la acomoda, y luego se lleva la mano al bolsillo izquierdo e introduce el pulgar.

21. 1:21 a 1:22. Mano izquierda. Con el pulgar en el bolsillo cierra los dedos mayor, anular y meñique hacia la palma.

22. 1:22 a 1:23. Mano derecha. 2 momentos: (i) señala hacia adelante, con los dedos mayor y pulgar en pinza, anular y meñique semi cerrados, e índice levemente más estirados que los demás señalando hacia adelante (sm2.g); (ii) sm2.b más adelante en el plano sagital y más abajo en el plano vertical que la posición anterior, pero señalando un punto más alto con el índice. (Planos vertical y sagital)

23. $1: 23$ a 1:25. Lleva las manos hacia la espalda y se toma la muñeca derecha con la mano izquierda.

24. 1:27 a 1:30. Mano derecha. 4 momentos: (i) levanta el índice levemente y lo vuelve a bajar; (ii) arrolla el pulgar y con ese dedo presiona el mayor moviéndolo hacia abajo, luego vuelve a estirar el pulgar; (iii) arrolla nuevamente el pulgar y lo vuelve a estirar (similar al m1) (manos detrás de la espalda)

25. 1:54 a 1:56. Mano derecha. 2 momentos: (i) Arrolla el dedo índice y con el costado de la falange distal empuja el pulgar corriéndolo levemente hacia la palma (m2 ayudado); (ii) con movimientos hacia adelante y hacia atrás del dedo índice roza la uña del pulgar (manos detrás de la espalda) (m4).

26. 1:57 a 1:59. Mano derecha. 2 momentos: (i) m4 y luego frota las yemas de los dedos índice y pulgar: (ii) m1 y continúa el mov presionando el dedo meñique con el pulgar hasta bajarlo de la línea de los otros dedos y vuelve a la posición anterior (manos detrás de la espalda)

27. 2:01 a 2:03. Mano derecha. 3momentos: (i) $\mathrm{m} 1$; (ii) $\mathrm{m} 1$ más arrollado que el anterior y acompañado de un leve descenso del meñique y su vuelta a la posición anterior; (iii) m1 más arrolado aun que los dos anteriores, acompañado hacia el final con un leve movimiento de descenso y ascenso de los otros dedos (manos detrás de la espalda) 
28. 2:11 a 2:12. Mano izquierda. Suelta a la mano derecha y la desplaza hacia adelante y hacia la derecha hasta tomarse el costado derecho del cuerpo como en el m3.

29. 2:11 a 2:16. Mano derecha. 5 momentos: (i) desplaza la mano hacia adelante con el dedo índice y el mayor en forma de pinza, los otros dedos están cerrados. Luego señala un punto hacia adelante (a la pantalla aparentemente) con el dedo índice estirado, los otros dedos se mantienen mayormente arrollados (sm2.b); (ii) sm2.b más a la derecha que el anterior, prácticamente a la misma altura. Describe una parábola larga desde la posición anterior hasta llegar a la nueva; (plano horizontal) (iii) sm2.b levemente hacia adelante; (iv) realiza 3 sm2.b muy cortos y seguidos, comenzando más arriba que la posición anterior, y señalando más abajo en cada sm, luego se detiene levemente; (v) sm2.b en el mismo lugar que el anterior, desplaza levemente hacia atrás y adelante. (la mayoría de estos movimientos, plano sagital)

30. 2:16 a 2:20. Mano derecha. 5 momentos: (i) rota la muñeca hasta quedar con la palma hacia arriba, dedos semi cerrados y señala con el índice hacia atrás acercándolo a la palma (sm2.i leve); (ii) sm2.h y luego sm2.i.; (iii) sm2.h en 2 posiciones distintas (1. con el índice apuntando hacia arriba y 2. con el índice hacia adelante). La segunda posición está acompañada de un desplazamiento de la mano hacia adelante; (iv) sm2.i en 2 posiciones, 1. dirigiendo la mano levemente hacia atrás y retrayendo levemente el índice, hasta quedar apuntando en diagonal hacia arriba y atrás, 2. Apuntando hacia atrás, y desplazando la mano hacia atrás; (v) en la posición anterior (sm2.i) realiza 3 rebotes de la mano, levantándola y bajándola.

31. 2:20 a 2:23. Mano derecha. 3 momentos: (i) $s m 2 . c$ hacia adelante y arriba; (ii) con la palma hacia arriba y los dedos arrollados, realiza un movimiento hacia abajo y atrás respecto de la posición anterior (sm2.j), y luego vuelve a realizar este movimiento más atrás y un poco más abajo, rotando levemente la muñeca hacia atrás, acercando la mano al cuerpo (iii) levanta la mano abriendo un poco los dedos y luego realiza el sm2.j dos veces en la misma posición, el segundo levantando menos la mano antes de volverla a bajar, (iv) luego levanta levemente la mano abriendo muy poquito los dedos como para volver a realizar el sm2.j, pero la detiene arriba. (plano sagital) 
32. $2: 23$ a 2:24. Mano derecha. Levanta la mano hasta casi tocar su pera, a medida que la va abriendo, cuando llega a la máxima altura la abre completamente. (plano vertical y en menor medida sagital)

33. 2:24 a 2:30. Mano derecha. 7 momentos: (i) $\mathrm{m} 5$ pero solamente la baja porque comienza el mov desde la posición anterior, en la que la mano ya estaba arriba; (ii) m5 más amplio que el anterior, llega a un punto más bajo; (iii) m5 más amplio aun que el anterior, va más arriba y más abajo; (iv) m5 más reducido que los anteriores, cuando desciende llega a un punto más alto que estos; (v) m5 muy similar al iv, levemente más reducido; (vi) m5 muy similar al v, levemente más reducido aun; (vii) m5 más reducido que todos los anteriores, levanta levemente la mano pero realiza el chasquido arriba, sin volver a bajarla; luego detiene levemente la mano. (planos vertical y sagital)

34. 2:30 a 2:31. Mano derecha. M5 similar al vii del mov anterior, pero más arriba, y detiene levemente luego del chasquido.

35. 2:31 a 2:36. Mano derecha. 4 momentos: (i) m5, finalizando más abajo que el anterior; (ii) m5 más abajo que (i); (iii) m5 más amplio y más bajo que (ii); (iv) $\mathrm{m} 5$ reducido, poco recorrido, finaliza más arriba que el anterior. (planos vertical y sagital); (v) luego levanta levemente la mano y abre los dedos un poco, como para realizar el $\mathrm{m} 5$, pero detiene el movimiento ligeramente.

36. 2:36 a 2:42. Mano derecha. 5 momentos: (i) $\mathrm{m} 5$, pero bastante amplio y veloz, y rotando levemente la muñeca casi hasta poner la palma hacia abajo; (ii) $\mathrm{m} 5$ más reducido y descendiendo menos que el anterior; (iii) $\mathrm{m} 5$ nuevamente aumentando el descenso y rotando la muñeca; (iv) m5 igual al (ii); (v) m5 muy reducido realizado más arriba que los demás, y girando un poco la palma hacia arriba. (planos vertical y sagital)

37. 2:42 a 2:44. Mano derecha. 3 momentos: (i) mueve la mano hacia su propio cuerpo, a la altura del hombro hasta quedar con la palma de cara hacia atrás y estira los dedos hacia arriba, haciendo un pequeño movimiento hacia adelante (sm2.k); (ii) mueve la mano otra vez hacia su cuerpo y luego hacia adelante, a la altura del hombro, con la palma hacia atrás, mientras arrolla ligeramente los dedos (sm2.I); (iii) sm2.I reducido en desplazamiento. (planos vertical y sagital)

38. 2:44 a 2:47. Mano derecha. 4 momentos: (i) $\mathrm{m} 5$ con la palma orientada hacia su cuerpo, con muy poco recorrido comenzando a la altura del hombro; (ii) 
m2.i; (iii) m2.h adelante y arriba, estirando un poco los demás dedos; (iv) m5 similar al (i) pero con la mano un poco más abajo, posición que genera que la palma esté mayormente orientada hacia arriba. (planos vertical y sagital)

39. 2:47 a 2:48. Mano derecha. sm2.g con el índice mayormente estirado hacia adelante, cara dorsal de la mano hacia arriba. (plano sagital) 


\section{Anexo 2}

\section{Protocolo para jueces (Estudio 2)}

\section{Clasificación de los gestos manuales en las tareas de lectura a primera vista}

Estimado colega: muchas gracias por colaborar en esta investigación. La tarea que se le solicita es clasificar los gestos señalados en los videos de acuerdo a las categorías presentadas en el gráfico. Para ello, se adjunta un archivo de Excel que contiene dos tablas (una para la mano derecha y otra para la izquierda) en las que deberá indicar la/s categoría/s de cada uno de los gestos.

La primera columna es para la categoría que considera más adecuada para cada gesto. En ella debe escribir alguno de los códigos resaltados con amarillo que representan las categorías (en la primera columna no deben quedar celdas en blanco).

Si considera que un mismo gesto puede incluirse en más de una categoría, señale todas ellas (completando las columnas siguientes de acuerdo al orden que considere apropiado), siempre y cuando esas categorías no estén relacionadas de forma inclusiva. Si usted cree que un gesto está acompañado del canto, está directamente vinculado a un aspecto musical, y es un batido, debe consignar en la primera celda A.1.2 únicamente, porque se sobreentiende que pertenece además a las categorías A y A.1. Con respecto a los gestos vinculados a las alturas, debe indicar A.1.1 y luego señalar si es un gesto deíctico o no deíctico. Proceda del mismo modo en la categoría de los gestos vinculados a aspectos melódicos.

Observe los gestos en la toma de perfil, y utilice la toma de frente en caso de dudas, o de que el gesto no pueda observarse completamente en la primera.

Si considera que no es posible incluir alguno de los gestos analizados en las categorías presentadas, le pedimos que lo indique con la letra $\mathbf{C}$, y que describa brevemente el gesto y las razones por las que considera que no encuadra en ninguna categoría. 


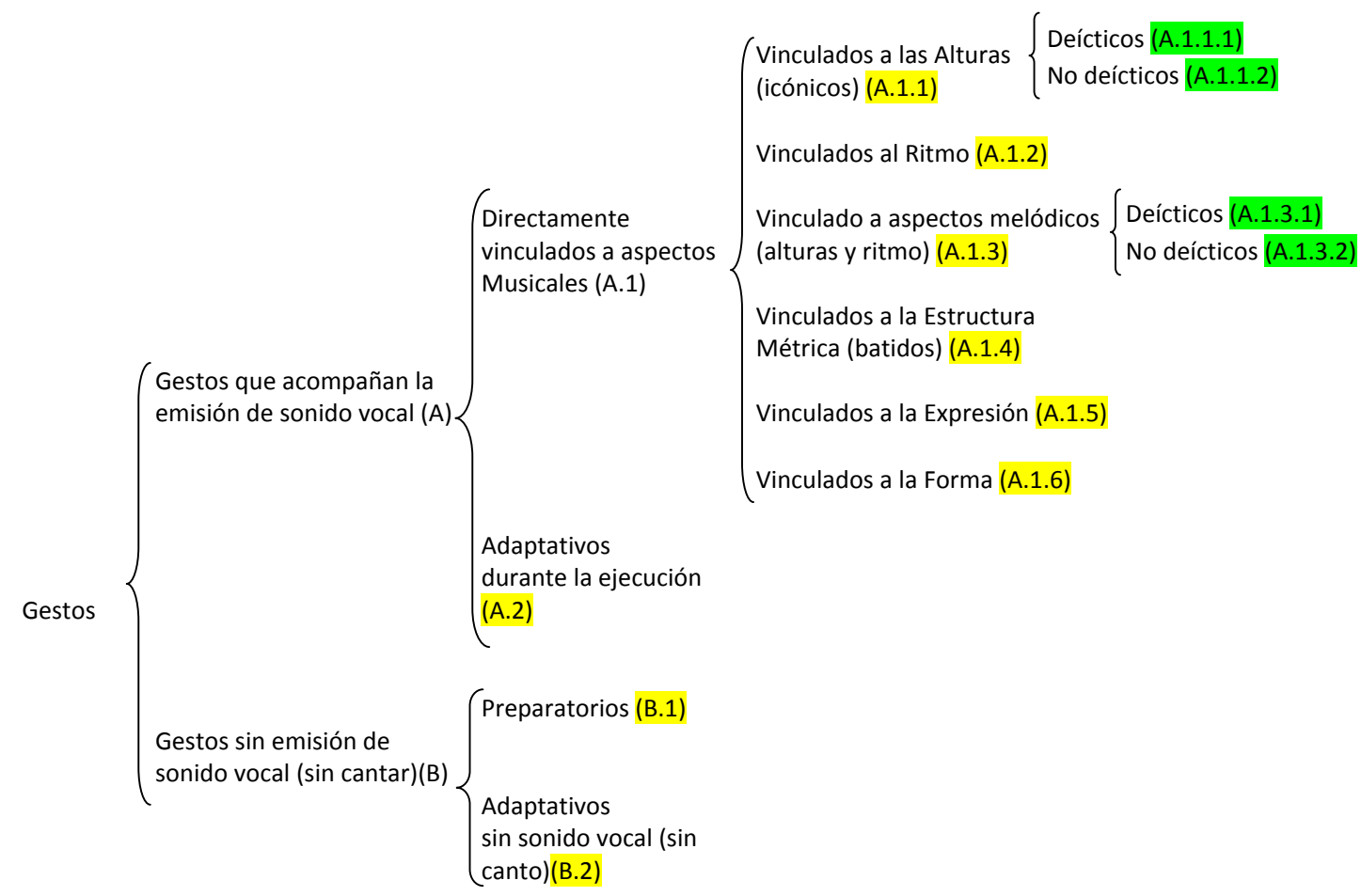

Gestos que no se ajustan a ninguna de las categorías anteriores (C)

Gráfico. Categorías de gestos manuales desplegados en tareas de lectura musical cantada a

primera vista

\section{Descripción de las categorías}

Para este tipo de tareas, el gesto fue definido como todo movimiento o grupo de movimientos que conforma una unidad mínima de sentido completo, observando que no se pierdan las posibles vinculaciones con la estructura musical.

La clasificación inicial de los movimientos en gestos que acompañan la emisión de sonido vocal y gestos sin emisión de sonido vocal (sin canto) obedece a la necesidad de distinguir los gestos que poseen relación directa y explícita con las características de la estructura musical de aquellos de los que no se tiene una referencia explícita. La primera alude a todos los movimientos que el sujeto realiza mientras canta; y la segunda, a aquellos producidos en ausencia del canto, aun cuando se perciban palabras u otros sonidos.

Los gestos adaptativos, entendidos como movimientos que surgen como respuesta a estados internos del sujeto y se orienta a compensarlos, equilibrarlos, modificarlos, etc.; ayudan a la autoestimulación y autoequilibrio, podrían aparecer tanto durante la emisión de sonido vocal 
como en momentos de silencio, es por ello que forman parte de ambas categorías. Son movimientos que pueden exhibir características personales y estados internos, como rascarse, acomodarse la ropa, acariciarse, etc.

Los gestos directamente vinculados a aspectos musicales refieren a todos aquellos movimientos que representan algún rasgo musical, y por lo tanto, puede advertirse una relación entre el gesto y la estructura musical de la melodía leída. Para poder establecer este tipo de relaciones es necesario que los gestos sean desplegados al mismo tiempo que la ejecución vocal de la melodía. A su vez, estos gestos se pueden clasificar de acuerdo al aspecto musical con el que se vinculan en: vinculados a las alturas (por ejemplo, señalar puntos sucesivos en el espacio, cada vez más abajo, mientras se canta un giro melódico descendente); vinculados a la estructura métrica (o batidos, por ejemplo, mover una mano hacia arriba y hacia abajo varias veces coincidiendo con algún nivel de pulso de la estructura métrica de la melodía); vinculados al ritmo (por ejemplo, golpear la pierna coincidiendo con las articulaciones del canto); vinculados a aspectos melódicos (gestos que representan tanto relaciones de altura como aspectos rítmicos); vinculados a la expresión (por ejemplo, movimientos continuos en partes cantadas legato); y vinculados a la forma (por ejemplo, movimientos que marcan puntos de articulación formal). Los gestos que se vinculan a las alturas y a aspectos melódicos pueden ser tanto deícticos, en los que las relaciones entre alturas se representan a través del señalamiento de puntos en el espacio, como no deícticos, en los que el vínculo puede establecerse por otro tipo de movimientos, como por ejemplo, cambios de posición de la mano.

Los gestos preparatorios son muy similares a los gestos que se vinculan a algún aspecto musical, pero que al presentarse en ausencia del canto, no puede establecerse una relación directa con dichos aspectos. 


\section{Anexo 3}

\section{Protocolo para jueces (estudio 3)}

\section{Evaluación de ejecuciones de melodías cantadas a primera vista}

Estimado colega, le agradecemos por acceder a participar en esta investigación. La tarea que usted debe realizar consiste en evaluar ejecuciones de melodías cantadas a primera vista, de acuerdo al criterio que utiliza normalmente para evaluar este tipo de tareas. Cada ítem deberá ser evaluado en una escala de 0 a 10, en la cual 0 representa un nivel nulo de desempeño y 10 un desempeño excelente. Por favor, utilice únicamente 0 ó números enteros. Le pedimos que vuelque su evaluación en el cuadro que se encuentra más abajo. Recuerde que puede volver a escuchar, volver atrás, comparar las ejecuciones, etc.

En la página siguiente encontrará las partituras de las 4 melodías que fueron leídas en estas ejecuciones.

A continuación se presenta una breve explicación de cada ítem.

1. Ejecución: aquí deberá completar el número de la ejecución que figura en el reproductor y que está evaluando. Esto nos permitirá corroborar que le fue dado el orden correctamente.

2. Evaluación global: refiere a una evaluación de la ejecución en términos generales.

3. Ritmo: refiere al ajuste rítmico de la ejecución.

4. Afinación: alude a cuan afinada es la ejecución.

5. Fidelidad: refiere a cuánto se ajusta la ejecución al modelo de la partitura leída.

6. Expresión: refiere a cuan expresiva es la ejecución. 
Planilla para el volcado de datos

\begin{tabular}{|c|c|c|c|c|c|c|}
\hline $\begin{array}{l}\text { Nro. de } \\
\text { Orden }\end{array}$ & $\begin{array}{l}\text { Nro. de } \\
\text { Ejecución }\end{array}$ & $\begin{array}{c}\text { Evalución } \\
\text { global }\end{array}$ & Ritmo & Afinación & Fidelidad & Expresión \\
\hline 1 & & & & & & \\
\hline 2 & & & & & & \\
\hline 3 & & & & & & \\
\hline 4 & & & & & & \\
\hline 5 & & & & & & \\
\hline 6 & & & & & & \\
\hline 7 & & & & & & \\
\hline 8 & & & & & & \\
\hline 9 & & & & & & \\
\hline 10 & & & & & & \\
\hline 11 & & & & & & \\
\hline 12 & & & & & & \\
\hline 13 & & & & & & \\
\hline 14 & & & & & & \\
\hline 15 & & & & & & \\
\hline 16 & & & & & & \\
\hline 17 & & & & & & \\
\hline 18 & & & & & & \\
\hline 19 & & & & & & \\
\hline 20 & & & & & & \\
\hline 21 & & & & & & \\
\hline 22 & & & & & & \\
\hline 23 & & & & & & \\
\hline 24 & & & & & & \\
\hline 25 & & & & & & \\
\hline 26 & & & & & & \\
\hline 27 & & & & & & \\
\hline 28 & & & & & & \\
\hline 29 & & & & & & \\
\hline 30 & & & & & & \\
\hline 31 & & & & & & \\
\hline 32 & & & & & & \\
\hline
\end{tabular}


Partituras de las melodías utilizadas como estímulos en el estudio 3
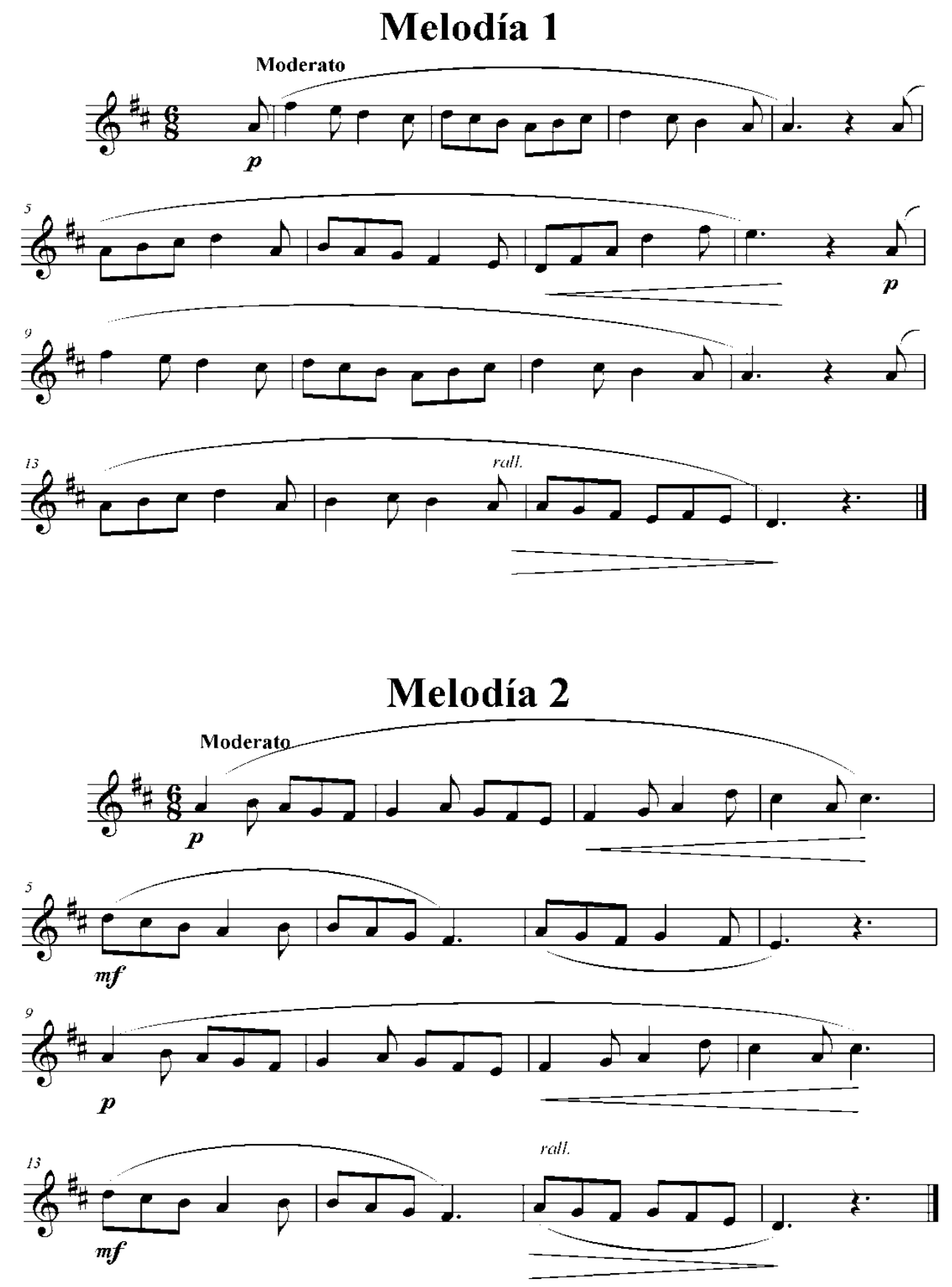
El Movimiento Corporal en la Lectura Cantada a Primera Vista
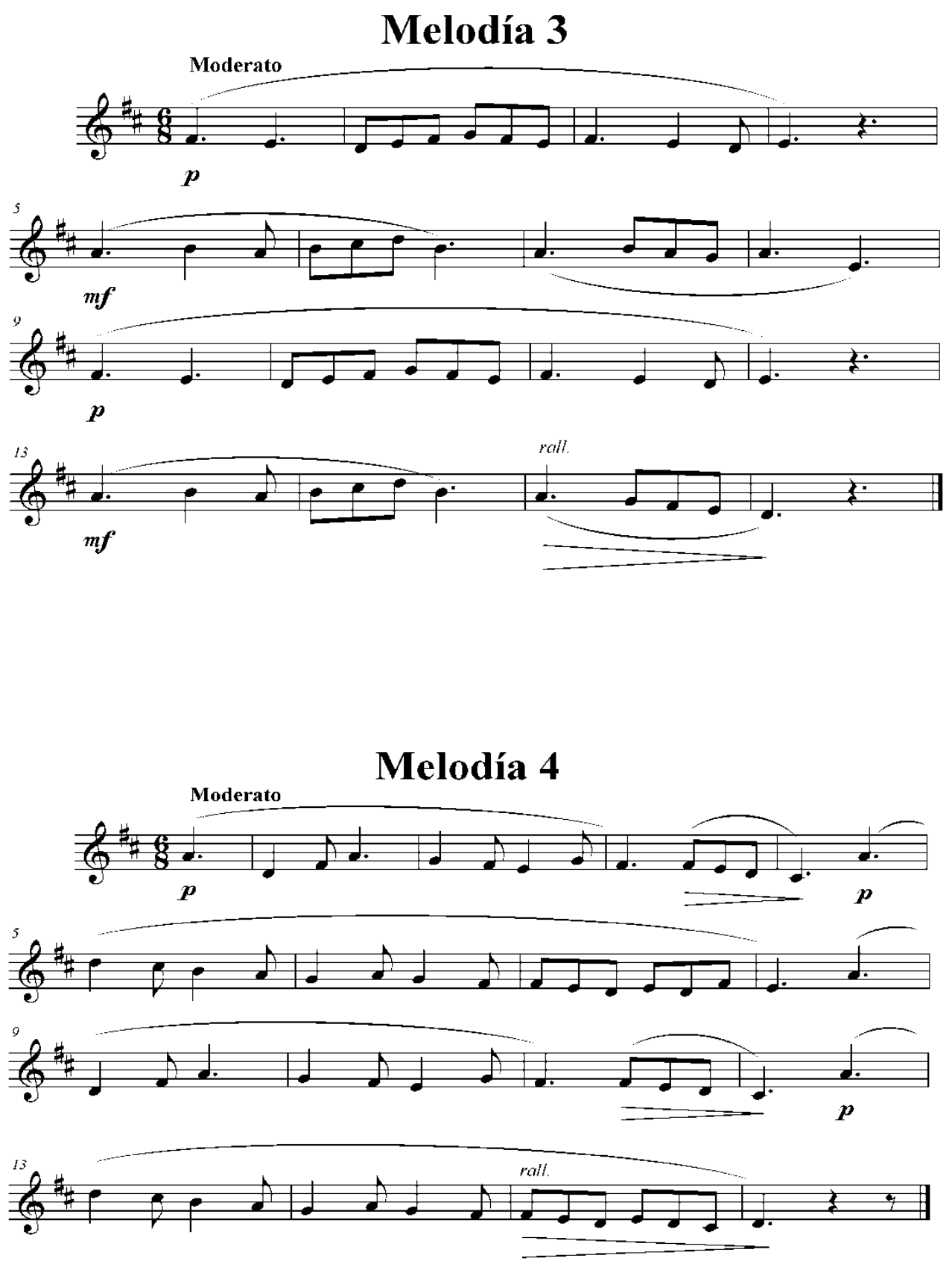

151 